\title{
LAS DONACIONES ENTRE CÓNYUGES EN DERECHO INTERNACIONAL PRIVADO
}

\section{DONATIONS BETWEEN SPOUSES IN PRIVATE INTERNATIONAL LAW}

\author{
Laura García Álvarez* \\ Profesora Ayudante Dra. de Derecho internacional privado \\ Universidad Pablo de Olavide \\ ORCID ID: 0000-0001-7302-292X
}

Recibido: 09.07.2020 / Aceptado: 16.07.2020

DOI: https://doi.org/10.20318/cdt.2020.5616

\begin{abstract}
Resumen: Este trabajo aborda el tratamiento de las donaciones entre cónyuges con al menos un elemento internacional desde la perspectiva del Derecho internacional privado. La naturaleza híbrida de dichas donaciones, a caballo entre el Derecho contractual, el Derecho de familia y, en ocasiones, el Derecho sucesorio, unida al elemento de internacionalidad, hacen que su calificación sea compleja y discutida y, en consecuencia, también lo sea su abordaje desde el Derecho internacional privado. El trabajo evidencia la necesidad de desarrollo de los conceptos autónomos contenidos en los instrumentos europeos -especialmente, del "régimen económico matrimonial"-, de sus ámbitos de aplicación, así como de la interacción entre ellos para clarificar la cuestión y garantizar la uniformidad y seguridad jurídica en el espacio europeo de justicia.
\end{abstract}

Palabras clave: donación entre cónyuges, calificación, competencia judicial internacional, ley aplicable, Derecho internacional privado.

\begin{abstract}
This paper looks at how donations between spouses with at least one international element are treated from a private international law perspective. The characterisation of these donations is complex and often contested. This is mainly due to its hybrid nature, which can be covered by contract law, family law and at times inheritance law. The paper highlights the need to develop: a) autonomous concepts included in the European legal instruments meant to be applicable to the case, particularly that of "marital economic regime"; and b) regulation's scopes and the interaction between them in order to clarify the question and to ensure uniformity and legal certainty in the European area of justice.

Keywords: donations between spouses, characterisation, jurisdiction, applicable law, private international law.

Sumario: I. Las donaciones internacionales entre cónyuges. Introducción. II. Naturaleza de las donaciones entre cónyuges y su carácter transfronterizo. III. La calificación de la donación entre cónyuges en DIPr. 1. Las obligaciones que se deriven de regímenes económicos matrimoniales, de regímenes económicos resultantes de relaciones que la legislación aplicable a las mismas considere que tienen efectos comparables al matrimonio [...]. Artículo 1.2. c). 2. Las obligaciones que se deriven [...] de testamentos y de sucesiones. Artículo 1.2.c) in fine. 3. Las obligaciones que se deriven de relaciones familiares y de relaciones que la legislación aplicable a las mismas considere que tienen
\end{abstract}

*1garalva@upo.es 
efectos comparables [...]. Artículo 1.2. b). IV. La donación entre cónyuges sujeta a la ley sucesoria. 1. Determinación de la competencia judicial internacional. 2. Determinación de la ley aplicable. V. La donación entre cónyuges vinculada al régimen económico matrimonial. 1. Determinación de la competencia judicial internacional. 2. Determinación de la ley aplicable. VI. La donación entre cónyuges "puramente" contractual, no vinculada a otras categorías. 1. Determinación de la competencia judicial internacional. 2. Determinación de la ley aplicable. A) Consideraciones previas: ámbito de aplicación del Reglamento Roma I respecto de las donaciones entre cónyuges. B) Ámbito de aplicación de la lex donationis. C) Las normas de conflicto en el Reglamento Roma I. VII. La ley aplicable a otras cuestiones. 1. La ley aplicable a la forma de una donación entre cónyuges. 2. Ley aplicable a la capacidad para ser parte en una donación entre cónyuges. 3. Ley aplicable a los derechos reales que se transmiten o crean mediante el acto de donación entre los cónyuges. VIII. Artículo $10.7 \mathrm{Cc}$. Norma de conflicto interna específica para las donaciones. IX. Efectos en España de las donaciones otorgadas en el extranjero. X. Especial referencia a las donaciones complejas. XI. Conclusiones y reflexión final.

\section{Las donaciones internacionales entre cónyuges. Introducción}

1. El presente trabajo pretende abordar la regulación en Derecho internacional privado (DIPr, en adelante) de las donaciones entre cónyuges en las que se verifica, al menos, un elemento de internacionalidad. Esto implica determinar qué instrumentos normativos determinarán la competencia judicial internacional, la ley aplicable y la validez y efectos de las donaciones otorgadas en el extranjero así como la concreción de dichas cuestiones. El interés del presente texto sobre las donaciones entre cónyuges con un elemento de internacionalidad se encuentra en que sigue siendo una cuestión escasamente estudiada y cuyo tratamiento normativo en el sistema español de DIPr es complejo.

2. En efecto, no es una cuestión suficientemente abordada por la doctrina ${ }^{1}$ ni por la jurisprudencia, como veremos. A los tradicionales problemas calificatorios que presentan las donaciones, $\mathrm{y}$, en especial, las donaciones entre cónyuges, que se mueven entre el Derecho contractual y el Derecho de familia, hay que sumar el efecto de que, al verificarse un elemento internacional, la normativa supraestatal institucional de la Unión Europea (en adelante, UE) tiene un papel fundamental, en atención a la jerarquía de fuentes del sistema español de DIPr. Este Derecho europeo contiene conceptos autónomos en algunos extremos y remisiones a los Derechos estatales, diversos en la consideración de esta cuestión ${ }^{2}$, en otros. Además, existen diversos Reglamentos de la UE en vigor con vocación de regular este supuesto y su coordinación y relación no siempre es clara, en parte por la dificultad siempre presente de abordar de manera armonizada todo lo atinente a las relaciones familiares en el ámbito de la UE.

\footnotetext{
${ }^{1}$ Los escasos trabajos que abordan las donaciones en el ámbito del DIPr no tienen por objeto las donaciones entre cónyuges de manera específica. En general, sobre donaciones y DIPr desde la perspectiva española, destacan los trabajos siguientes: J. CARRASCOSA GonZÁlez, "Apuntes sobre la competencia judicial internacional y la ley aplicable a las donaciones: antes y después del Reglamento Roma I", Cuadernos de Derecho Transnacional, vol. I, n², 2009, pp. 320-327; N. GoÑ UrRIZA, "La ley aplicable a las donaciones internacionales", Cuadernos de Derecho Transnacional, octubre 2019, Vol. 11, n², pp. 100-116; Ibidem, "Las liberalidades en el Derecho Internacional Privado", en: M.A. Egusquiza Balmaseda y C. Pérez de Ontiveros Baquero (dir.), Tratado de las Liberalidades, Homenaje al Profesor Enrique Rubio Torrano, Thomson Reuters Aranzadi, 2017, pp.1785-1817; o, con más antigüedad y por tanto sin considerar la normativa supraestatal institucional, esencial en la actualidad, P. JiMÉNEZ BlANCO, "El derecho aplicable a las donaciones”, Revista española de Derecho internacional, 1997-I, pp. 63-90; A. MARTín LóPEZ, "Las donaciones en Derecho internacional privado", Revista española de Derecho internacional, $\mathrm{n}^{\circ} 6$, 1953, pp. 563-595. Sí existen referencias a las donaciones, de manera genérica y/o escueta en las numerosas obras doctrinales sobre los reglamentos europeos que respectivamente regulan la cuestión y que veremos más adelante.

${ }^{2}$ En España la donación tiene carácter contractual, como en Francia, Alemania o Italia pero en Derecho escocés, por ejemplo, se considera un acto unilateral y no contractual. Vid., N. GoÑ URRIZA, "La ley aplicable...", op.cit., p. 102. Igualmente, en Italia, por ejemplo, existe una regulación específica de las donaciones entre cónyuges, como veremos más adelante, mientras que en España no existe. Vid., para un estudio de Derecho comparado sobre la naturaleza de las donaciones, vid., A.J. BELOHLÁVEK, Rome Convention- Rome I Regulation. Commentary, Juris Publishing, vol. I, 2010, pp. 201-233. En especial respecto al ordenamiento italiano, vid., G. PASSARELLI, "Donation: Short notes between italian civil law and EU Private International law", Cuadernos de Derecho Transnacional, octubre 2015, vol. 7, n², pp. 478 y 479.
} 
3. Todo ello hace de las donaciones internacionales entre cónyuges un tema de especial relevancia, más ahora que los Reglamentos $\mathrm{n}^{\circ} 2016 / 1103$, en materia de regímenes económicos matrimoniales ${ }^{3}$ $\mathrm{y} \mathrm{n}^{\circ} 2016 / 1104$, relativo a los efectos patrimoniales de las uniones registradas ${ }^{4}$, ya son aplicables, desde el 29 de enero de 2019, para determinar la competencia judicial internacional, la ley aplicable y la validez extraterritorial -en aquellos países que los adoptaron- ${ }^{5}$, y pueden tener un papel importante en la regulación de las donaciones entre cónyuges desde la óptica del DIPr, sumándose a otros instrumentos de Derecho europeo con vocación de ser aplicables al caso, como los Reglamentos $n^{\circ}$ 1215/2012 o Bruselas I bis ${ }^{6}$, el 593/2008 o Roma I ${ }^{7}$, el no 650/2012, de sucesiones ${ }^{8}$ y el n ${ }^{\circ} 2201 / 2003^{9}$, así como a las normas de producción interna contenidas en la Ley Orgánica del Poder Judicial (en adelante, LOPJ) y en el Código civil (en adelante, $\mathrm{Cc}$ ).

4. Por todo ello, el tratamiento de las clásicas cuestiones de DIPr - determinación de la autoridad competente, de la ley aplicable y la validez extraterritorial de actos y decisiones judiciales- es complejo, sumándose la naturaleza híbrida de la donación a la ya de por sí dificultad que la pluralidad de fuentes del sistema español de Derecho internacional privado -y la interpretación de estos instrumentos, controvertida en varios aspectos, como veremos- supone para el operador jurídico.

5. Teniendo esto en consideración, el presente trabajo se divide en varios epígrafes: En primer lugar, comenzaremos haciendo una reflexión sobre la naturaleza, híbrida, de las donaciones, y las implicaciones de este hecho en su tratamiento normativo desde el punto de vista del Derecho internacional privado, para lo que será necesario abordar el carácter transfronterizo de la misma, analizado en el apartado segundo. El tercer epígrafe se dedica íntegramente a la calificación de la donación entre cónyuges que es, sin duda, el punto clave de este trabajo, tanto por su complejidad como por las distintas posiciones doctrinales existentes y las implicaciones que dicha calificación tendrá, lógicamente, en la

\footnotetext{
${ }^{3}$ Reglamento (UE) 2016/1103 del Consejo, de 24 de junio de 2016, por el que se establece una cooperación reforzada en el ámbito de la competencia, la ley aplicable, el reconocimiento y la ejecución de resoluciones en materia de regímenes económicos matrimoniales, DO L 183 de 8.7.2016, p. 1/29.

${ }^{4}$ Reglamento (UE) 2016/1104 del Consejo, de 24 de junio de 2016, por el que se establece una cooperación reforzada en el ámbito de la competencia, la ley aplicable, el reconocimiento y la ejecución de resoluciones en materia de efectos patrimoniales de las uniones registradas. DO L 183 de 8.7.2016, p. 30/56. En esta contribución, con la intención de simplificar y dado que el título hace referencia a las donaciones realizadas entre cónyuges, nos referiremos únicamente al Reglamento 2016/1103, pero en esencia lo que va a estudiarse, en especial respecto del régimen normativo de la UE previsto en el Reglamento 2016/1103, puede extenderse a las uniones registradas ya que ambos reglamentos, el 2016/1103 y el 2016/1104 son paralelos y prácticamente idénticos en contenido y forma. Vid., P. Franzina \& I. Viarengo, "General Introduction”, en: P. Franzina \& I. Viarengo, The EU Regulations on the property regimes of international couples, Edward Elgar, 2020, pp.1-13, p.2; A.L. CALVO CARAVACA y J. Carrascosa González, Derecho internacional privado, vol. II, 18 a ed., 2018, pp. 161-227, p. 165, citando a E. GaLlant, "Le nouveau droit international privé européen des régimes patrimoniaux de couples", Europe, mars 2017, pp. 5-10; C. NouRISSAT Y M. REVILLARD, "Règlements européens du 24 juin 2016 sur les régimes matrimoniaux et les effets patrimoniaux des partenariats enregistrés", Défrenois, n¹7, 15 septembre 2016, pp. 878-894; y L. UsunIER, "Libre, mobile, divers: le couple au miroir du droit international privé de l'Union européenne”, Revue Trimestrielle de droit civil, nº4, 2016, pp. 806-813.

${ }^{5}$ En materia de competencia judicial internacional y validez extraterritorial, en efecto, comenzó a aplicarse a todas las demandas que se presentaran a partir del 29 de enero de 2019. No obstante, en materia de determinación de la ley aplicable, se aplicará a los matrimonios que se hayan celebrado desde esa fecha o hayan elegido ley a partir de ese día, lo cual supone que en muchos casos que se diriman en la actualidad y en el futuro ante los tribunales españoles seguirán aplicándose normas de producción interna para determinar la ley aplicable al caso, no así a la competencia judicial internacional.

${ }^{6}$ Reglamento (UE) n ${ }^{\circ}$ 1215/2012 del Parlamento Europeo y del Consejo, de 12 de diciembre de 2012, relativo a la competencia judicial, el reconocimiento y la ejecución de resoluciones judiciales en materia civil y mercantil, DO L 351 de 20.12.2012, p. 1/32. También Reglamento Bruselas I bis.

${ }^{7}$ Reglamento (UE) $n^{\circ}$ del Parlamento Europeo y del Consejo de 17 de junio de 2008 sobre la ley aplicable a las obligaciones contractuales (Roma I).

${ }^{8}$ Reglamento (UE) $n{ }^{\circ}$ 650/2012 del Parlamento Europeo y del Consejo, de 4 de julio de 2012 , relativo a la competencia, la ley aplicable, el reconocimiento y la ejecución de las resoluciones, a la aceptación y la ejecución de los documentos públicos en materia de sucesiones mortis causa y a la creación de un certificado sucesorio europeo, DO L 201 de 27.7.2012, p. 107/134.

${ }^{9}$ Reglamento (CE) ${ }^{\circ}$ 2201/2003 del Consejo, de 27 de noviembre de 2003, relativo a la competencia, el reconocimiento y la ejecución de resoluciones judiciales en materia matrimonial y de responsabilidad parental, por el que se deroga el Reglamento (CE) n 1347/2000, DO L 338 de 23.12.2003, p. 1/29.
} 
elección del instrumento normativo que determinará competencia judicial internacional y ley aplicable, teniendo, por tanto, un papel clave en el acceso a la justicia de las partes y en la resolución del conflicto en cuestión que se plantee en torno a una donación entre cónyuges. Los epígrafes siguientes abordarán respectivamente la regulación internacional privatista de, lo que hemos llamado, "donación vinculada al régimen económico matrimonial", "donación vinculada a la sucesión" y "donación puramente contractual". Terminaremos haciendo una reflexión sobre la complejidad de la cuestión para el operador jurídico y esbozando algunas conclusiones.

\section{Naturaleza de las donaciones entre cónyuges y su carácter transfronterizo}

6. La donación es una institución que presenta una naturaleza híbrida, a caballo entre distintas instituciones jurídicas. Por una parte, y principalmente, tiene naturaleza contractual ${ }^{10}$, con independencia de que surjan de ella obligaciones para ambas partes o para una sola, ya que existe un acuerdo entre las partes. Además, implica el cambio en la propiedad de un bien, por lo que también tiene eficacia jurídico-real, con tratamiento especial si se trata de un bien inmueble. Por otra parte, la calificación contractual de la donación también puede descartarse para las donaciones efectuadas en un contexto familiar, especialmente en este supuesto que nos ocupa de las donaciones entre esposos, usuales para la planificación patrimonial de la pareja (por ejemplo, en caso de una donación en razón de matrimonio) $\mathrm{y}$, también, entre otros supuestos posibles ${ }^{11}$, cuando la donación está íntimamente relacionada con una sucesión o ley sucesoria, entre otras cosas, porque no son pocos los ordenamientos que, para proteger la masa hereditaria, prevén limitaciones a los actos de disposición del patrimonio del (cónyuge) donante.

7. Por último, hay que señalar que, en una misma donación podemos encontrar elementos contractuales típicos (interpretación de los términos de la donación, consentimiento o plazo de prescripción de las obligaciones nacidas de la misma) y otros vinculados al Derecho de familia (como la admisibilidad o no de la donación entre esposos, la posibilidad de revocación por, por ejemplo, el nacimiento de un hijo del donante ex artículo $644 \mathrm{Cc})^{12}$, que pueden llevar al fraccionamiento de la ley rectora de la donación o dépeçage, como veremos más adelante. Si la donación no es inter vivos sino mortis causa (art. $620 \mathrm{Cc}$ ), normalmente irrevocable, se encontrará íntimamente vinculada a la sucesión del causante y esto determinará la aplicación del régimen regulador de la sucesión, no sin controversia, como veremos más adelante. Además, podemos encontrar donaciones inter vivos que también se verán relaciona-

\footnotetext{
${ }^{10}$ Salvo en el caso, difícil de imaginar, de la donación "forzosa", aunque cabría plantearse si, en el caso de ser forzosa podríamos seguir hablando de donación en tanto que acto de liberalidad. Hay algunos precedentes históricos en este sentido, aunque en el actual marco de derechos y garantías serían impensables, son: la donación forzosa de sangre impuesta por ley en la Ley en 1954 en Francia (vid., Loi du 14 avril 1954, permettant de soumettre à un prélèvement de sang les hommes appartenant aux classes 1944 et 1945 et qui n'ont pas accompli de service militaire) o, en España, la Orden por la que se dispone que todo ciudadano español afecto de enfermedad infecto-contagiosa que haya sido tratado en los Centros Hospitalarios o Sanatoriales del Estado, Provincia y Municipio viene obligado a ceder aquella cantidad de sangre que los Organismos competentes precisen para el tratamiento de otros enfermos (vid., BOE, núm. 247, de 04/09/1941, p. 6.749). Sobre ello, vid., P. Cuadros Aguilera, “UUn servicio civil de donación de sangre? En torno a una propuesta de Cécile Fabre”, Cuadernos Electrónicos de Filosofía del Derecho, no 40, 2019, pp. 68-85, pp. 77-78. Sobre estas posibles donaciones forzosas hace alguna referencia en el DIPr español J. Carrascosa González, en “Apuntes...”, op.cit., p. 322

${ }^{11}$ Por ejemplo, su vinculación con las obligaciones de alimentos cuyo estudio excluimos del presente artículo al tratarse de obligaciones impuestas por ley a raíz de una ruptura del vínculo conyugal, mientras que las donaciones entre cónyuges son actos de liberalidad que surgen y se realizan normalmente mientras existe el matrimonio o, en algunos casos, antes de su celebración. Sí podrían considerarse por tanto parte de este estudio las obligaciones de mantenimiento que se pacten en contratos privados de manera voluntaria por los esposos. Vid., A. Rodríguez Benot, "Los efectos patrimoniales de los matrimonios y de las uniones registradas en la Unión Europea”, Cuadernos de Derecho Transnacional, Vol. 11, № 1, pp. 8-50, p. 18. No obstante, quedarían excluidas del Reglamento Roma I y su régimen dependería del Reglamento específico no 4/2009 del Consejo, de 18 de diciembre de 2008, relativo a la competencia, la ley aplicable, el reconocimiento y la ejecución de las resoluciones y la cooperación en materia de obligaciones de alimentos, cuyo estudio desborda el objeto del presente trabajo.

${ }^{12}$ N. GoÑ URriza, “La ley aplicable..", op.cit., p. 105, citando a P. WAUTELEt, Les donations dans un contexte international, Guide pratique, Anthemis, pp. 213-251, p. 218.
} 
das con la sucesión en determinadas cuestiones, como en el régimen particular de protección de ciertos herederos que es aplicable a la donación en el marco de la sucesión del donante ${ }^{13}$. Todo ello, además, teniendo en cuenta que puede que la ley o leyes rectoras de la donación entre cónyuges en cuestión, simplemente complementen o sirvan para interpretar las estipulaciones que libremente se han dado las partes, o para determinar su suficiencia y validez.

8. Por otra parte, para que la donación entre cónyuges sea objeto de disciplina por el Derecho internacional privado y por los instrumentos normativos supraestatales y de producción interna que hemos mencionado, es preciso que se verifique su repercusión transfronteriza. Sin que encontremos en los textos normativos cuándo una donación entre cónyuges produce tal repercusión, podemos afirmar que la naturaleza transfronteriza de una donación entre cónyuges se verifica cuando está vinculada con dos o más ordenamientos jurídicos nacionales de tal manera que surge la duda de cuál de ellos es el que debe regularlas.

9. Así, el carácter transfronterizo puede derivar bien de un elemento endógeno de la situación (personal, objetivo o territorial ${ }^{14}$ ), bien de un elemento exógeno a la misma, esto es, de la voluntad de los cónyuges al pactar como competente de una autoridad extranjera o como aplicable de un ordenamiento foráneo, todo ello para una situación en principio meramente interna (algo que en principio permitirían todos los textos normativos con vocación de ser aplicados al caso, con las excepciones o salvaguardas que ellos mismos prevén; por ejemplo, los artículos 3.3 y 3.4 del Reglamento Roma I, vid. infra).

10. Ahora bien, el elemento extranjero debe ser mínimamente significativo para que justifique un tratamiento legal distinto del que recibiría un supuesto interno. La importancia de este elemento extranjero se calibrará, en el ámbito de aplicación de los Reglamentos de la UE, como señala doctrina reconocida, por su impacto en el correcto desarrollo de las libertades comunitarias ${ }^{15}$.

11. Por tanto, para que estemos ante una donación entre cónyuges objeto de estudio por el DIPr, debe ocurrir bien que alguno de los elementos intrínsecos del matrimonio sea de naturaleza transfronteriza -en cuyo caso la donación también lo sería, por ejemplo una donación entre cónyuges que tuvieran distinta nacionalidad o residencia habitual- o que encontrándose todos los elementos del matrimonio vinculados con el mismo ordenamiento estatal, sea la donación en sí la que tuviera repercusión transfronteriza porque, por ejemplo, se trate de la donación de un bien inmueble sito en un país extranjero. Por último, cabe mencionar la posibilidad de que los cónyuges acuerden la ley aplicable a la donación haciendo uso de la facultad de elección que, por ejemplo, les otorga el Reglamento Roma I, siempre que el supuesto encaje en su ámbito de aplicación, cuestión que veremos más adelante. En este caso, el elemento internacional sería "exógeno" y hay que recordar que si la elección es de una ley distinta a la que se encuentra en esencia vinculada al supuesto esto no impedirá la aplicación de todas las disposiciones de ley que no puedan excluirse mediante acuerdo del ordenamiento que habría sido aplicable en defecto de elección (ex artículo 3.3 Reglamento 593/2008 ${ }^{16}$ ).

\footnotetext{
${ }^{13}$ Incluye cuestiones como en qué medida una persona puede disponer de sus bienes para efectuar donaciones entre vivos, la imputabilidad de la donación a la cuota disponible o a la legitimaria, en su caso, así como las condiciones de su sujeción a la acción de reducción. Vid., A. Bonomi, P. Wautelet y S. Álvarez González, “Artículo 1”, en: El Derecho europeo de sucesiones [Comentario al Reglamento (UE) $n^{\circ}$ 650/2012, de 4 de julio de 2012], $1^{\text {a }}$ ed., Cizur Menor (Navarra), Aranzadi, 2015 [Consultado online, sin paginación].

${ }^{14}$ Vid., A. Rodríguez Benot (Dir.), Manual de Derecho internacional privado, Tecnos, $6^{\text {a }}$ ed., pp. 21-22. Por ejemplo, un cónyuge de nacionalidad francesa dona al otro de nacionalidad belga un bien situado en España, donde residen ambos; un cónyuge español residiendo en España dona al otro, igualmente español residiendo en España, un inmueble situada en el extranjero; los cónyuges, ambos españoles, pactan la donación en unas capitulaciones matrimoniales firmadas en Bruselas.

${ }^{15}$ A. Rodríguez Benot, "Los efectos...", op.cit, p. 16.

${ }^{16}$ Reglamento ${ }^{\circ}$ 593/2008, del Parlamento Europeo y del Consejo, de 17 de junio 2008, sobre la ley aplicable a las obligaciones contractuales o Roma I (DOUE L 177/6, 4/7/2008).
} 


\section{La calificación de la donación entre cónyuges en DIPr.}

12. Dicho esto acerca de su naturaleza, es evidente que, en presencia de una donación entre cónyuges con al menos un elemento internacional, nos encontraremos ante un problema característico del DIPr: la calificación. Esto es, tenemos una situación privada internacional - donación entre cónyuges con al menos un elemento internacional significativo- que puede ser subsumida en distintas normas de DIPr según se considere su naturaleza jurídica, tanto para seleccionar la norma de conflicto y el ordenamiento aplicable al fondo -pudiendo ser una única ley o varias- como para determinar la competencia judicial internacional y la validez extraterritorial de resoluciones extranjeras sobre la cuestión.

13. Veamos un ejemplo: El Sr. A, español, dona a su cónyuge, francés, ambos residentes en Sevilla, en acuerdo privado, su parte de un inmueble sito en Alemania propiedad de ambos a partes iguales hasta entonces. ¿Consideramos el carácter consensual, contractual, de la donación y por tanto sería subsumible en el Reglamento Roma I, de ley aplicable, y en el Reglamento 1215/2012, en lo que respecta a la determinación de la competencia judicial internacional y a la validez extraterritorial, siempre que no entre dentro de alguna de sus exclusiones, especialmente la prevista para aquellos negocios jurídicos vinculados al régimen económico matrimonial -en ambos instrumentos- o la referida a las obligaciones que "deriven de relaciones familiares" -exclusión de Roma I? Por el contrario, ¿se puede considerar, -porque, por ejemplo, se comprenda esa donación en un conjunto de actos que pretenden una planificación patrimonial de la pareja en el marco de su régimen económico matrimonial-, que es una donación vinculada al régimen matrimonial? Si añadimos que la donación vulnera las legítimas de la sucesión del donante respecto del hijo de este o bien que se trata de un pacto sucesorio, ¿podría considerarse que al encontrarse vinculada a la sucesión hay que acudir al Reglamento 650/2012, de sucesiones?

14. $Y$ es que, aunque nuestro Código civil define la donación como " (...) un acto de liberalidad por el cual una persona dispone gratuitamente de una cosa a favor de otra, que la acepta" (artículo $618 \mathrm{Cc}$ ) y aunque la donación tenga en nuestro país un claro carácter consensual, no regulada por el Derecho de familia -aunque se dé entre cónyuges ${ }^{17}$, al verificarse al menos un elemento internacional y entrar en juego el sistema español de DIPr, con normas supraestatales institucionales aplicables a la cuestión que contienen "conceptos autónomos" y también remisiones a leyes estatales, la calificación de la figura, como veremos, ya no dependerá, en la mayor parte de los casos, de las normas de producción interna. Por tanto, en primer lugar es necesario "calificar" esa concreta situación jurídica atendiendo a la jerarquía de fuentes del sistema español de DIPr. Así, acudimos en primer a las normas supraestatales, en concreto, a las de origen institucional.

15. Si bien no existe una norma de funcionamiento general para resolver el problema de la calificación, sí existe en el ámbito de la normativa de la UE el método unilateral europeo "Reglamento por Reglamento"'18. Veamos el funcionamiento general del método antes de ver cómo se concreta para cada Reglamento, a propósito de la determinación de la competencia judicial internacional y ley aplicable.

16. Este método se basa en que cada Reglamento determina, de manera autónoma, las situaciones a las que es aplicable el mismo. Para ello hace uso de, por una parte, "conceptos generales" (como "obligaciones contractuales", "régimen económico matrimonial", "sucesión mortis causa"...) que define el mismo Reglamento y/o que desarrolla la jurisprudencia del TJUE en la mayoría de casos, y, por otra parte, de una descripción del ámbito de aplicación material del Reglamento. Esta descripción contiene, por lo general, una lista detallada de todas las cuestiones que sí deben considerarse reguladas por

\footnotetext{
${ }^{17}$ Salvedad hecha de la donación en razón de matrimonio en Derecho común (art. 1336 -1343 Cc), en nuestro supuesto, cuando sea un cónyuge el que la hace a favor del otro.

${ }_{18}$ Amplia explicación sobre la calificación y el método europeo en: A.L. Calvo Caravaca y J. Carrascosa González, Derecho internacional privado, vol. I, $18^{\mathrm{a}}$ ed., 2018, p. 218-228.
} 
el Reglamento y/o una lista detallada de exclusiones con aquellas cuestiones que no deben considerarse reguladas por el mismo, por si hubiera dudas a la hora de calificar ciertos supuestos, en ambos casos.

17. Esto es, resulta irrelevante, aunque algunos autores aún hacen eco esta teoría ${ }^{19}$, la calificación que se mantiene en el Derecho interno del Estado cuyos tribunales conocen del asunto ${ }^{20}$. Lo determinante, en presencia de instrumentos supraestatales institucionales aplicables ${ }^{21}$, es que dicha situación encaje en el ámbito de aplicación de un Reglamento de la UE.

18. Así, por ejemplo, y respecto de instrumentos que nos atañen en este trabajo, el Reglamento Roma I, dedicado a la determinación de la ley aplicable respecto de las "obligaciones contractuales en materia civil y mercantil", incluye en su ámbito de aplicación material, al calificarla como una cuestión "contractual" y no "procesal", la prescripción de la acción para la entrega de la cosa en la compraventa (artículo 12.1) 22. Por su parte, el mismo Reglamento contiene en el artículo 1.2 una serie de exclusiones de materias que no podrán considerarse "materia contractual" a efectos del Reglamento con independencia de los ordenamientos de los Estados miembros, como veremos ampliamente en este mismo epígrafe, más adelante.

19. Entonces, una vez visto este marco general sobre cómo resolver el problema de la calificación en nuestro supuesto de hecho, veamos cómo se interpreta la normativa con vocación de ser aplicable en el ámbito de la UE ante un caso de donación entre cónyuges con, al menos, un elemento internacional. Habrá que estar a la concreta situación jurídica que se presente en la práctica para determinar, finalmente, el instrumento aplicable tanto para determinar la competencia judicial internacional como para determinar el ordenamiento aplicable al fondo ${ }^{23}$.

20. Nótese que, como norma general, la interpretación de los conceptos incluidos en la normativa de la UE debe ser uniforme y coherente para garantizar el principio de igualdad. En este sentido, y aunque no sea vinculante, el concepto que el TJUE desarrolla de un determinado término jurídico, por ejemplo, de "régimen económico matrimonial" o de "obligación contractual" debería ser semejante al que se dé a esos mismos términos en otros instrumentos europeos ${ }^{24}$. Por último, recordemos que, según el art. 4 bis LOPJ, los jueces y tribunales aplicarán el Derecho de la Unión Europea de conformidad con la jurisprudencia del Tribunal de Justicia de la Unión Europea.

${ }^{19}$ Vid., en artículo de 2019, cit. supra: N. GoÑ UrrizA, “La ley aplicable..”, op.cit., p. 101, párrafo 4: “(...) Al igual que en la mayoría de ordenamientos jurídicos, la calificación de un negocio jurídico como la donación o la compraventa debe realizarse conforme a la ley española (artículo 12.1 Cc)”.

${ }^{20}$ Nos estamos refiriendo al Derecho material interno y a las normas de producción interna de Derecho internacional privado, porque, lógicamente, los reglamentos de la UE son también Derecho interno desde que se publican debidamente. Cuando se apliquen las normas de producción interna en materia de competencia judicial internacional (artículo 22 LOPJ) o de ley aplicable $(10.7 \mathrm{Cc}$, exclusivamente relegado a regular los conflictos de leyes interregionales, o 9.2 y $9.3 \mathrm{Cc}$, aplicables para matrimonios celebrados con anterioridad al 29 de enero de 2019 y casos interregionales), sí será relevante la calificación según el Derecho interno.

${ }^{21}$ No mencionamos aquí la solución a la calificación para la aplicación de un convenio internacional porque no hay convenios aplicables en España que regulen los aspectos de DIPr de las donaciones entre cónyuges con elemento internacional. Dependerá del convenio y de las soluciones que este prevea. Mencionamos, no obstante, el Convenio de la Haya de 14 de marzo de 1978 relativo a la Celebración y al Reconocimiento del Matrimonio, en el que España no es parte, y los "Principles of European Family Law" de la Commission on European Family Law (CEFL), con diferentes categorías, una de ellas dedicada a las relaciones patrimoniales entre los cónyuges, todas disponibles online: http://ceflonline.net/principles/ [Consulta: 1/4/2020]. Para más información respecto de la calificación en convenios internacionales, vid., A.L. CAlvo CARAvACA y J. CARRASCOSA GonZÁlez, Derecho..., op. cit., p. 222.

${ }^{22}$ Ejemplo citado en Ibídem, p. 220.

${ }^{23}$ Incluso, como veremos más adelante, puede ocurrir que debamos atender a diversos aspectos dentro de un mismo acto de donación, fraccionando la ley aplicable al mismo.

${ }^{24}$ Así se refleja en numerosa jurisprudencia del TJUE. Respecto a ello, vid., V.M. RoJAs AMANDI, "La interpretación del Derecho de la Unión Europea", Revista de Derecho de la Unión Europea, nº 4, 2003, pp. 47-64, pp. 49, 57, 58, disponible en: http://62.204.194.45/fez/eserv/bibliuned:1217/IntDchoUE.pdf [Consulta: 10/12/2019]. 
21. En nuestro supuesto de estudio, esto es, las donaciones entre cónyuges, cada instrumento supraestatal con vocación de ser aplicado al caso contiene conceptos autónomos que deberán examinarse, siempre que sea posible, a la luz de la jurisprudencia del TJUE para calificar el supuesto y determinar, en función de sus respectivos ámbitos de aplicación, si debe aplicarse uno u otro. Atendiendo siempre a la jerarquía de fuentes del sistema español de Derecho internacional privado, la elección del instrumento aplicable dependerá de una cuestión previa fundamental, que es la de calificar la donación, algo que se realizará, en primer lugar, siguiendo el método unilateral europeo de "Reglamento por Reglamento" y, en defecto de instrumento supraestatal aplicable, en base a las normas de producción interna para determinar la norma interna aplicable.

22. En los Estados miembros de la UE, la ley que en principio va a aplicarse a una donación es la que se determine, como veremos, en base al Reglamento 593/2008, Roma I, y la competencia será regulada por el Reglamento 1215/2012, al considerarse su carácter consensual de manera prioritaria -salvo en el caso, bastante inverosímil, de que estuviéramos ante una "donación no voluntaria" o "forzosa" porque nacen de la voluntad de ambas partes con independencia de que generen obligaciones para una de las partes o para ambas, como vimos en el primer apartado.

23. Esta interpretación se basa en el contenido del considerando 7 del Reglamento Roma I, que establece que el ámbito de aplicación material y las disposiciones del Reglamento deben garantizar la coherencia con el Reglamento (CE) 44/2001 del Consejo, de 22 de diciembre de 2000, relativo a la Competencia judicial, el Reconocimiento y la Ejecución de Resoluciones Judiciales en materia civil y mercantil (Bruselas I), y con el Reglamento (CE) 864/2007 del Parlamento Europeo y del Consejo, de 11 de julio de 2007, sobre la Ley aplicable a las Obligaciones Extracontractuales (Roma II) ${ }^{26}$. Así, aunque no existe una definición del término "obligaciones contractuales" ni en el Convenio de Roma ni en el Reglamento Roma I, las definiciones autónomas adoptadas por el TJUE para la noción "materia contractual" en relación al Convenio de Bruselas y posteriores Reglamentos 44/2001 y 1215/2012, se extienden por los Tribunales a los instrumentos citados en materia de ley aplicable ${ }^{27}$. De esta manera, tal y como la doctrina ha recogido, toda donación que requiere la aceptación del donatario debe ser considerada como un "acuerdo libre de voluntades" y por tanto genera "obligaciones contractuales" a efectos del Reglamento Roma I ${ }^{28}$.

24. Así lo ha reafirmado el TJUE haciendo también referencia al principio de coherencia con el concepto de "obligaciones contractuales" del Reglamento 1215/2012. En la STJUE de 21 de enero de $2016^{29}$, el tribunal afirma lo siguiente: “(...) en relación con los respectivos ámbitos de aplicación de los Reglamentos Roma I y Roma II, los conceptos de «obligación contractual» y de «obligación extracontractual» que figuran en éstos deben interpretarse de manera autónoma, remitiéndose a su sistema y a los objetivos de dichos Reglamentos (véase, por analogía, la sentencia ÖFAB, C147/12, EU:C:2013:490, apartado 27). Asimismo, debe tenerse en cuenta, como resulta del considerando 7 de cada uno de los dos Reglamentos, el objetivo de coherencia en la aplicación recíproca de estos Regla-

${ }^{25}$ En cuyo caso - siempre que se trate de un supuesto de DIPr- estaríamos ante una obligación extracontractual y deberíamos acudir al Reglamento Roma II, esto es, Reglamento (CE) n864/2007 del Parlamento Europeo y del Consejo, de 11 de julio de 2007, relativo a la ley aplicable a las obligaciones extracontractuales (Roma II), DO L 199 de 31.7.2007, p. 40/49. Excluimos, por la rareza del supuesto, el estudio de las mismas en el presente artículo, vid. supra, nota 10.

${ }^{26}$ Vid., A.L. Calvo Caravaca y J. Carrascosa González, "Chapter I: Scope. Article 1”, en U. Magnus y P. Mankowski, European Commentaries on Private International Law, Commentary Brussels I bis Regulation, vol.I, OttoSchmidt, Köln, 2016, p. 46-75, p. 62, y jurisprudencia del TJUE allí citada; M. GiULIANo y P. LAGARDE, Informe relativo al Convenio sobre ley aplicable a las obligaciones contractuales, DOCE de 11 de diciembre de 1992, C 327, pp. 1-47.

${ }^{27}$ Entre otras, la STJCE de 17 de junio de 1992, as.26/91, Jakob Handte, nos dice que hay materia contractual (concepto autónomo del artículo 5.1 CB) cuando existe un compromiso libremente asumido por una parte frente a la otra.

${ }^{28}$ De este criterio, siguiendo el Considerando 7 del Reglamento Roma I, vid., J. CARrascosa GonzÁlez, “Apuntes sobre...", op.cit., p. 324.

${ }^{29}$ STJUE de 21 de enero de 2016, as. acumulados C359/14 y C475/14, "ERGO Insurance" SE contra "If P\&C Insurance" AS y "Gjensidige Baltic" AAS contra "PZU Lietuva" UAB DK [ECLI:EU:C:2016:40], fd. 43 y 44. 
mentos, y también del Reglamento Bruselas I, que, en particular, distingue, en su artículo 5, entre las materias contractual y delictual o cuasidelictual. Y que: "44. De la jurisprudencia del Tribunal de Justicia relativa a este último Reglamento resulta que sólo una obligación jurídica libremente consentida por una persona respecto a otra y en la que se basa la acción del demandante está comprendida en el ámbito de la «materia contractual», en el sentido del artículo 5, número 1, del citado Reglamento (véase la sentencia Kolassa, C375/13, EU:C:2015:37, apartado 39). Por analogía, y de conformidad con el objetivo de coherencia indicado en el apartado 43 de la presente sentencia, debe considerarse que el concepto de «obligación contractual», en el sentido del artículo 1 del Reglamento Roma I, designa una obligación jurídica libremente consentida por una persona respecto a otra" ${ }^{\prime 30}$.

25. Ahora bien, en ocasiones, aunque la donación sea "contractual", no podremos considerarla como tal a efectos de entenderla incluida en el ámbito de aplicación del Reglamento Roma I-y, también, del 1215/2012-, lo cual puede deberse a varios factores tratándose de una donación efectuada en el ámbito familiar, entre cónyuges, recogidos en las exclusiones de dichos textos normativos ${ }^{31}$. Nos referimos aquí a las excepciones que contiene el Reglamento Roma I en su artículo 1.2 que pueden concurrir en un supuesto de donación entre cónyuges, y que abordamos a continuación, ya que están necesariamente vinculadas a la calificación del supuesto de hecho de las donaciones entre cónyuges no solo para la determinación del instrumento normativo que determinará la ley aplicable sino también para seleccionar aquel que regulará la competencia judicial internacional ${ }^{32}$.

\section{Las obligaciones que se deriven de regímenes económicos matrimoniales, de regímenes eco- nómicos resultantes de relaciones que la legislación aplicable a las mismas considere que tienen efectos comparables al matrimonio [...]. Artículo 1.2. c).}

26. En primer lugar, pues, no procede considerar la donación -o elementos de ella- parte del ámbito de aplicación de Roma I si dicha donación -o determinados aspectos de la misma ${ }^{33}$ - aun siendo

${ }^{30}$ Nótese que el concepto de "materia contractual" que el TJUE ha desarrollado en su labor interpretativa del Reglamento 1215/2012 y de sus predecesores, el Reglamento 44/2001 y el Convenio de Bruselas, no es automáticamente vinculante en la interpretación del concepto "materia contractual" en el Reglamento Roma I. Vid., M. Virgós Soriano y F.J. Garcimartín AlféreZ, Derecho procesal civil internacional. Litigación internacional, Thomson Reuters, 2007, $\mathrm{n}^{\circ}$ párrafo 5.35. No obstante, se deberá tender a la uniformidad en la interpretación para procurar soluciones jurídicas consistentes y coherentes, tal y como se observa en la jurisprudencia del TJUE. Esto es, la regla general de interpretación debe ser la uniformidad en la interpretación de los conceptos, de manera que si una cuestión se considera "materia contractual" a efectos de determinar la competencia judicial internacional, también se considere "contractual" para determinar la ley aplicable a la misma. La parte que sostenga otra interpretación debe justificar dicha "separación conceptual”, vid., A.L. Calvo CaravaCa y J. Carrascosa GonzÁlez, Derecho...., Vol. II, op.cit., p. 219.

${ }^{31}$ Como veremos, esto ya se señaló en el Informe Giuliano/Lagarde: M. Giuliano y P. Lagarde, Informe relativo al Convenio sobre ley aplicable a las obligaciones contractuales, DOCE de 11 de diciembre de 1992, C 327, pp. 1-47, p.10: “A diferencia de lo que se ha dicho en el apartado 2 del artículo 1 del anteproyecto inicial, la redacción actual de la letra b) del apartado 2 no excluye de una manera general la materia de las donaciones. La mayoría de las Delegaciones se pronunció por la inclusión de las donaciones que proceden de un contrato en el ámbito de aplicación del Convenio, aun cuando se efectúen en el marco familiar, sin estar por ello cubiertas por el derecho de familia. Quedan, pues, fuera del ámbito de aplicación de las normas uniformes solamente las donaciones contractuales afectadas por el derecho de familia, de los regímenes matrimoniales o de las sucesiones. F. Zoll, "The Draft Common Frame of Reference as an instrument of the autonomous interpretation in the context of Rome I Regulation", en: F. Ferrari \& S. LeIBLE (ed.), The Law Applicable to Contractual Obligations in Europe, Sellier, pp. 17-26.

${ }^{32}$ Nótese que el Reglamento 1215/2012 contiene también las exclusiones de su ámbito de aplicación de "los regímenes matrimoniales o los que regulen relaciones con efectos comparables al matrimonio según la ley aplicable" (art. 1.2 a) y los "testamentos y sucesiones" (art. 1.2. f). Ambos son conceptos autónomos cuya interpretación debe ser semejante a la dada para los mismos términos en otros instrumentos de la UE. Vid., sobre la coordinación entre los términos en que se redacta el Reglamento 1215/2012 y Roma I, con especial referencia a la calificación de "relaciones familiares", M. Bodgan, "Convergence and diverence between Brussels I and Rome I with regard to contracts regulating matters of familiy law", en: J. MEEUSEN, Enforcement of International Contracts in the European Union. Convergence and divergence between Brussels I and Rome I, Intersentia, 2004, pp. 211-223.

${ }^{33} \mathrm{Y}$ es que podemos tener distintas cuestiones, algunas vinculadas al hecho de que se dé entre cónyuges -por ejemplo, la admisibilidad misma de la donación o su revocabilidad- y otras no, como puede ser la prescripción de la acción o la interpretación de las disposiciones del contrato. Vid., P. WAUtelet, Les donations ..., op.cit., p. 219. 
"contractual" en los términos vistos supra, puede encajar dentro del concepto, autónomo ya, de "régimen económico matrimonial". En este caso, dicha donación, excluida de Roma I ex art. 1.2. c) y tal y como reafirma el Informe Giuliano/Lagarde, debería ser regulada por las normas de conflicto relativas a los efectos del matrimonio, que en la actualidad se concretan en el Reglamento 2016/1103, dado que este instrumento supraestatal con vocación omnicomprensiva en materia de regímenes económico-matrimoniales ya es de aplicación tanto en competencia judicial internacional como para la determinación de la ley aplicable ${ }^{34}$. Este concepto, "régimen económico matrimonial" o "régimen matrimonial" -en terminología del Reglamento 1215/2012, que después analizaremos- es un concepto que ha planteado tradicionalmente dificultad en torno a su delimitación por varios motivos: por su transversalidad ${ }^{35}$, por la complicada distinción entre las relaciones personales y patrimoniales de los cónyuges y porque produce efectos entre los cónyuges y también respecto de terceros.

27. Su falta de definición concreta en una norma sustantiva, en el marco del Derecho de la UE, se ha solventado con la aprobación y entrada en vigor del Reglamento 2016/1103, sobre regímenes económicos matrimoniales, del que España forma parte ${ }^{36}$. Este, al describir su ámbito de aplicación, afirma que por "régimen económico matrimonial" se entiende el "conjunto de normas relativas a las relaciones patrimoniales entre los cónyuges y con terceros, como resultado del matrimonio o de su disolución" (artículo 3.1. a)). Según algunos autores, de la lectura conjunta de este artículo y del Considerando 18 del mismo texto ${ }^{37}$, se infiere que este término incluye las capitulaciones matrimoniales específica y exclusivamente previstas para el matrimonio por determinados ordenamientos jurídicos nacionales (así, el español, en los artículos 1318-1324 Cc en Derecho común, en todo lo que tenga carácter patrimonial ${ }^{38}$ ), y toda relación patrimonial entre los cónyuges y en sus relaciones con terceros que resulte directamente del vínculo matrimonial o de su disolución ${ }^{39}$. Esto es, si tenemos una donación por razón de matrimonio, por ejemplo, o bien una donación de bien futuro incluida en capitulaciones matrimoniales, la consideraremos vinculada al matrimonio.

${ }^{34}$ Sobre su ámbito de aplicación temporal, distinto en determinación de la competencia judicial internacional y en la determinación de la ley aplicable, vid. nota 5.

${ }^{35} \mathrm{Y}$ es que es un concepto jurídico vinculado a diversas áreas jurídicas: los derechos reales (porque los bienes de los cónyuges pueden tener diversa naturaleza, ser de carácter privativo o común, bienes muebles o inmuebles), el Derecho de familia, el Derecho de obligaciones, el Derecho registral (el acceso a los registros públicos se prevé en numerosos ordenamientos, y también respecto de determinados actos jurídicos en relación a los bienes conyugales) o el Derecho de sucesiones (se deberá coordinar la liquidación de la sociedad conyugal con la de la herencia, pueden existir limitaciones a la disposición de los bienes por el Derecho de sucesiones, entre otras). Vid., A. Rodríguez Benot, "Los efectos...", op.cit., p. 13.

${ }^{36}$ Al haberse adoptado este Reglamento mediante el procedimiento de cooperación reforzada, no se aplica en todos los EE.MM. de la UE, sino en los siguientes, hasta la fecha: Austria, Bélgica, Bulgaria, Croacia, Chipre, la República Checa, Alemania, Grecia, España, Francia, Italia, Luxemburgo, Malta, los Países Bajos, Portugal, Eslovenia, Finlandia y Suecia. Evidentemente, el hecho de que el Reglamento se haya adoptado mediante la cooperación reforzada va a dar lugar a situaciones resueltas de diversas maneras según dónde se presente la demanda, con la falta de previsibilidad y seguridad jurídica que esto conlleva dentro del espacio europeo de justicia.

37 "El ámbito de aplicación del presente Reglamento debe incluir todos los aspectos de Derecho civil de los regímenes económicos matrimoniales, relacionados tanto con la administración cotidiana del patrimonio matrimonial como con la liquidación del régimen, en particular como consecuencia de la separación de la pareja o del fallecimiento de uno de los cónyuges. A efectos del presente Reglamento, el término «régimen económico matrimonial» debe interpretarse de forma autónoma y ha de abarcar no solo las normas imperativas para los cónyuges, sino también las normas opcionales que los cónyuges puedan acordar de conformidad con el Derecho aplicable, así como cualesquiera normas por defecto del Derecho aplicable. Incluye no solo las capitulaciones matrimoniales especifica y exclusivamente previstas para el matrimonio por determinados ordenamientos jurídicos nacionales, sino también toda relación patrimonial, entre los cónyuges y en sus relaciones con terceros, que resulte directamente del vínculo matrimonial o de su disolución." Considerando 18 del Reglamento 2016/1103.

${ }^{38}$ No obstante, la contribución a las cargas familiares del artículo 1318 se califica como "alimentos", encontrándose por tanto excluido del ámbito de aplicación material del Reglamento 2016/1103 y considerándose incluido en el Reglamento 4/2009 de obligaciones de alimentos.

${ }^{39}$ Ampliamente sobre el ámbito de aplicación del Reglamento, vid., J. RodRíguez Rodrigo, Relaciones Económicas de los Matrimonios y las Uniones Registradas en España, Antes y Después de los Reglamentos (UE) 2016/1103 y 2016/1104, Dykinson, 2019, pp. 33-43; A. Rodríguez Benot, "Los efectos ...”, op. cit., p. 14. 
28. Este concepto lo recoge sin duda el legislador europeo de la jurisprudencia del TJUE en el caso Cavel vs. Cavel $^{40}$, referida al Convenio de Bruselas de 1968, basándose en el principio de interpretación uniforme del Derecho de la UE y la coherencia que debe salvaguardarse en la interpretación de las normas de la UE para garantizar el principio de igualdad, como ya mencionamos. En dicha sentencia se afirma que dicho concepto abarca tanto los regímenes económicos previstos de manera específica por determinadas legislaciones como todas las relaciones patrimoniales que resultan directamente del vínculo conyugal o de su disolución ${ }^{4142}$. Así, no se entienden excluidos del ámbito de aplicación del Reglamento 1215/2012 (por aplicación extensiva de la jurisprudencia del Tribunal de Justicia de la UE -entonces de la Comunidades Europeas- respecto del Convenio de Bruselas de 1968) ni tampoco del Reglamento Roma I, como veremos, los litigios sobre las "relaciones patrimoniales entre cónyuges que no tengan relación con el matrimonio" ${ }^{43}$.

\section{Las obligaciones que se deriven [...] de testamentos y de sucesiones. Artículo 1.2.c) in fine.}

29. En segundo lugar, puede ocurrir que se trate de una donación mortis causa, cuya calificación y tratamiento, no pacífico, será abordada en el siguiente apartado. O también que, aun tratándose de una donación inter vivos, entre cónyuges, existan aspectos sujetos a la ley sucesoria. Este puede ser el caso, como veremos, de las cuestiones que se dirigen a proteger a determinados herederos, como la reducción de liberalidades (incluyendo la imputabilidad de una liberalidad a la cuota disponible o legitimaria, así como las condiciones de su sujeción a la acción de reducción). En ambos casos excluiríamos la aplicación del Reglamento Roma I ex art. 1.2.c) -y, también, del Reglamento 1215/2012 ex art. 1.2 f)- y nos remitiríamos -aunque no es una cuestión pacífica-, como veremos ampliamente más adelante, al Reglamento 650/2012, de sucesiones.

\section{Las obligaciones que se deriven de relaciones familiares y de relaciones que la legislación apli- cable a las mismas considere que tienen efectos comparables [...]. Artículo 1.2. b).}

30. Por último, puede ocurrir que tengamos una donación entre cónyuges que no puede considerarse parte del régimen económico matrimonial ni está vinculada a la sucesión, ambas cuestiones excluidas claramente de Roma I, pero que queda excluida del ámbito de aplicación del Reglamento Roma I aun pudiendo ser "contractual" por encajar en la exclusión del art. 1.2.b), al derivar de relaciones familiares y de relaciones que la legislación aplicable a las mismas considere que tienen efectos

\footnotetext{
${ }^{40}$ Sobre la posible aplicación del Convenio de Bruselas de 1968 a la colocación de precintos y al embargo de bienes decretados contra la demandada por el Juez de familia en un proceso de divorcio pendiente ante un Tribunal francés, al tratarse de un procedimiento accesorio a un proceso judicial relativo al estado de las personas o a los regímenes matrimoniales. Vid., STJCE 27 marzo 1979, 143/78, Cavel c. Cavel [ECLI:EU:C:1979:83], FD. 8.

${ }^{41}$ Vid., M. Gómez Gene, “Artículo 1", pp. 57-88, en AA.VV., Comentario al Reglamento (UE) $n^{\circ}$ 1215/2012 relativo a la competencia judicial, el reconocimiento y la ejecución de resoluciones judiciales en materia civil y mercantil, Thomson Reuters-Aranzadi, 2016, p. 67.

${ }^{42} \mathrm{Al}$ respecto, aunque no sea objeto de estudio de este artículo, señalamos que el régimen de las uniones no registradas, siguiendo con la STJUE de 6 de junio de 2019 en el asunto Weil [ECLI:EU:C:2019:473], quedan fuera de la regulación del Reglamento 2016/1104 y sus relaciones patrimoniales podrían considerarse parte del Reglamento 1215/2012 -y de su predecesor, el 44/2001- ya que no forman parte de la exclusión que contiene el art. 1 respecto de los regímenes "matrimoniales".

${ }^{43}$ Literalmente: “(...)que de ello se deduce que el concepto de «regímenes matrimoniales» no sólo comprende los regímenes económicos concebidos especifica y exclusivamente por determinadas legislaciones nacionales con vistas al matrimonio, sino también todas las relaciones patrimoniales que resultan directamente del vínculo conyugal o de su disolución; que los litigios sobre los bienes de los cónyuges en un proceso de divorcio pueden, por ello, según los casos, afectar o estar estrechamente vinculados: 1) a cuestiones relativas al estado de las personas; 2) a relaciones jurídicas patrimoniales entre cónyuges que resultan directamente del vínculo conyugal o de su disolución; 3) a relaciones jurídicas patrimoniales existentes entre ellos, pero sin relación con el matrimonio; que, si bien los litigios de la última categoría están comprendidos en el ámbito de aplicación del Convenio, los relativos a las dos primeras deben excluirse de él." FD 7.
} 
comparables, incluida la obligación de alimentos ${ }^{44}$. Esta exclusión es determinante y su interpretación ha sido muy controvertida a pesar de que, como señalan algunos autores, es el mismo Informe GiULIANo/ LAGARDE, cit. supra, el que defiende una calificación ex lege causae, al hacer referencia a los Derechos nacionales aplicables eventualmente al fondo de la cuestión ${ }^{45}$.

31. A pesar de que el Reglamento Roma I recoge expresamente que, en lo que se refiere a la determinación de lo que debe entenderse por "relaciones familiares", se estará a lo dispuesto en la ley del foro (vid. Considerando 8), según la doctrina más autorizada, la intención del legislador fue la de respetar con esa exclusión las limitaciones que, en los Derechos nacionales de determinados Estados parte, pudieran existir en Derecho de familia para las donaciones verificadas en ese ámbito; esto, es, respetar a aquellos Estados que, en sus legislaciones nacionales - véase, la italiana-, disponen de "relaciones de familia" que comportan obligaciones contractuales y cuyos ordenamientos regulan específicamente, recogiendo, por ejemplo, limitaciones a las donaciones entre cónyuges por el hecho de ser cónyuges. Por tanto, a pesar de que las "relaciones familiares" se califiquen ex lege fori, la parte de la exclusión que, en castellano, se refiere a "obligaciones que deriven", se remitiría, así, a los Derechos nacionales respectivos ${ }^{46}$.

32. Respecto a la interpretación de esta exclusión cabe hacer una reflexión. Teniendo en cuenta el concepto autónomo que el Reglamento 2016/1103 ha dado para el "régimen económico matrimonial" incluyendo en este toda relación patrimonial entre los cónyuges y en sus relaciones con terceros que resulte directamente del vínculo matrimonial o de su disolución, cabe pensar en cuál es la intersección o diferencia entre ambas exclusiones (apartados b) y c)) para una donación entre cónyuges ${ }^{47}$. Esto es, si una donación "deriva" de relaciones familiares (apartado b), en el caso de una donación entre cónyuges, bien podría entenderse que se inserta dentro del régimen económico matrimonial, por lo que la excepción contenida en el art. 1.2 b) quedaría sin utilidad o vacía de contenido salvo que se entienda, como defiende parte de la doctrina ${ }^{48}$-, que existe una remisión a los Derechos nacionales, por lo que no depende de esa interpretación autónoma sino que, pudiendo ser una donación que en un país como España pudiera ser perfectamente contractual -no regulada de manera específica en Derecho de familia-, aplicándosele por tanto el Reglamento Roma I, no sería así en otro país como Italia en la que a pesar de no encajar en el concepto autónomo de "régimen económico matrimonial", dichas donaciones se regulen por el Derecho de familia, estableciendo limitaciones, cautelas, etc ${ }^{49}$.

${ }^{44}$ Sobre la misma, especialmente, vid., A. Rodríguez Benot, "La exclusión de las obligaciones derivadas del Derecho de familia y sucesiones del ámbito material de aplicación del Reglamento Roma I”, Cuadernos de Derecho Transnacional, 2009, Vol. I, Nº1, pp. 112-130, esp. p. 115.

${ }^{45}$ Entre otros, destaca: J. Carrascosa GonzÁlez, “Apuntes sobre...”, op.cit., p. 325 y nota 19, citando Informe Giuliano/ LAGARDE, pp. 17-19.

${ }^{46}$ P. WAUtelet, por su parte, considera que la exclusión se refiere solo a aquellas obligaciones que nacen por razón de la existencia de un vínculo familiar, debiéndose interpretar restrictivamente. Por ejemplo, si se planteara la revocación de una donación entre cónyuges por el nacimiento de un hijo del donante. Señala que la concurrencia de algún aspecto de la donación vinculado especialmente a la relación familiar y al Derecho de familia no descarta la aplicación general del Reglamento Roma I al conjunto de la donación, sino solo a aspectos como, por ejemplo, la admisibilidad misma de la donación entre cónyuges, que tiene su causa en ese vínculo familiar entre esposos. P. WAUTELET, Les donations ..., op.cit., pp. 218 y 219.

${ }^{47}$ Distinto sería entre familiares de otro tipo donde la exclusión del apartado c), referida a los regímenes económicos matrimoniales no entraría en juego.

${ }^{48}$ Entre otros: P. JimÉNEZ BlANCO, “El derecho...”, op.cit., p. 75-77 y amplia bibliografía allí citada; J. CARRASCOSA GONzÁlez, "Apuntes sobre...", op.cit., p. 325, citando también a H. Gaudemet-Tallon; A.L. Calvo Caravaca y J. Carrascosa GonZÁlez, Derecho..., vol.II, op.cit., p. 1067.

${ }^{49}$ Tradicionalmente, estas cuestiones se han vinculado a la ley aplicable a los efectos del matrimonio. Así en España, vid., P. JimÉnez Blanco, "El derecho...", op.cit., p. 75; En Francia: Cass., 15 de febrero de 1966, Révue critique de droit international privé, 1966, p. 273, nota de H. BATIFFOL; Cass., 2 de diciembre de 1969, Révue critique de droit international privé, 1971, p. 507, nota G. de la Pradelle. En Alemania, K. Siehr, Münchener Kommentar zum BGB, Internationales Privatrecht, $4^{\mathrm{a}}$ ed., München, Beck, 2006, art. 14, núm. 110. La cuestión ha resultado polémica en el ordenamiento italiano: N. BoschIERo, "Donazione nel diritto internazionale privato”, en: Digesto. Discipline privatistiche. Sezione civil, t. VII, Utet, 1991, pp. 196 y ss. Más referencias en Derecho comparado en: A. Bonomi, P. Wautelet y S. Álvarez GonzÁlez, “Artículo 1”, op.cit., nota 57. 
33. Siguiendo con la posición de la doctrina dominante, la remisión del legislador a los Derechos estatales en este punto, algo criticable y criticado, complejiza el tratamiento de la cuestión y es el punto clave porque condicionará la calificación (ex lex causae) y la elección del instrumento aplicable al caso ${ }^{50}$. Hay varias soluciones doctrinales a este "círculo inextricable", como veremos más adelante, y de la misma dependerá la aplicación un instrumento normativo u otro.

34. En consecuencia, vamos a dividir el análisis del régimen de DIPr de las donaciones entre cónyuges en tres bloques: el primero, dedicado a la donación con efectos sucesorios, que es aquella que realiza un cónyuge con intención de planificar una ordenación futura de sus bienes, para cuando fallezca; también nos referiremos en este bloque a las cuestiones relativas a donaciones inter vivos que quedarían no obstante sujetas a la ley sucesoria. El segundo, a la donación en el marco matrimonial, esto es, aquella cuya finalidad es la ordenación de los bienes para el desarrollo del matrimonio o dentro de él y que encaja en el concepto autónomo de "régimen económico matrimonial", con independencia de que se realice el acto de donación antes o durante el matrimonio. Y el tercero, a la donación puramente patrimonial o contractual entre cónyuges, que es aquella que, aun realizándose entre cónyuges, no guarda vinculación con el matrimonio, esto es, no tiene su razón en él ni pretende afectar de manera específica la ordenación presente de los bienes en el matrimonio ni tampoco la ordenación futura de los bienes tras su fallecimiento. En este último bloque, realizaremos una distinción en materia de ley aplicable cuando se trate de una donación derivada de las relaciones familiares al estar regulada por el Derecho de familia y que será excluida de Roma I, algo que se determinará de acuerdo a la lex causae que determine el Reglamento 2016/1103 o los arts. 9.2 y 9.3 Cc, según se cumpla o no el ámbito de aplicación temporal del primero.

35. La donación que hemos llamado "puramente contractual" la estudiaremos en último lugar puesto que, si no se puede identificar con la institución sucesoria ni tampoco se puede considerar parte del concepto autónomo de régimen económico matrimonial que incorpora el Reglamento 2016/1103 ${ }^{51}$, aún carente del necesario desarrollo jurisprudencial por el TJUE, se verá sujeta al régimen de las obligaciones contractuales -que prevalecerá, no obstante, en la práctica, de manera general- y que, en Derecho internacional privado de la UE, se concreta, principalmente, como es sabido, en los Reglamentos n ${ }^{\circ} 1215 / 2012$, relativo a la competencia judicial, el reconocimiento y la ejecución de resoluciones judiciales en materia civil y mercantil, y el n ${ }^{\circ} 593 / 2008$, sobre la ley aplicable a las obligaciones contractuales o Roma I, en materia de ley aplicable, con la salvedad que ya hemos anunciado y que estudiaremos en profundidad.

36. Nótese que la estructura de este trabajo, aquí planteada, responde a una posición concreta de la autora sobre la calificación de la donación entre cónyuges y su encuadre en uno u otro instrumento normativo de la UE en atención a la relación entre ellos y a los objetivos de uniformidad, coherencia, seguridad jurídica y evitación de lagunas sin justificación del Espacio europeo de justicia. No obstante, dicha estructura podría no ser la adecuada, como explicaremos en la reflexión final para que pueda comprenderse mejor tras la lectura del trabajo, bajo una interpretación distinta.

37. Una vez realizada la calificación, Reglamento por Reglamento, caso por caso, tenemos que recordar que, en materia de ley aplicable, los tres Reglamentos que nos ocupan tienen eficacia erga om-

\footnotetext{
${ }^{50} \mathrm{Y}$ es que, aplicando la calificación lege fori a esta cuestión podemos estar aplicando normas de determinación de la competencia judicial internacional o normas de conflicto pensadas para obligaciones contractuales - por tanto menos ajustadas y menos capaces de dar una respuesta satisfactoria al caso, especialmente si tenemos en cuenta la posibilidad de encontrarnos con regímenes imperativos de las donaciones entre esposos, razón por la cual algunos autores han señalado las dificultades de aplicación que pueden surgir por la incompatibilidad de aplicar normas de conflicto relativas a los contratos con los regímenes imperativos de las donaciones entre esposos, por lo que consideran más razonable aplicar las normas pensadas para las relaciones económicas en el marco del matrimonio. Vid., D. Bureau y H. Muir Watt, Droit..., op.cit., pp. 117 y 252.

${ }^{51}$ En esta contribución, como ya anunciamos supra, con la intención de simplificar y dado que el título hace referencia a las donaciones realizadas entre cónyuges, nos referiremos únicamente al Reglamento 2016/1103, pero en esencia lo que va a estudiarse, en especial respecto del régimen normativo de la UE previsto en el Reglamento 2016/1103, puede extenderse a las posibles donaciones entre miembros de uniones registradas ya que ambos reglamentos, el 2016/1103 y el 2016/1104 son rigurosamente paralelos, tanto en la forma como en el fondo. Vid. supra nota 4.
} 
nes por lo que no es necesario que los ordenamientos extranjeros vinculados con el supuesto sean de un país cuyas autoridades apliquen los Reglamentos para que aquellos resulten de aplicación.

\section{La donación entre cónyuges sujeta a la ley sucesoria}

38. En este apartado distinguiremos dos cuestiones: en primer lugar, las donaciones mortis cau$s a \mathrm{y}$, en segundo lugar, aquellos aspectos de las donaciones inter vivos que se considerarán sujetas a la ley sucesoria, como, por ejemplo, la reducción de liberalidades (vid. supra párrafo 29), pudiendo producirse, en este último caso, un fraccionamiento de la ley reguladora de la donación, según el aspecto del cual se trate, como veremos.

39. En el ámbito europeo, el instrumento normativo por excelencia es el Reglamento n ${ }^{\circ} 650 / 2012$, relativo a la competencia, la ley aplicable, el reconocimiento y la ejecución de las resoluciones, a la aceptación y la ejecución de los documentos públicos en materia de sucesiones mortis causa y a la creación de un certificado sucesorio europeo ${ }^{52}$. Su amplio ámbito de aplicación ha relegado las normas de producción interna en materia de competencia judicial internacional contenidas en la Ley Orgánica del Poder Judicial y, ese amplio ámbito de aplicación, unido a su carácter erga omnes, hacen que las normas del Código civil en materia de ley aplicable se apliquen ya, únicamente, en conflictos interregionales o a aspectos no regulados por el Reglamento, como veremos.

40. El Reglamento 650/2012, de sucesiones, establece, al definir su ámbito de aplicación material, ex artículos 1, 3.1 a) y Considerando 9, que el Reglamento se aplicará a cualquier forma de transmisión mortis causa de bienes, derechos y obligaciones, que derive:

a) de un acto voluntario en virtud de una disposición mortis causa: testamento, testamento mancomunado -testamento otorgado en un acto por dos o más personas ex art. 3.1.d)- o pacto sucesorio -todo acuerdo, incluido el resultante de testamentos recíprocos, por el que se confieran, modifiquen o revoquen, con o sin contraprestación, derechos relativos a la sucesión o las sucesiones futuras de una o más personas que sean partes en dicho acuerdo artículo 3.1. b)-

b) de una sucesión abintestato.

41. Por tanto, en primer lugar, debemos calificar la figura de "donación mortis causa". Es sin duda una cuestión muy delicada y controvertida, más aún si tenemos en cuenta la pluralidad que existe en la definición de estos actos en los distintos Derechos nacionales ${ }^{53}$. No obstante, subyace la idea en todas ellas de que determinadas donaciones estarán sometidas a las normas de Derecho sucesorio porque pretenden ${ }^{54}$ regular el destino de bienes del donante una vez este fallezca.

${ }^{52}$ Cit. supra, nota 8. Es aplicable: 1) temporalmente, a los litigios sobre sucesiones con decesos ocurridos el 17 de agosto de 2015 o después de esa fecha ex art. 83.1;2) territorialmente, en todos los Estados miembros salvo Dinamarca, Reino Unido e Irlanda (Considerandos 82 y 83).

${ }^{53}$ Así, por ejemplo, en nuestro Cc hay una sola referencia a esta figura en el art. 620 Cc; en Derecho francés e italiano la donación mortis causa trata sobre bienes futuros que formarán parte del patrimonio del donante cuando fallezca, siendo nulas aquellas que se identifican con la prohibición de pactos sucesorios o sucesión futura; en Derecho alemán es aquella sometida a una condición suspensiva o resolutoria del pre-fallecimiento del donante; en common law, es aquella que se realiza cuando se teme que el donante fallezca próximamente, siendo revocada de pleno derecho y de manera automática si no es así. Vid., A. Bonomi, P. Wautelet y S. Álvarez GonzÁlez, El Derecho.., op. cit., notas 66-71. Un análisis de Derecho comparado en J.M. FontANellas i Morell, "Las donaciones mortis causa ante la reglamentación comunitaria de las sucesiones", Anuario español de Derecho internacional privado, $\mathrm{n}^{\circ} 11,2011$, pp. 465-484.

${ }^{54}$ Lo determinante es el "animus" con el que se realiza la donación entre cónyuges. Si se realiza con idea de ordenar relaciones jurídicas con posterioridad al óbito del futuro causante sería donación conyugal de naturaleza sucesoria; si lo fuera con el objeto de ordenar tales relaciones en el marco de las relaciones patrimoniales entres los cónyuges vigente el matrimonio sería donación conyugal de orden económico-matrimonial. 
42. Teniendo en cuenta esta diversidad de aproximaciones, la doctrina ha planteado diversas soluciones a la calificación de las donaciones mortis causa. Siguiendo a A. Bonomi, P. WaUtelet y S. ÁLVAREZ GonZÁLEZ, destacamos tres. En primer lugar, utilizar, para calificarla, criterios de Derecho material interno, algo que choca con la incorporación de conceptos autónomos que predomina en el Derecho de la UE, como ya hemos apuntado en el epígrafe tercero; en segundo lugar, hacer depender su calificación de la ley aplicable a la sucesión, en concreto, la ley que rige los pactos sucesorios según el art. 25 del Reglamento 650/2012, de manera que, si según esa ley, la donación en cuestión es considerada "mortis causa", así será calificada y se actuará en consecuencia; si no es asís5, se considerará "neutra" y quedará sometida a la ley aplicable para las donaciones inter vivos. Por último, se plantea incluirlas dentro del ámbito de aplicación del Reglamento sucesorio de acuerdo a una calificación autónoma, criterio que defiende, entre otros, J.M. FonTANellas i Morell ${ }^{56}$, y que compartimos, entre otras cosas, por los términos en los que está redactado el ámbito de aplicación material del Reglamento 650/2012 que pretende abarcar cualquier forma de transmisión "mortis causa". En definitiva, consideramos que cuando la donación entre cónyuges tiene como finalidad o animus la ordenación futura de los bienes tras el fallecimiento del cónyuge donante, entonces estamos ante una donación vinculada a la institución sucesoria ${ }^{57}$.

43. Entonces, en presencia de una donación entre cónyuges mortis causa que, por ejemplo, se haya hecho mediante pacto sucesorio (en el caso de España solo permitido en algunos Derechos forales, no en Derecho común) o cuando se trate de donaciones de última voluntad (recogidas en el artículo 620 Cc a las que se refiere el artículo 25 del Reglamento 650/2012), descartaremos la aplicación del Reglamento 1215/2012 ${ }^{58}$ y del Reglamento 593/2008 en materia de ley aplicable, así como del 2016/1103, para aplicar el 650/2012 en tanto que quedan comprendidas en su ámbito de aplicación ${ }^{59}$.

44. En el artículo 1.2 letra g), el Reglamento señala que quedan excluidos del ámbito de aplicación del Reglamento "los bienes, derechos y acciones creados o transmitidos por título distinto de la sucesión, por ejemplo mediante liberalidades, propiedad conjunta de varias personas con reversión a favor del supérstite, planes de pensiones, contratos de seguros y transacciones de naturaleza análoga, sin perjuicio de lo dispuesto en el artículo 23, apartado 2, letra i)". En este art. 23.2. $\mathrm{i}^{60}$ se establece precisamente que quedarán comprendidas dentro del ámbito de aplicación del Reglamento la reducción de liberalidades entre vivos. La ley que resulte aplicable a la sucesión regulará, en nuestro caso, en qué medida una persona puede disponer de sus bienes para efectuar donaciones a su cónyuge, si dicha donación debe imputarse una vez fallecido el donante a la cuota disponible o legitimaria, así como las condiciones de su sujeción a la acción de reducción o la obligación del cónyuge donatario de colacionar las liberalidades recibidas del causante ${ }^{61}$. Esto es, se trata de aspectos de las donaciones inter vivos que se considerarán sujetos a la ley sucesoria.

${ }^{55}$ Esto puede deberse a que la ley sucesoria no prevea regla especial para las donaciones por causa de muerte o a que no se califique la donación objeto de controversia como donación mortis causa. A. Bonomi, P. Wautelet y S. Álvarez GonzÁLez, El Derecho.., op. cit., nota 76.

56 J.M. Fontanellas i Morell, "Las donaciones..", op.cit., En contra, considerando que el Reglamento 650/2012 parece excluirlas de su ámbito de aplicación, por lo que quedarían sujetas a Roma I, vid., AL. Calvo CaravaCA y J. CARrascosa GonZÁLEZ, Derecho internacional..., vol. II, op. cit., p. 1068.

${ }^{57}$ Existen casos claros y otros híbridos, como por ejemplo el caso de la "donation-partage" (donación-partición) que contemplan países como Francia o Bélgica, similar a un pacto sucesorio pero limitado a los bienes presentes del cónyuge donante. Aunque se trate de un acto híbrido entre las liberalidades y la partición anticipada de la sucesión, debe calificarse como "sucesoria", sin que se encuentre por tanto afectada por la exclusión del Reglamento 650/2012 del art. 1.2 g). En ese sentido, A. BONOMI, op.cit., párrafo 54.

${ }^{58}$ El Reglamento 1215/2012 plantea a su vez una exclusión referida a la materia sucesoria que hace de estos dos instrumentos complementarios. Así, quedan excluidos de su ámbito de aplicación, como veremos, "f) los testamentos y sucesiones, incluidas las obligaciones de alimentos por causa de muerte".

${ }^{59}$ Así, si estamos ante una donación ligada claramente a la sucesión, aplicaremos este Reglamento a los fallecimientos ocurridos a partir del 17 de agosto de 2015, incluido ese día. Recuérdese que no forman parte del ámbito territorial del Reglamento ni Dinamarca, ni Irlanda ni Reino Unido, vid. supra, nota 52.

${ }^{60}$ (...) "la obligación de reintegrar o computar las donaciones o liberalidades, adelantos o legados a fin de determinar las cuotas sucesorias de los distintos beneficiarios".

${ }^{61}$ P. JiMÉneZ Blanco, op. cit., p. 88. 
45. En el considerando 14, en el mismo sentido: "Los bienes, derechos y acciones creados o transmitidos por otros medios distintos de la sucesión, por ejemplo mediante liberalidades, también deben quedar fuera del ámbito de aplicación del presente Reglamento. Con todo, debe ser la ley que el presente Reglamento considere como la ley aplicable a la sucesión la que determine si las liberalidades o cualquier otra forma de disposición inter vivos que tenga por efecto la adquisición de un derecho real con anterioridad al fallecimiento deben ser reintegrados o tenerse en cuenta a los efectos del cálculo de las cuotas hereditarias de los beneficiarios según la ley aplicable a la sucesión." ${ }^{2}$

46. Además de estas consideraciones debemos tener en cuenta también que, cuando el causante estaba casado, como ocurre en nuestro caso, la sucesión entra en relación con el régimen económico matrimonial, que presenta un impacto claro en la sucesión al tener que disolverse y liquidarse para poder determinar el patrimonio hereditario y las cuotas y situación de los herederos en dicha sucesión, entre ellos la del cónyuge. Las cuestiones relativas a la liquidación del régimen matrimonial quedan excluidas del ámbito de aplicación del Reglamento (artículo 1.2.d) ${ }^{63}$, y, en general, se deberán abordar con carácter previo a la aplicación del Reglamento sucesorio ${ }^{64}$, siguiendo con lo establecido en el Reglamento 2016/1103, que veremos más adelante.

47. La "coordinación" o "descoordinación" entre ambos reglamentos, esto es, el 650/2012 y el 2016/1103, ha sido estudiada por la doctrina ${ }^{65}$ y jurisprudencia, entre otras, a raíz del asunto Mahnkopf, que veremos en el epígrafe dedicado a la determinación de la ley aplicable. En lo que aquí respecta, aplicaremos para la determinación de la competencia judicial internacional y la ley aplicable el Reglamento 650/2012 siempre que la donación esté íntimamente vinculada a la sucesión en los supuestos descritos supra.

\section{Determinación de la competencia judicial internacional.}

48. En materia de competencia judicial internacional, debemos hacer una aclaración antes de comenzar a analizar qué foros ofrece el Reglamento para los litigios sobre donaciones mortis causa y aspectos vinculados a la ley sucesoria.

49. Precisamente respecto de la posible vinculación del régimen económico matrimonial con la sucesión, el Reglamento 2016/1103 ${ }^{66}$ establece en su artículo 4 que, cuando un órgano jurisdiccional

${ }^{62}$ Este aspecto fue problemático en el proceso de adopción del Reglamento al no existir una calificación unánime de estas cuestiones como "sucesorias". Así, en Derecho inglés, la acción de reducción de una liberalidad en vida del donante se regularía por la ley aplicable a la donación -y no a la sucesión- porque es considerada como una impugnación de la validez de la donación. Sin embargo, en el Reglamento se optó por esa redacción sujetando a la ley sucesoria la colación y la reducción. Vid., A. Bonomi, A. Bonomi, P. Wautelet y S. Álvarez González, El Derecho..., op.cit., notas 60-63.

${ }^{63}$ Extendiéndose también, ex. Considerando 12, a «los acuerdos matrimoniales tal como se conocen en algunos sistemas jurídicos en la medida en que no aborden asuntos sucesorios».

${ }^{64}$ A. Fernández-Tresguerres García, Las sucesiones "mortis causa” en Europa: aplicación del Reglamento (UE) Núm. 650/2012, Cizur Menor, Aranzadi, 2016, pp. 150-157.

${ }^{65}$ Entre otros muchos, vid., A. Álvarez Torné, "The dissolution of the matrimonial property regime and the succession rights of the surviving spouse in Private International Law", en K. Boele-WoelKI, y T. Sverdrup (eds.), European Challenges in Contemporary Family Law, Intersentia, Amberes, 2008, pp. 395-410; I. ANTÓN JuÁREZ, "Régimen económico matrimonial, derechos sucesorios del cónyuge supérstite y Certificado Sucesorio Europeo: ¿una combinación explosiva?”, Cuadernos de Derecho Transnacional, 2018, $\mathrm{n}^{\circ}$ 2, pp. 769-780; A. BonOMI, "The interaction among the future EU instruments on matrimonial property, registered partnerships and successions", Yearbook of Private International Law, 2011, vol. 13, pp. 217-231; P. QUINZÁ REDONDO y J. GreY, "La (des) coordinación entre la propuesta de reglamento de régimen económico matrimonial y los reglamentos en materia de divorcio y sucesiones", Anuario Español de Derecho Internacional Privado, No. 13, 2013, pp. 513-542; A. RodRíGUEZ BENOT, "Los Reglamentos de la UE en materia de sucesión por causa de muerte y de régimen económico matrimonial: justificación y caracteres comunes", en E.M. VÁzQUEZ GÓMEZ ET AL (coords.), El arreglo pacífico de controversias internacionales, Tirant lo Blanch, Valencia, 2013, pp. 583-591, esp. 587-588; A. Rodríguez Benot, “Artículo 1" en: J.L. Iglesias Buigues, G. Palao MoReno y P. Quinzá Redondo, Régimen económico matrimonial y efectos patrimoniales de las uniones registradas en la Unión Europea, Comentarios a los Reglamentos (UE) no 2016/1103 y 2016/1104, Tirant lo Blanch, 2018, pp. 21-40, p. 32.

${ }^{66}$ En materia de competencia judicial internacional comenzó a aplicarse a todas las demandas que se presentaran a partir 
de un Estado miembro conozca de la sucesión de uno de los cónyuges en aplicación del Reglamento 650/2012, los órganos jurisdiccionales de dicho Estado serán competentes para resolver sobre el régimen económico matrimonial en conexión con esa sucesión. Por tanto, siempre que estemos en presencia de una sucesión, los litigios que abarquen una donación entre cónyuges y que tengan que valorarse en la liquidación del régimen económico matrimonial, serán de competencia del tribunal que conozca de la sucesión, como veremos a propósito de los foros de los reglamentos respectivos.

50. Dicho esto, el Reglamento 650/2012 prevé una serie de foros de aplicación jerárquica. En primer lugar, es aplicable un foro de sumisión. Este debe ser únicamente el foro de la nacionalidad del causante condicionado a la elección de la ley de la nacionalidad en el momento de la elección o de su fallecimiento según disponen los arts. 5 a $7^{67}$. Este foro es válido, por tanto, solo si los órganos jurisdiccionales elegidos son los del Estado parte cuya ley ha sido elegida por el causante como reguladora de su sucesión ${ }^{68}$, y que no puede ser otra que la ley del Estado de su nacionalidad, bien en el momento de la elección bien en el momento del fallecimiento.

51. Esto es, el Reglamento ofrece en primer lugar la posibilidad de elección de foro siempre que el causante elija la ley de un Estado miembro para regular la sucesión y las partes elijan los tribunales de ese Estado de manera escrita, firmada y fechada (art. 5.2) o tácitamente (ex art. 6.a y $7 \mathrm{c}^{69}$ ). Nótese que debe ser un país de la UE. Si fuera otro país el de la nacionalidad del causante, si bien sí podría regular el fondo de la sucesión dado el carácter erga omnes del Reglamento, no cabría elección de foro.

52. Por tanto, tal y como establece el art. 7, los tribunales del Estado miembro cuya ley haya sido elegida por el causante en virtud del artículo 22 tendrán competencia para resolver sobre la sucesión: a) si el tribunal al que se haya sometido previamente el asunto se hubiese inhibido en virtud del artículo $6^{70}$; b) si las partes del procedimiento acuerdan, de conformidad con el artículo 5, atribuir la competencia a un tribunal o a los tribunales de dicho Estado miembro, o c) si las partes del procedimiento admiten expresamente la competencia del tribunal al que se ha sometido el asunto.

53. Este supuesto de elección de foro podríamos encontrarlo en una donación mortis causa entre cónyuges o cuando, a propósito de una sucesión, exista una donación inter vivos hecha a favor del cónyuge, de la cual se discuta su carácter inoficioso por perjudicar la legítima de los hijos. En este caso, para que exista elección de foro válida, el cónyuge donante -el causante- debe haber elegido válidamente en testamento (ex art. 22) la ley de su nacionalidad, por ejemplo, la francesa, para regular su sucesión, siendo así que se verifique también alguna de las siguientes circunstancias: a) las partes han acordado expresa o tácitamente litigar ante los tribunales franceses; o bien, b) siendo la residencia habitual del

del 29 de enero de 2019. Recordemos que en materia de ley aplicable se aplicará a los matrimonios que se hayan celebrado desde esa fecha o hayan elegido ley a partir de ese día, lo cual supone que en muchos casos que se diriman en la actualidad y en el futuro en los tribunales, seguirán aplicándose normas de producción interna para determinar la ley aplicable al caso, no así la competencia judicial internacional.

${ }^{67}$ Art. 5: Cuando la ley elegida por el causante para regir su sucesión con arreglo al artículo 22 sea la ley de un Estado miembro, las partes interesadas podrán acordar que un tribunal o los tribunales de dicho Estado miembro tengan competencia exclusiva para sustanciar cualquier causa en materia de sucesiones. Y art. 7: Los tribunales del Estado miembro cuya ley haya sido elegida por el causante en virtud del artículo 22 tendrán competencia para resolver sobre la sucesión: a) si el tribunal al que se hay a sometido previamente el asunto se hubiese inhibido en virtud del articulo 6; b) si las partes del procedimiento acuerdan, de conformidad con el artículo 5, atribuir la competencia a un tribunal o a los tribunales de dicho Estado miembro, $o$ c) si las partes del procedimiento admiten expresamente la competencia del tribunal al que se ha sometido el asunto.

${ }^{68}$ El fundamento de esta limitación es el hacer coincidir el forum y el ius, esto es lo que se denomina lex fori in foro proprio, garantizando que la autoridad competente aplique al fondo su propio Derecho y no uno extranjero.

${ }^{69}$ Aunque el Reglamento no lo diga expresamente, se entiende que también es posible la sumisión tácita cuando el causante no haya elegido tribunal competente pero sí la ley de un Estado miembro para que regule su sucesión válidamente ex art. 7 . Vid., P. Blanco-Morales Limones, "Las sucesiones y su régimen jurídico", Revista de Derecho de la Unión Europea, nº 22 enero-junio 2012, pp. 67-98, p. 95.

${ }^{70}$ Se acoge así, como afirma, al forum non conveniens, vid., Ibídem, p. 95. 
causante España, los tribunales españoles se han abstenido, a instancia de parte, de conocer del caso porque consideran que los tribunales franceses están en mejor situación para pronunciarse sobre la cuestión.

54. En este caso, si existe sumisión válida, ese tribunal es el competente para conocer de la totalidad de la sucesión, con independencia de la situación y naturaleza de los bienes. Nótese que este acuerdo de sumisión va a tener repercusiones cuando se acumulen competencias sobre el régimen económico matrimonial según hemos explicado antes. Y es que la voluntad de las partes -una de ellas, necesariamente, el cónyuge supérstite, para que se produzca la acumulación ${ }^{71}$ - respecto del proceso sucesorio va a determinar que el tribunal competente sea ese y no el designado por el Reglamento 2016/1103 en caso de una donación entre cónyuges vinculada al régimen económico matrimonial y a la institución sucesoria.

55. En defecto de elección, el Reglamento prevé que sean competentes los tribunales del Estado miembro de la residencia habitual del causante ${ }^{72}$ en el momento de su fallecimiento, ex art. 4. La "residencia habitual" es un concepto autónomo y propio del Reglamento que debe interpretarse de manera uniforme en clave europea sin recurrir a su concepto en cada Derecho interno. No obstante, no se recoge su definición en el art. 3 del Reglamento, sino que en los Considerandos 23 y 24 se dan criterios para su determinación en base a ejemplos de lo que, en caso de duda, debe considerar un tribunal para poder declararse competente en base a la residencia habitual (entre otras, la presencia física, la integración, la duración de su estancia en ese territorio, el animus manendi, etc.).

56. En su defecto, el artículo 10 establece un foro de competencia subsidiaria, según el cual, aun en el supuesto de que el causante no tuviera su residencia habitual en el momento del fallecimiento en un Estado miembro, los tribunales del Estado miembro en el que se encuentren los bienes de la herencia serán competentes para pronunciarse sobre el conjunto de la sucesión siempre que: a) el causante poseyera la nacionalidad de dicho Estado miembro en el momento del fallecimiento, o, en su defecto, b) el causante hubiera tenido previamente su residencia habitual en dicho Estado miembro, siempre y cuando, en el momento en que se someta el asunto al tribunal, no haya transcurrido un plazo de más de cinco años desde el cambio de dicha residencia habitual ${ }^{73}$. Si no se dieran estos requisitos, serán competentes los tribunales del lugar donde se encuentren los bienes pero solo respecto de esos bienes (art. 10.2) ${ }^{74}$.

${ }^{71}$ A.L. Calvo Caravaca y J. Carrascosa González (dir.), Derecho..., Vol. II, op.cit., p. 174, citando a P. Quinzá Redondo y A. BonOMI.

${ }^{72}$ El Reglamento incorpora el criterio de la residencia habitual, criterio plenamente fáctico que, tras la Segunda Guerra Mundial se comienza a generalizar, en parte por la labor de la Conferencia de La Haya de Derecho internacional privado, para superar los inconvenientes del criterio de la nacionalidad, que podía llevar a ordenamientos que no siempre están conectados con el caso en cuestión, y del criterio del "domicilio", con claras diferencias en su concepción entre países de tradición jurídica continental y los anglosajones (con el concepto de "domicile"). Esto garantiza un nexo real entre la sucesión y el Estado miembro que ejerce la competencia, ahorra costes y favorece que la autoridad que sea competente aplique su propio Derecho, lo que garantiza la buena administración de justicia. Vid., entre otros muchos, J. CARrascosa GonZÁlez, "Reglamento sucesorio europeo y residencia habitual del causante", Cuadernos de Derecho Transnacional, Marzo 2016, Vol. 8, No 1, pp. 47-75. También encontramos críticas en la doctrina a la incorporación de este criterio frente a la nacionalidad, por su mayor inseguridad jurídica o, también, por la posibilidad de alteración fraudulenta: D.F. CAVERS, "Habitual Residence: A Useful Concept?", The American University Law Review, 1971-1972, pp. 475-493, p. 482; A. Devaux, “The European Regulations on Succession of July 2012: A Path Towards the End of the Succession Conflicts of Law in Europe, or not?", The International Lawyer, Vol . $47, \mathrm{n}^{\circ} 2$ (Fall 2013), pp. 229-248, pp. 232 y ss., y bibliografía en nota 20. Ventajas e inconvenientes de los tres criterios de conexión mencionados a propósito de la determinación del estatuto personal en: A. RodRíGuez Benot, "El criterio de conexión para determinar la ley personal: un renovado debate en Derecho internacional privado", Cuadernos de Derecho Transnacional, (Marzo 2010), Vol. 2, № 1, pp. 186-202.

${ }^{73}$ Por ejemplo, teniendo el cónyuge que ha fallecido residencia habitual en los EE.UU. en el momento de fallecer, encontrándose bienes de la herencia en España, los tribunales españoles podrían conocer de la sucesión -y con ello, de la donación en cuestión- cuando a) el causante tuviera la nacionalidad española en el momento de su fallecimiento o b) no hubieran transcurrido más de cinco años desde que el causante tuviera su residencia habitual en España.

${ }^{74}$ Artículo sobre el que se han señalado diversos problemas de aplicación, como puede ser la concurrencia de jurisdicciones o el foro exorbitante. Vid., entre otros, A. BоnомI, "Il regolamento europeo sulle successioni", Rivista di diritto internazionale privato e processuale, vol. $49, \mathrm{n}^{\circ} 2,2013$, pp. 293-324. 
57. La doctrina critica que los tribunales competentes según este artículo puedan conocer del régimen económico matrimonial ${ }^{75}$, ya que esos puntos de conexión que se emplean para determinar la competencia pueden no tener relación con el cónyuge supérstite ${ }^{76}$. Esta crítica es lógicamente extensible al litigio por la donación entre los cónyuges que nos ocupa cuando esta se encontrase íntimamente vinculada al régimen económico matrimonial y a la sucesión.

58. Por último, mencionamos el foro de necesidad del art. 11, al igual que en el Reglamento 2016/1103, de aplicación restrictiva y excepcional, subsidiario, "de cierre" y de aplicación voluntaria por los tribunales de los Estados miembros para casos que se encuentren estrechamente vinculados con terceros Estados pero en los que exista una vinculación "suficiente" -no estrecha- con el Estado que vaya a conocer en base a este foro (art. 11.2). La "imposibilidad" de plantear el caso en un Estado con el que existe vinculación estrecha podría hacer referencia, por ejemplo, a que exista una guerra civil. Por su parte, el que "no pudiera razonablemente iniciarse" en dicho Estado podría atribuirse, por ejemplo, a que no sea razonable esperar la obtención de justicia por discriminación debida a sexo, etnia o religión.

59. Antes de finalizar el análisis de los foros de competencia judicial internacional del Reglamento de sucesiones, señalamos el foro específico y alternativo del art. 13 para la aceptación de herencia, legado o renuncia a los mismos. En ese caso, serán también competentes los tribunales del Estado miembro de la residencia habitual del cónyuge que deba efectuar la declaración relativa a la aceptación o renuncia de legado a estos efectos, cuando en el Derecho del Estado miembro en cuestión dichas declaraciones puedan efectuarse ante un tribunal ${ }^{77}$. Supongamos que el causante ha dejado un legado a su cónyuge. A efectos de que este, si residiera habitualmente en un Estado distinto de aquel en el que va a dirimirse la sucesión, pueda declarar la aceptación o renuncia de dicho legado, serán competentes los tribunales de ese Estado en el que reside el cónyuge supérstite en lo que respecta a dicha declaración, siempre que su ordenamiento así lo prevea.

60. En el caso de que estemos ante una donación mortis causa o de algún aspecto de la donación inter vivos regulada por la ley sucesoria, el Reglamento 650/2012 se aplicará siempre, en los Estados parte del mismo, a todas las sucesiones de las personas que hayan fallecido con posterioridad al 17 de agosto de 2015. Por tanto, a estas alturas, la relevancia de los foros recogidos en el artículo 22 quáter g) de la LOPJ carecen de relevancia práctica. Solamente podrá ser relevante el artículo 22 sexies LOPJ respecto de medidas cautelares y provisionales que se solicitaran en España aunque sea otro Estado el que está conociendo o va a conocer de la sucesión en virtud de la regla específica que prevé el Reglamento 650/2012 en el art. 19 que remite a las normas internas de competencia judicial internacional en esta cuestión.

\section{Determinación de la ley aplicable}

61. En cuanto a la determinación de la ley aplicable, tanto las donaciones mortis causa como aquellos aspectos de las donaciones inter vivos regulados por la ley sucesoria (supra) quedarán sujetos al

\footnotetext{
${ }^{75}$ Como ya apuntamos supra y como se verá en el siguiente epígrafe, el Reglamento 2016/1103 prevé un foro de acumulación de competencias (arts. 4 y 5), de manera que, de manera obligatoria y no opcional para los cónyuges (como ocurre con el Reglamento 4/2009, de alimentos), se acumulará la demanda sobre la donación relacionada con el régimen económico matrimonial a la competencia del tribunal que resuelva sobre el proceso sucesorio conexo ya abierto en la UE (art. 4) en virtud del Reglamento 650/2012, ya que para poder resolver una cuestión sucesoria tendrá que determinar previamente la masa hereditaria y por tanto disolver el régimen económico matrimonial.

${ }^{76} \mathrm{Al}$ tratarse de un caso de competencia parcial no tiene sentido que el tribunal competente para conocer de la sucesión respecto de "determinados bienes" (ex art. 10.2) conozca también del entero régimen económico matrimonial, más aún cuando el Reglamento 2016/1103 recoge la competencia parcial -esto es, solo respecto de esos bienes- del tribunal en el que el matrimonio o cualquiera de los cónyuges tenga bienes. A.L. Calvo Caravaca y J. Carrascosa González (dir.), Derecho..., Vol. II, op. cit., p. 175.

${ }^{77}$ Vid. también al respecto Considerando 32.
} 
Reglamento 650/2012 ${ }^{78}$, que, siendo de aplicación erga omnes, desplaza las normas de producción interna en la materia (relegadas a la determinación de la ley aplicable en conflictos interregionales o a aspectos no regulados por el Reglamento) para los fallecimientos ocurridos a partir del 17 de agosto de 2015. El Reglamento consagra los principios de universalidad en el supuesto de hecho y unidad en la consecuencia jurídica, por lo que el ordenamiento que resulte aplicable regulará la totalidad de la sucesión (art. 23).

62. En lo que a nuestro supuesto de estudio respecta ${ }^{79}$, de donación mortis causa entre cónyuges, podremos tener dos supuestos básicos en el marco de la sucesión testada. Que el cónyuge donante haya elegido la ley aplicable a la donación, que no podrá ser otra que la de su nacionalidad en el momento de la elección o de su fallecimiento (art. 22), o que, en defecto de elección, se aplique la ley del lugar de residencia habitual del causante (art. 21), que, por lo general, será residencia compartida con su cónyuge y, por tanto, será la ley del lugar de residencia habitual, también, del donatario. Esto salvo que, del conjunto de circunstancias del caso, este se halle más estrechamente vinculado con otro ordenamiento (art. 21.2), algo que habrá que valorar caso por caso. A la capacidad para realizar la donación mortis causa y validez material se aplicará la ley reguladora del fondo de la donación (arts. 24 y 26.1) y, respecto de la forma del acto -salvo para pactos sucesorios, vid. párrafo siguiente-, estaremos al Convenio de La Haya de 5 de octubre de 1961 sobre conflictos de leyes en materia de forma de las disposiciones testamentarias $^{80}$, según dispone el art. 75.1.2 del Reglamento, con diversos criterios de conexión alternativos en aras del principio favor testamentii.

63. Respecto de la sucesión pactada, de especial relevancia en el supuesto que nos ocupa, el Reglamento prevé aplicar al fondo los mismos artículos que para la sucesión testada (art. 22 y en su defecto 21), a la forma el art. 27 del Reglamento y a la capacidad, la ley que resultaría aplicable al fondo de la sucesión en el momento de concluir el pacto (arts. 25 y 26.1). Así, para facilitar que los derechos sucesorios adquiridos como consecuencia de un pacto sucesorio -de donación entre cónyuges u otra- sean aceptados en los Estados miembros, a pesar de que pueden no estar aceptados en algunos, el Reglamento determina qué ley debe regir la admisibilidad de esos pactos, su validez material y sus efectos vinculantes ${ }^{81}$.

64. Sobre la coordinación entre el Reglamento 650/2012 y el 2016/1103 en materia de ley aplicable, recordamos que tal "coordinación" -o "descoordinación"- entre los mismos ha sido estudiada por la doctrina y jurisprudencia, entre otras, a raíz del asunto Mahnkopf. Al respecto podemos sintetizar de la siguiente forma: el legislador europeo quiso evitar que la ley reguladora de la sucesión se escindiera, de manera que en el art. 23.2 del Reglamento 650/2012 incluye la regulación de los derechos sucesorios del cónyuge viudo a pesar de que en su artículo 1.2 d) excluya las cuestiones relativas a los regímenes económico matrimoniales al igual que el Reglamento 2016/1103 excluye las sucesiones, con ánimo de no solapar sus respectivos ámbitos de aplicación. Esto en la práctica puede traducirse en un problema cuando, al aplicar normas de conflicto distintas, esto nos lleva a la aplicación de dos Derechos nacionales diferentes, uno para la sucesión y otro para la liquidación del régimen económico matrimonial. Si ocurre que estos, además, tienen sistemas distintos (esto es, en uno un régimen económico matrimonial supletorio beneficioso para el cónyuge, siendo sus derechos sucesorios limitados, y en otro un régimen económico matrimonial de "separación de bienes" o equivalente, con derechos sucesorios para el cónyuge más generosos) puede darse un resultado claramente indeseable e injusto. Ejemplo: matrimonio entre nacional alemán y nacional holandesa que trasladan su residencia a España cuando se jubilan. Se

\footnotetext{
${ }^{78}$ Siendo competentes tribunales españoles, se entiende.

${ }_{79}$ Se abordan a continuación de manera breve las normas de conflicto de los principales aspectos de la regulación en el Reglamento 650/2012 de la donación mortis causa, en los que no nos alargamos puesto que ya han sido ampliamente tratados por la doctrina y dado que no presentan especial dificultad o especificidad en relación a nuestro supuesto de estudio.

${ }^{80} \mathrm{Si}$ conociera del asunto una autoridad española, ya que España forma parte del Convenio. Para aquellos países de la UE que no formen parte del mismo, se aplicará el Reglamento, art. 27, para determinar la ley aplicable a la forma de las disposiciones testamentarias, con algunas diferencias (por ejemplo, la prohibición en éste último de las disposiciones mortis causa orales).

${ }^{81}$ J.M. FontanelLas i Morell, “Las donaciones...”, op.cit., pp. 465-484.
} 
compran una casa en territorio español y varios años después el marido fallece sin haber elegido ley que regule su sucesión, se aplicaría la ley española a la sucesión pero los efectos del matrimonio se regirían por Derecho alemán al ser Alemania donde fijaron su residencia habitual tras el matrimonio ${ }^{82}$. Ante estos problemas de coordinación, que bien pueden afectar a una donación entre los cónyuges vinculada a la sucesión o al régimen económico matrimonial, la doctrina señala como posible solución práctica la elección de la misma ley o de leyes compatibles por parte de los interesados para ambas cuestiones ${ }^{83}$.

\section{La donación entre cónyuges vinculada al régimen económico matrimonial}

65. En atención a la jerarquía de fuentes del sistema español de DIPr, acudiendo al Reglamento 2016/1103, y a falta de jurisprudencia del TJUE que sin duda llegará sobre el concepto autónomo de "régimen económico matrimonial", ya visto en el epígrafe tercero a propósito de la calificación, la cuestión clave parece ser determinar, en cada caso, cuándo puede entenderse que una donación está vinculada al matrimonio, por tener como finalidad la ordenación de los bienes de los cónyuges en el marco del matrimonio, en cuyo caso se aplicará el Reglamento 2016/1103 y cuándo no, aplicando entonces el Reglamento 1215/2012 y Roma I -siempre que no estemos ante una donación mortis causa o ante alguno de los aspectos vinculados a la ley sucesoria tal y como vimos supra-.

66. Obviamente, esto así siempre que no se trate de cuestiones excluidas del ámbito de aplicación material del Reglamento 2016/1103 ${ }^{84}$ y de que se cumplan sus restantes ámbitos de aplicación, territorial y temporal. Esto es, en el ámbito de aplicación material cubierto por el Reglamento 2016/1103, de aplicación erga omnes, quedan desplazadas las normas de producción interna del Código civil relativas a los efectos patrimoniales del matrimonio - relegadas a los conflictos interregionales-, si bien hay que recordar que, ex art. 69, su ámbito de aplicación temporal difiere en sede de competencia judicial internacional (aplicable a las demandas presentadas a partir del 29 de enero de 2019) y en sede de ley aplicable (a los cónyuges que hayan celebrado su matrimonio o especificado la ley aplicable el 29 de enero de 2019 o después de esa fecha). Si se trata, por ejemplo, de un litigio por una donación entre cónyuges cuyo matrimonio - o elección de ley- se formalizara antes de 2019 pero cuya demanda se pre-

${ }^{2}$ Vid., I. ANTÓN JuÁREZ, "Régimen económico matrimonial, derechos sucesorios del cónyuge supérstite y Certificado Sucesorio Europeo: ¿una combinación explosiva?”, Cuadernos de Derecho Transnacional, 2018, nº 2, pp. 769-780, ejemplo citado en p. 774.

${ }^{83}$ Vid., sobre la interacción entre el Reglamento de sucesiones y el de régimen económico matrimonial, entre otros posibles: M. Álvarez ToRnÉ, "The dissolution of the matrimonial property regime and the succession rights of the surviving spouse in Private International Law”, en: K. Boele-Woelki y T. Sverdrup (eds.), European Challenges in Contemporary Family Law, Intersentia, Amberes, 2008, pp. 395-410; I. ANTÓN JuÁREZ, "Régimen económico matrimonial, derechos sucesorios del cónyuge supérstite y Certificado Sucesorio Europeo: ¿una combinanción explosiva?”, Cuadernos de Derecho Transnacional, 2018, ${ }^{\circ}$ 2, pp. 769-780; A. BonOMI, "The interaction among the future EU instruments on matrimonial property, registered partnerships and successions", Yearbook of Private International Law, vol. 13, 2011, pp. 217-231; D. DAMASCELLI, "Brevi note sull'efficacia probatoria del certificato successorio europeo riguardante la successione di un soggetto coniugato o legato da unione non matrimoniale", Rivista di diritto internazionale privato e processuale, 2017, nº 1, pp. 67-81; P. Quinzá Redondo y J. GrAY, "La (des) coordinación entre la propuesta de Reglamento de régimen económico matrimonial y los Reglamentos en materia de divorcio y sucesiones", AEDIPr, T. XIII, 2013, pp. 513-542; M. REQUEJO IsIDRO, "La coordinación de la competencia judicial internacional en el Derecho procesal europeo de la familia (sucesiones y régimen económico matrimonial y de las uniones registradas)", en A. Domínguez Luelmo y M.P. García Rubio (dir.), Estudios de Derecho de sucesiones. Liber amicorum T.F. Torres García, La Ley, Madrid, 2014, pp. 1195-1217; A. Rodríguez Benot, "Los Reglamentos de la UE en materia de sucesión por causa de muerte y de régimen económico matrimonial: justificación y caracteres comunes”, en E.M. VÁzQuez Gómez, M.D. AdAm MuÑoz y N. Cornago Prieto (coords.), El arreglo pacifico de controversias internacionales, Tirant lo Blanch, Valencia, 2013, pp. 583-591.

${ }^{84}$ Exclusiones que son (art. 1.2): a) la capacidad jurídica de los cónyuges; b) la existencia, validez y reconocimiento del matrimonio; c) las obligaciones de alimentos; d) la sucesión por causa de muerte de uno de los cónyuges; e) la seguridad social; f) el derecho de transmisión o ajuste entre los cónyuges, en caso de divorcio, separación judicial o anulación del matrimonio, de los derechos de pensión de jubilación o de invalidez devengados durante el matrimonio y que no hayan dado lugar a ingresos en forma de pensión durante este; g) la naturaleza de los derechos reales sobre un bien, y h) cualquier inscripción en un registro de derechos sobre bienes muebles o inmuebles, incluidos los requisitos legales para llevarla a cabo, y los efectos de la inscripción o de la omisión de la inscripción de tales derechos en un registro. 
sentase a partir del 29 de enero de 2019, tendremos que aplicar este Reglamento para la determinación de la competencia judicial internacional, siempre que se cumplan sus restantes ámbitos de aplicación, pero no para la determinación del ordenamiento aplicable, como veremos posteriormente.

\section{Competencia judicial internacional}

67. Si se trata de una donación que sí afecta o se entiende ligada al "régimen matrimonial", debemos acudir al Reglamento UE 2016/1103 ${ }^{85}$. Este reglamento recoge un conjunto amplio de foros de competencia judicial internacional y se aplica, en sede de competencia, a toda demanda que se presente a partir del 29 de enero de 2019. Pensando en nuestro supuesto de estudio, esto es, donaciones entre cónyuges, relacionaremos a continuación aquellos foros que pueden resultar relevantes, en orden jerárquico.

68. En primer lugar, el Reglamento prevé un foro de acumulación de competencias (arts. 4 y 5), de manera que, de manera obligatoria y no opcional para los cónyuges (como ocurre con el Reglamento $4 / 2009$, de alimentos), se acumulará la demanda sobre la donación relacionada con el régimen económico matrimonial a:

1) la competencia del tribunal que conozca del proceso sucesorio conexo ya abierto en la UE (art. 4) en virtud del Reglamento 650/2012 -vid. análisis de los foros aplicables supra-, ya que para poder resolver una cuestión sucesoria tendrá que determinar la masa hereditaria y por tanto disolver el régimen económico matrimonial. Esto es, si un tribunal español conoce de un proceso sucesorio en virtud del Reglamento 650/2012, será también competente del litigio que surja por una donación entre cónyuges que se entienda parte del régimen económico matrimonial -por ejemplo, una donación en razón de matrimonio- y cuya determinación sea fundamental para disolver dicho régimen y proceder a resolver la sucesión, y esto aunque el resto de foros del Reglamento 2016/1103 no le otorgaran la competencia.

2) la competencia del tribunal que conozca del proceso de divorcio, separación judicial o anulación del matrimonio en virtud del Reglamento 2201/2003, con justificación paralela a la primera. Ahora bien, cuando no exista una vinculación suficiente de ese foro con las partes, debe existir acuerdo de los cónyuges para activar la acumulación de competencias ex art. 5.2 ${ }^{86}$.

69. Si no se produce acumulación en virtud del 4 o del 5.1, entonces podemos considerar el foro de sumisión tácita previsto en el artículo 8, que determinará la competencia por comparecencia del demandado sin impugnar la competencia en cualquiera de los siguientes tribunales de algún Estado parte del Reglamento ${ }^{87}$ : los tribunales del Estado cuyo ordenamiento haya sido elegido por las partes para regular su régimen económico matrimonial (ex art. 22), los de la primera residencia habitual común del matrimonio tras su celebración (ex art. 26.1 a) o los de la nacionalidad común de los cónyuges en el momento de celebración del matrimonio (ex art. 26.1.b). Este foro, al contrario que el resto de foros del Reglamento -excepto, entendemos, la sumisión expresa si las partes lo deciden así-, determinaría el concreto tribunal competente, siendo por tanto un foro de competencia judicial territorial, también. Por ejemplo: A y B, franceses, se casan en Madrid, donde residen habitualmente, otorgando capitulaciones matrimoniales ese mismo año y eligiendo como ley reguladora la española. En un eventual litigio por

\footnotetext{
${ }^{85}$ Esto siempre desde la óptica del sistema español de Derecho internacional privado ya que al tratarse de un Reglamento adoptado por el mecanismo de la cooperación reforzada no todos los tribunales de Estados Miembros se ven obligados a aplicar este instrumento normativo.

${ }^{86}$ Remitimos su análisis, entre otros muchos, a: J.P. QuinZÁ Redondo, Régimen económico matrimonial. Aspectos sustantivos y conflictuales, Tirant lo Blanch, Valencia, 2016, pp.; N. JouBerT, "La dernière pierre (provisoire?) à l'édifice du droit international privé européen en matière familiale. Les règlements du 24 juin 2016 sur les régimes matrimoniaux et les effets patrimoniaux des partenariats enregistrés", $R C D I P, \mathrm{n}^{\mathrm{o}}$ 1, 2017, pp. 1-26; A.L. Calvo Caravaca y J. Carrascosa GonzÁlez (dir.), Derecho..., Vol. II, op.cit., pp. 176-178.

${ }^{87} \mathrm{Si}$ estuviéramos en algún supuesto del apartado 5.2, sí podría considerarse el foro del art. 8, de sumisión tácita.
} 
una donación por razón de matrimonio entre ambos, podrán ser competentes tanto los tribunales españoles como los franceses si hay sumisión tácita ante cualquiera de ellos.

70. Siempre que no se dé la acumulación de competencias ni exista sumisión tácita que derogue el acuerdo expreso anterior, podemos aplicar el foro de la sumisión expresa del art. 7, por el cual los cónyuges podrían elegir ${ }^{88}$ entre: los tribunales del país cuya ley sea aplicable (ex arts. 22, 26.1 a) y 26.1 b)) o los del Estado donde se haya celebrado el matrimonio ${ }^{89}$.

71. En defecto de estos foros, aplicaríamos el foro general del Reglamento ex art. 6, según el cual, cuando ningún órgano jurisdiccional de un Estado miembro sea competente con arreglo a los artículos 4 o 5 o en otros casos distintos de los previstos en estos artículos ${ }^{90}$, serán competentes para resolver sobre el régimen económico matrimonial los órganos jurisdiccionales del Estado miembro: a) en cuyo territorio tengan los cónyuges su residencia habitual en el momento de la interposición de la demanda ante el órgano jurisdiccional, o, en su defecto, b) en cuyo territorio hayan tenido los cónyuges su última residencia habitual, siempre que uno de ellos aún resida allí en el momento de la interposición de la demanda ante el órgano jurisdiccional, o, en su defecto, c) en cuyo territorio tenga el demandado su residencia habitual en el momento de la interposición de la demanda ante el órgano jurisdiccional, o, en su defecto, d) de la nacionalidad común de los cónyuges en el momento de la interposición de la demanda ante el órgano jurisdiccional. Nótese que se trata de una redacción jerárquica, por lo que, si por ejemplo, los cónyuges residen habitualmente en el mismo país en el momento de presentar la demanda, los tribunales de ese país tendrán la competencia sin que pasemos al apartado b).

72. Existen otros foros para casos excepcionales. Respecto del foro de inhibición (art. 9), brevemente, diremos que, si la pareja no pudiera considerarse un "matrimonio" según las normas de conflicto del Estado del foro (porque según estas normas no se pueda considerar un "matrimonio" a la unión entre personas del mismo sexo), estando éste reconocido en el Derecho del foro, el tribunal puede inhibirse de conocer sobre el régimen económico matrimonial y, en concreto, sobre la donación vinculada al mismo si estamos en ese supuesto (ex art. 9) ${ }^{91}$.

73. Respecto de los foros contemplados en los artículos 10 y 11, respectivamente, solo se aplicarán cuando ningún otro foro del Reglamento sea aplicable (ex art 4,5,6,7 u 8). En el primer caso, el foro de competencia subsidiaria, serán competentes para conocer del régimen económico matrimonial los tribunales del Estado miembro donde se encuentre un bien inmueble de los cónyuges pero solo respecto de ese bien inmueble. Este foro puede ser interesante cuando la donación entre cónyuges fuera de un bien inmueble y estuviera vinculada al régimen económico matrimonial y ningún otro foro de este Reglamento otorgara competencia, además, por su cercanía al bien inmueble, puede resultar un foro útil a pesar del riesgo de resoluciones incompatibles por la fragmentación de la competencia judicial internacional en lo que respecta al régimen económico matrimonial.

${ }^{88}$ Condiciones de validez formal ex art. 7.2.: deberá expresarse por escrito, fechado y firmado por las partes. Se considerará escrito toda comunicación efectuada por medios electrónicos que proporcione un registro duradero del acuerdo.

${ }^{89}$ Ex considerando 37, el Estado miembro de la celebración del matrimonio será el Estado miembro ante cuyas autoridades se haya celebrado el matrimonio.

${ }^{90}$ Por ejemplo, que haya otro tribunal competente conociendo de un proceso de divorcio o sucesiones pero no sea competente en virtud de Reglamento europeo sino de otra norma de producción interna. Vid., A.L. Calvo CaravaCA Y J. CARRASCosa GonZÁlez (dir.), Derecho..., Vol. II, op.cit., p. 184, citando a I. Barrière Brousse.

${ }^{91}$ Vid., ejemplo en L. Calvo Caravaca y J. Carrascosa González (dir.), Derecho..., Vol. II, op.cit., p. 187. Recogemos aquí la observación que hacen dichos autores sobre la incoherencia al respecto de esta cuestión comparándola con el Reglamento 2201/2003: el juez que esté conociendo de un divorcio de una pareja homosexual puede considerar que existe matrimonio a efectos del divorcio y sin embargo podría inhibirse respecto del régimen económico matrimonial porque el DIPr no reconoce esa unión como matrimonio. Esto está relacionado con nuestro objeto de estudio ya que podríamos encontrarnos en esa situación si tenemos una controversia sobre una donación entre cónyuges homosexuales que surge a propósito de su divorcio. Vid., Ibidem, p. 188. 
74. Por último, por el foro de necesidad del art. 11, de uso excepcional y con el único fin de evitar la denegación de justicia, un tribunal podría declararse competente cuando exista una vinculación "suficiente" con su territorio y cuando no haya otro artículo del Reglamento que le dé la competencia, siempre que no pueda incoarse el proceso y desarrollarse razonablemente en otro Estado que sí pueda ser competente. Creemos que la relevancia práctica de este foro en general y, en especial, para el supuesto que nos ocupa, es muy limitada ${ }^{92}$.

\section{Determinación de la ley aplicable}

75. Para los matrimonios celebrados a partir del 29 de enero de 2019 o celebrados con anterioridad pero que hayan realizado un acuerdo de elección de ley con posterioridad a esta fecha, siempre que se verifiquen los restantes ámbitos de aplicación del mismo, analizados supra, se aplicarán las normas de conflicto de este Reglamento sin que sea posible que la ley aplicable en base al mismo sea también la que regule la sucesión o la disolución o separación del matrimonio. Recordemos que es un Reglamento de aplicación erga omnes.

76. Este Reglamento permite a los cónyuges elegir la ley aplicable, por lo que si estamos ante una donación regulada por el Derecho de familia por su vinculación al matrimonio, por ejemplo, donación por razón de matrimonio, podemos encontrarnos con que los cónyuges hayan elegido, bien en el acto de donación bien al otorgar capitulaciones matrimoniales si aquella se incluyó en estas, la ley aplicable, que será válida siempre que sea una de las siguientes: a) ley del Estado en el que los cónyuges o futuros cónyuges, o uno de ellos, tengan su residencia habitual en el momento de la celebración del acuerdo o b) ley del Estado de la nacionalidad de cualquiera de los cónyuges o futuros cónyuges en el momento en que se celebre el acuerdo. Esto es, vemos que el Reglamento da un cierto margen a la autonomía de la voluntad pero la limita a ordenamientos ciertamente "vinculados" con los cónyuges.

77. Si existe pues elección válida de ley (ex arts. 22, 23 y 24), esta se aplicará con independencia de la naturaleza o ubicación de los bienes donados (Considerando 45). La elección podrá hacerse antes de la celebración del matrimonio, en el momento de contraer matrimonio o después de haberlo contraído, aunque un acuerdo posterior no podrá perjudicar a los terceros de buena fe (art. 22.3).

78. Por último, la existencia y validez del acuerdo se regularán de acuerdo a la ley que se hubiera elegido y que sería aplicable en virtud del art. 22 salvo que, ex art. 24, uno de los cónyuges, para establecer que no ha dado su consentimiento, invoque la ley del país donde tenga su residencia habitual en el momento de sustanciar el asunto ante el órgano jurisdiccional si de las circunstancias resulta que no sería razonable determinar el efecto de su conducta de conformidad con la ley especificada en el apartado 1.

79. En defecto de elección válida de ley, el Reglamento prevé una serie de normas de conflicto en el art. 26.1, estableciendo un punto de conexión principal y otros subsidiarios, de manera que tienen aplicación jerárquica: a) de la primera residencia habitual común de los cónyuges tras la celebración del matrimonio, o, en su defecto, b) de la nacionalidad común de los cónyuges en el momento de la celebración del matrimonio, o, en su defecto ${ }^{93}$, c) con la que ambos cónyuges tengan la conexión más

\footnotetext{
${ }_{92}$ Podríamos pensar en un supuesto en el que un matrimonio formado por un colombiano y una española, que litigan en España para aclarar la posible invalidez de una donación efectuada entre ambos. Si el matrimonio se celebró en Colombia, sin que hayan elegido ley rectora para su régimen económico matrimonial, ambos vivieron la mayor parte de su matrimonio en España pero ahora, desde hace un año, él vive en Argentina y ella en Panamá. Sin que existan bienes de la pareja en España ni en ningún país de la norma, los tribunales españoles podrían ser competentes por el foro de necesidad, teniendo en cuenta que existe conexión con España al tener la esposa nacionalidad española y haber residido la mayor parte de su matrimonio en España. Compartimos totalmente la reflexión de L. Calvo Caravaca y J. Carrascosa González (dir.), Derecho..., Vol. II, op.cit., p. 190. Vid., también, J. Rodrigo Rodrigo, Relaciones..., op.cit., p. 62.

${ }^{93}$ Como establece el mismo artículo, si los cónyuges tienen más de una nacionalidad común en el momento de la celebración del matrimonio, solo se aplicarán las letras a) y c) del apartado 1.
} 
estrecha en el momento de la celebración del matrimonio, teniendo en cuenta todas las circunstancias. Esta última cláusula de los "vínculos más estrechos" que, aunque tiene carácter subsidiario, permite flexibilizar la determinación de la ley aplicable -algo que refuerza el art. 3 que se expone a continuación-.

80. Según el apartado 3, a modo de excepción y a instancia de cualquiera de los cónyuges, la autoridad judicial que tenga competencia para resolver sobre el régimen económico matrimonial podrá decidir que la ley de un Estado distinto del Estado cuya ley sea aplicable en virtud del apartado 1, letra a), regirá el régimen económico matrimonial si el demandante demuestra que: a) los cónyuges tuvieron su última residencia habitual común en ese otro Estado durante un período de tiempo considerablemente más largo que en el Estado designado en virtud del apartado 1, letra a), y b) ambos cónyuges se basaron en la ley de ese otro Estado para organizar o planificar sus relaciones patrimoniales. La ley de ese otro Estado solo se aplicará desde la celebración del matrimonio, a menos que uno de los cónyuges no esté de acuerdo. En este último caso, la ley de ese otro Estado surtirá efecto a partir del establecimiento de la última residencia habitual común en dicho Estado.

81. La aplicación de la ley de ese otro Estado no afectará negativamente a los derechos de terceros derivados de la ley aplicable en virtud del apartado 1, letra a). Esta previsión de excepción no se aplicará cuando los cónyuges hayan celebrado capitulaciones matrimoniales con anterioridad al establecimiento de su última residencia habitual común en ese otro Estado.

82. En caso de que se trate de un matrimonio celebrado con anterioridad al 29 de enero de 2019 , se aplicarán las normas de producción internas para la determinación de la ley aplicable a una donación entre cónyuges, esto es, arts. $9.2^{94}$ y $9.3{ }^{95} \mathrm{Cc}$. El primero de ellos, para efectos personales y patrimoniales entre cónyuges y, el segundo, solo para los patrimoniales cuando existe un pacto entre ambos, operando éste supletoriamente al primero, esto es, existiendo entre ambos una relación de jerarquía ${ }^{96}$. Recordemos que, si tenemos una donación entre cónyuges a la que no es aplicable el Reglamento 2016/1103, la calificación de esta figura sería ex lege fori. Si bien algunos autores excluyen del ámbito de aplicación de esta norma las donaciones entre cónyuges ${ }^{97}$, entendemos que una donación entre cónyuges -0 aspecto de la misma- que se encuentra vinculada al régimen económico matrimonial, a la "planificación" económica matrimonial (por ejemplo, una donación por razón de matrimonio recogida en capitulaciones matrimoniales $^{98}$ ) sí se vería sujeta, en este caso, al artículo $9.3 \mathrm{Cc}$.

94 Textualmente: "Los efectos del matrimonio se regirán por la ley personal común de los cónyuges al tiempo de contraerlo; en defecto de esta ley, por la ley personal o de la residencia habitual de cualquiera de ellos, elegida por ambos en documento auténtico otorgado antes de la celebración del matrimonio; a falta de esta elección, por la ley de la residencia habitual común inmediatamente posterior a la celebración, $\mathrm{y}$, a falta de dicha residencia, por la del lugar de celebración del matrimonio."

${ }_{95}$ Textualmente: "Los pactos o capitulaciones por los que se estipule, modifique o sustituya el régimen económico del matrimonio serán válidos cuando sean conformes bien a la ley que rija los efectos del matrimonio, bien a la ley de la nacionalidad o de la residencia habitual de cualquiera de las partes al tiempo del otorgamiento".

${ }^{96}$ En este mismo sentido, vid., J. Rodrigo Rodrigo, Relaciones..., op.cit., p. 113, quien realiza un amplio estudio en esta obra sobre estas normas reguladoras de los efectos del matrimonio. En contra, esto es, defendiendo que no hay una relación jerárquica sino complementaria, operando el 9.2 en defecto de pacto y el 9.3 cuando se han otorgado capitulaciones, vid., P. QuinzÁ Redondo, "Inscripción en el Registro de la Propiedad de una escritura de compraventa bajo régimen económico-matrimonial extranjero: La DGRN de 10 de mayo de 2017”, Bitácora Millenium DIPr, $\mathrm{n}^{\circ}$ 6, 2017, p. 5, y bibliografía allí citada.

${ }^{97}$ F. B. IRIARTE ÁnGEL, "Competencia de los tribunales españoles y ley aplicable a los efectos del matrimonio", Revista de Derecho UNED, núm. 16, 2015, pp. 871-891, p. 878, respecto de la aplicación del art. 9.2 Cc.

${ }_{98}$ Según algunos autores, el título (contrato, capitulaciones, contrato de seguro...) en el que se recoja el acto de liberalidad determinará la norma de conflicto aplicable a los aspectos obligacionales de la donación. Según otros, si la donación se incluye en capitulaciones matrimoniales, habrá que diferenciarla y analizarla de manera independiente al régimen económico matrimonial. Siguiendo con la doctrina del TS, el régimen económico matrimonial no es automáticamente extensible a las donaciones efectuadas por escrito en capitulaciones matrimoniales, de manera que hay que probar el régimen jurídico establecido en la ley extranjera aplicable a la donación con independencia de que se hayan probado las disposiciones relativas a las capitulaciones matrimoniales que la contienen. Vid., STS 5 junio 2000, [RJ 2000, 5094], citada por N. GoÑI UrRIZA, "La ley aplicable a la forma en las donaciones internacionales. En torno a la STSJ Cataluña de 18 de marzo de 2019”, Cuadernos de Derecho Transnacional, vol.12, nº1 2020, p. 591 


\section{La donación entre cónyuges "puramente” contractual, no vinculada a otras categorías.}

83. Por último, dedicaremos este epígrafe al estudio de las donaciones que, si bien produciéndose entre cónyuges, no guardan relación directa con el régimen económico matrimonial ni con la sucesión de ninguno de ellos. Por ejemplo, cuando un cónyuge dona al otro el porcentaje de propiedad que le corresponde de una finca, en un acto de donación entre vivos, sin que guarde relación con su régimen económico matrimonial ni con su sucesión en los términos ya vistos. La calificación "puramente contractual" de la donación entre cónyuges será habitual -nótese que en los anteriores casos, sigue tratándose de "obligaciones contractuales" según el concepto europeo de las mismas, pero se entienden excluidas del régimen previsto para ellas- y, por tanto, el papel de los Reglamentos 1215/2012 y 593/2008, en la determinación de la competencia judicial internacional y ley aplicable, respectivamente, fundamental en nuestro supuesto de hecho.

\section{Determinación de la autoridad competente}

84. El Reglamento 1215/2012 "se aplicará en materia civil y mercantil con independencia de la naturaleza del órgano jurisdiccional (...)". (Artículo 1.1). No obstante, el mismo Reglamento contiene una lista de exclusiones entre las que destacamos, por tener que ver con el supuesto que nos ocupa, las de los apartados a) y f) del artículo 1.2, esto es: a) el estado y la capacidad de las personas fisicas, los regímenes matrimoniales o los que regulen relaciones con efectos comparables al matrimonio según la ley aplicable; $y$ f) los testamentos y sucesiones, incluidas las obligaciones de alimentos por causa de muerte. Estos conceptos son autónomos y su interpretación no dependerá del Derecho de los EEMM ${ }^{99}$.

85. Lo que ha de entenderse por "materia civil y mercantil" ha sido objeto de un amplio desarrollo por la jurisprudencia del TJUE ${ }^{100}$. Según el TJUE estamos ante una materia civil o mercantil cuando el litigio se da entre particulares, esto es, cuando estamos ante relaciones jurídicas de Derecho privado ${ }^{101}$. Lo determinante es la "naturaleza de los derechos" debe garantizarse, no la naturaleza de la materia, del procedimiento judicial o del órgano competente ${ }^{102}$. Además, podemos añadir a esta amplia jurisprudencia la definición que da el TJUE respecto del concepto de "obligación contractual", tanto respecto del Reglamento Roma I como respecto al mismo Reglamento 1215/2012 y sus predecesores, el Reglamento UE 44/2001 y el Convenio de Bruselas de $1968^{103}$. Así, se refiriere con

${ }^{99}$ Sobre la misma, vid., entre otros muchos, A.L. Calvo Caravaca y J. Carrascosa GonzÁlez, "Chapter I: Scope. Article 1", en U. Magnus y P. Mankowski, European Commentaries on Private International Law, Commentary Brussels I bis Regulation, vol.I, OttoSchmidt, Köln, 2016, pp. 46-75.

${ }^{100}$ Respecto del Reglamento Bruselas I bis y de sus predecesores, el Reglamento 44/2001 o Bruselas I y el Convenio de Bruselas de 1968. La jurisprudencia dictada para interpretar estos dos últimos instrumentos es válida, según confirma el mismo tribunal, para interpretar el Reglamento 1215/2012 actualmente vigente. Vid., entre muchas posibles, STJUE 31 de enero de 2018, C-106/17, Pawel, [ECLI:EU:C:2018:50], FD. 36, en el que se citan a su vez, por analogía, las sentencias de 21 de mayo de 2015, CDC Hydrogen Peroxide, C352/13, [ECLI:EU:C:2015:335], FD. 60, y de 21 de enero de 2016, SOVAG, C521/14, [ECLI:EU:C:2016:41], FD. 43

${ }^{101}$ Entre muchas posibles, vid., STJUE 18 de octubre de 2011, C-409/09, Realchemie, [ECLI:EU:C:2011:668], FD.39 y en este sentido véase, en particular, la sentencia de 28 de abril de 2009, Apostolides, C420/07, [ECLI:EU:C:2009:271], FD. 42, 45 y 46 y jurisprudencia que allí se cita.

${ }_{102}$ Más jurisprudencia citada en: A.L. Calvo Caravaca y J. Carrascosa GonzÁlez, Derecho...., Vol.II, op.cit., p. 720.

${ }^{103}$ Nótese que el concepto de "materia contractual" que el TJUE ha desarrollado en su labor interpretativa del Reglamento 1215/2012 y de sus predecesores, el Reglamento 44/2001 y el Convenio de Bruselas, no es automáticamente vinculante en la interpretación del concepto "materia contractual" en el Reglamento no 593/2008, del Parlamento Europeo y del Consejo, de 17 de junio 2008, sobre la ley aplicable a las obligaciones contractuales o Roma I (DOUE L 177/6, 4/7/2008). No obstante, se deberá tender a la uniformidad en la interpretación de las normas y términos europeos para procurar soluciones jurídicas consistentes y coherentes, tal y como se observa en la jurisprudencia del TJUE. Esto es, la regla general de interpretación debe ser la uniformidad en la interpretación de los conceptos, de manera que si una cuestión se considera "materia contractual" a efectos de determinar la competencia judicial internacional, también se considere "contractual" para determinar la ley aplicable a la misma. La parte que sostenga otra interpretación debe justificar dicha "separación conceptual", vid., M. VIRGós SoRIANO y F.J. Garcimartín AlfÉrez, Derecho procesal civil internacional. Litigación internacional, Thomson Reuters, 2007, nº́rafo 5.35. 
"obligación contractual" a cualquiera que surja del "compromiso libremente asumido por una parte frente a otra" $" 104$.

86. Por todo ello, podemos decir que, al tener carácter consensual, una donación entre cónyuges con al menos un elemento internacional ha de entenderse comprendida en el ámbito de aplicación material del Reglamento 1215/2012, salvo que pueda considerarse parte de las exclusiones de su ámbito de aplicación material, esto es, del "régimen matrimonial" (o régimen equiparable) ${ }^{105} \mathrm{o}$ de la institución de la sucesión ${ }^{106}$, conceptos que ya hemos abordado. En este sentido, conviene traer a colación los comentarios del Abogado General de la UE en sus conclusiones en el asunto Mahnkopf ${ }^{107}$ :

87. "Los ámbitos de aplicación respectivos de los Reglamentos $n{ }^{\circ}$ 650/2012, 2016/1103 y $n{ }^{\circ}$ 1215/2012 deben ser complementarios", afirmando que el concepto de "régimen matrimonial" debe ser interpretado de manera similar, conforme a la jurisprudencia del TJUE sobre la exclusión de los "regímenes matrimoniales" del ámbito de aplicación del Convenio de Bruselas. Añade una reflexión que compartimos respecto de la aplicabilidad de dicho concepto tanto a las normas de competencia judicial internacional como a las de conflicto de leyes: “(...) soy consciente de que las normas de competencia y las normas de conflicto de leyes (a las que se refiere la remisión prejudicial en el caso de autos) no tienen idéntica finalidad. Sin embargo, el Reglamento $n .^{\circ}$ 650/2012 no sólo comprende normas de conflicto de leyes, sino también normas de competencia. El ámbito de aplicación material del Reglamento $n .{ }^{\circ}$ 650/2012, definido por su artículo 1 , se refiere a ambos tipos de normas. A falta de razones imperiosas a este respecto, no existe motivo alguno para interpretar de manera diferente, según se trate de normas de conflicto de leyes o de normas de competencia, los conceptos generales en los que se basan los Reglamentos para definir su respectivo ámbito de aplicación material." ${ }^{108} \mathrm{Y}$ esto puede entenderse de igual manera respecto de los Reglamentos triples restantes que nos ocupan en este trabajo.

88. Por tanto, cuando se trate de una obligación que no se encuentre vinculada al "régimen matrimonial" 109 o a una "sucesión" 110 , y siempre que se verifiquen, junto con el ámbito material, el resto de ámbitos de aplicación del Reglamento 1215/2012 ${ }^{111}$, este se aplicará para determinar la competencia judicial internacional a un caso de donación entre cónyuges ${ }^{112}$. Dicho esto, no existen referencias espe-

${ }^{104}$ Entre otras, vid., STJUE 14 marzo 2013, C419-11, as. Feichter. [ECLI:EU:C:2013:165], FD. 47: "la aplicación de la regla de competencia especial prevista en materia contractual en dicho 5, punto 1, letra a), del Reglamento $n^{\circ} 44 / 2001$ presupone la determinación de una obligación jurídica libremente consentida por una persona respecto a otra y en la que se basa la acción del demandante (véase, por analogía, la sentencia Engler, antes citada, apartado 51)".

${ }_{105}$ Nótese que la determinación de si se trata de un matrimonio o una pareja de hecho se hará en función art. 3 del Reglamento 2016/1103. Vid., A. Rodríguez Benot, "Los efectos...", p. 15.

${ }^{106}$ Como pueden ser las donaciones de última voluntad recogidas en el artículo $620 \mathrm{Cc}$ a las que se refiere el artículo 25 del Reglamento 650/2012. Estas exclusiones deben interpretarse de manera estricta, tal y como recuerda el TJUE en, entre otras, la sentencia de 23 de octubre de 2014, as. flyLAL-Lithuanian Airlines, C302/13, [ECLI:EU:C:2014:2319], FD. 27.

${ }^{107}$ Conclusiones del Abogado General Sr. Maciej Szpunar, presentadas el 13 de diciembre de 2017 en el asunto C-558/16, Mahnkopf, po 89. [ECLI:EU:C:2017:965]. Vid, sobre la misma, notas 82 y 83.

${ }^{108}$ Ibidem, $\mathrm{p}^{\mathrm{o}} 90$.

${ }_{109} \mathrm{Al}$ respecto, recordamos la sentencia Cavel vs. Cavel, cit. supra, sobre el concepto de régimen matrimonial del Convenio de Bruselas de 1968 y, también, el concepto autónomo contenido en el Reglamento 2016/1103, tratado ampliamente en el epígrafe dedicado a la calificación y a la donación en el marco del régimen económico matrimonial.

${ }^{110}$ Vid., al respecto, los epígrafes tercero y cuarto.

111 Esto es, que se trate de una demanda presentada desde el 10 de enero de 2015 ante los tribunales de un Estado miembro que se ve obligado a aplicarlo -ya que todos forman parte del mismo, incluidos Dinamarca, mediante Acuerdo, e Irlanda y Reino Unido (que a fecha de junio de 2020 continúa aplicándolo, aunque ya ha solicitado su ingreso en el Convenio de Lugano)-; y que el demandado se encuentre domiciliado en un Estado miembro, salvo en casos de sumisión válida, de competencias exclusivas o de demandantes privilegiados como consumidores o trabajadores - excepción esta última que no aplicaría en este caso de donaciones entre cónyuges-.

112 Vid., N. GoÑ Urriza, "Las liberalidades en Derecho internacional privado" en: M.A. Egusquiza Balsameda y C. Pérez de Ontiveros Baquero (Dir), Tratado de las Liberalidades, Cizur Menor, Aranzadi, 2017, pp. 1785-1818, p. 1788-1791. 
cíficas en el Reglamento $1215 / 2012$ a las donaciones ${ }^{113}$, por lo que a continuación estudiamos los foros que podrían aplicarse a este supuesto.

89. Siguiendo con la jerarquía de foros del Reglamento, lo primero que analizamos es la posibilidad de encontrarnos ante un foro exclusivo.

90. En primer lugar, respecto de la donación de un inmueble, habría que diferenciar claramente si la acción es sobre el contrato de donación o sobre el bien en sí y el derecho real que se tenga sobre el mismo ${ }^{114}$, cuestión esta última que dejaría al margen, en principio, la donación en sí misma y, por tanto, escapa de nuestro supuesto de estudio ${ }^{115}$.

91. En caso de una donación entre cónyuges de, por ejemplo, derechos de propiedad industrial o análogos, sometidos a registro, tendríamos que considerar el foro exclusivo previsto en el art. 24.4. según el cual, en materia de inscripciones o validez de patentes, marcas, diseños o dibujos y modelos y demás derechos análogos sometidos a depósito o registro, independientemente de que la cuestión se haya suscitado por vía de acción o por vía de excepción, los órganos jurisdiccionales del Estado en que se haya solicitado, efectuado o tenido por efectuado el depósito o registro en virtud de lo dispuesto en algún instrumento de la Unión o en algún convenio internacional. Si, por ejemplo, un francés dona a su cónyuge, española, residiendo ambos en Francia, los derechos de propiedad industrial derivados de una patente registrada en Francia, y el litigio surgiera en torno a la validez de aquella, serían competentes los tribunales franceses exclusivamente. En cualquier caso, la aplicación del foro exclusivo no será frecuente en materia de donaciones entre cónyuges y deberá analizarse con detenimiento la naturaleza de la acción ejercitada ${ }^{116}$.

${ }^{113}$ No existen referencias específicas a la cuestión de las donaciones. Sí encontramos algunas referencias secundarias en los Informes oficiales relativos al Convenio de Bruselas de 27 de septiembre de 1968. Vid., P. Jenard, Informe sobre el Convenio de 27 de septiembre de 1968 relativo a la competencia judicial y a la ejecución de resoluciones judiciales en materia civil y mercantil e Informe sobre el Protocolo de 3 de junio de 1971 relativo a la interpretación por el Tribunal de Justicia del Convenio de 27 de septiembre de 1968 sobre la competencia judicial y la ejecución de resoluciones judiciales en materia civil y mercantil (DOCE C 189, 28 julio 1990, pp. 122-180 y pp. 180-184, respectivamente); P. SCHLOsSER, Informe sobre el Convenio de 9 de octubre de 1978 relativo a la adhesión del Reino de Dinamarca, de Irlanda y del Reino Unido de Gran Bretaña e Irlanda del Norte al Convenio relativo a la competencia judicial y a la ejecución de resoluciones judiciales en materia civil y mercantil, así como al Protocolo relativo a su interpretación por el Tribunal de Justicia (DOCE C 189, 28 julio 1990, pp. 184-256); D. EyrigENIS y K. KeRAmEUS, Informe relativo a la adhesión de la República Helénica al Convenio relativo a la competencia judicial y a la ejecución de resoluciones judiciales en materia civil y mercantil (DOCE C 189 de 28 julio 1990, pp. 257-284); D.M. Dealmeida Cruz, M. Desantes Real y P. Jenard, Informe relativo al Convenio de adhesión del Reino de España y de la República Portuguesa al Convenio de Bruselas relativo a la competencia judicial y a la ejecución de resoluciones judiciales en materia civil y mercantil de 1968 (DOCE C/189 28 julio 1990, pp. 35-56).

114 Nótese que el TJUE ha señalado que el foro exclusivo del artículo 24.1 se aplicará siempre que esté basada la acción en un derecho real, no personal. Vid., Auto TJUE 5 abril 2011, C-518/99, asunto Gaillard [ECLI:EU:C:2001:209]. Es oportuno recordar que, en virtud de reiterada jurisprudencia del Tribunal de Justicia, la diferencia entre un derecho real y un derecho personal reside en el hecho de que el primero, al gravar un bien corporal, surte sus efectos frente a todos, mientras que el segundo únicamente puede invocarse contra el deudor. Vid., STJUE, de 3 de abril de 2014, asunto Weber, C438/12, [ECLI:EU:C:2014:212], FD. 43 y la jurisprudencia allí citada.

${ }^{115} \mathrm{Si}$ la donación transmitiera la propiedad de un bien inmueble y el litigio versase sobre un derecho real, podríamos aplicar el foro previsto en el artículo 24.1. Esto podría ocurrir, en el caso que nos ocupa, por ejemplo, porque el cónyuge donatario reclamara, en tanto que propietario, la salvaguarda de las facultades inherentes a su título de propietario de un bien inmueble que le fue dado a título de liberalidad, o porque la acción estuviera encaminada a determinar la existencia, extensión de la propiedad o posesión del bien (STJUE de 15 de diciembre de 2015, C-605/14, asunto Komu y otros. [ECLI:EU:C:2015:833], FD. 26; STJUE, de 3 de abril de 2014, asunto Weber, C438/12, [ECLI:EU:C:2014:212], FD. 42 y jurisprudencia allí citada). Sería aplicable el foro exclusivo del artículo 24.1 a una demanda que tuviera por objeto la cancelación en el registro de la propiedad de los asientos relativos al derecho de propiedad del donatario, como determinó el TJUE en la sentencia de 16 de noviembre de 2016 en el asunto Schmidt (STJUE de 16 de noviembre de 2016, C-417/15, asunto Schmidt [ECLI:EU:C:2016:881], FD.40 y 41), a la vez que excluía el Tribunal, del ámbito de aplicación de este artículo, una acción de anulación de un acto de donación de un inmueble por incapacidad para otorgarlo del donante, que no correspondería a la competencia exclusiva del tribunal del Estado miembro en el que se halla el inmueble, sino a la competencia especial prevista en el artículo 7.1.a), del mismo Reglamento, que veremos más adelante (Ibidem, FD. 34-39).

${ }^{116}$ Hay que recordar que el control de la competencia judicial internacional respecto de los foros exclusivos puede producirse de oficio o a instancia de parte. 
92. Siguiendo con la jerarquía de foros del Reglamento 1215/2012, cabe hacer una breve referencia a la sumisión. Compartimos con N. GoÑ URRIZA que, al tratarse de un acto de donación en el que solo una de las partes asume obligaciones y lo hace a título de liberalidad, no será común que exista un acuerdo de sumisión expresa en el documento en que se otorgue dicha donación ${ }^{117}$. En caso de que exista y sea válido, en atención a los requisitos previstos en el artículo 25 del Reglamento, serán competentes, siempre que no se trata de una acción englobable en un foro exclusivo, los tribunales señalados por las partes. Sí puede verificarse con mayor frecuencia una sumisión tácita, que prevalecería sobre la expresa, de existir esta, de manera que, en virtud del artículo 26 del Reglamento, si el demandado comparece sin impugnar la competencia, con independencia de que éste esté domiciliado en algún Estado miembro ${ }^{118}$, serán competentes los tribunales del país de la UE ante el cual se ha presentado la demanda y ha comparecido el demandado sin impugnar la competencia, siempre que no estemos ante una acción englobable en un foro exclusivo del artículo 24.

93. En ausencia de sumisión y de foros exclusivos, y siempre que el demandado tuviera su domicilio en un país de la UE, por ser condición para la aplicación del Reglamento 1215/2012 en los foros que siguen, el demandante podría escoger -si fueran distintos- entre el foro general del domicilio del demandado (ex artículo 4$)^{119}$ o el foro especial previsto en el artículo $7.1^{120}$ para las obligaciones derivadas de un contrato, ya que en ausencia de regla específica para las donaciones y dado que hemos considerado su carácter contractual ${ }^{121}$, este es el foro especial que generalmente podrá ser aplicado.

94. Según este foro, y de acuerdo con la interpretación que la amplísima jurisprudencia del TJUE ha hecho de él ${ }^{122}$, serán competentes las autoridades del lugar donde se haya cumplido o deba cumplirse la obligación que sirva de base a la demanda según el apartado general 7.1. a) ${ }^{123}$, ya que no puede identificarse la donación con una compraventa a efectos de aplicar el artículo 7.1. b) ${ }^{124}$. No obstante, esto se concretará normalmente en que serán competentes los tribunales del Estado miembro donde se hubiera entregado o debiera haberse entregado el objeto de la donación (según la ley aplicable al fondo, cuya determinación analizaremos más adelante), ya que en una donación normalmente será la entrega de la cosa la única prestación que deba cumplirse. Se trata de un foro que designa directamente al concreto tribunal territorialmente competente, en base a que se considera el tribunal "más idóneo para conocer del caso por razones de cercanía con la controversia y por razones de facilidad en la gestión de las pruebas" 125 .

${ }^{117}$ N. GoÑI URriZA, “Las liberalidades...”, op.cit., p. 1789.

${ }^{118}$ Respecto a la no necesidad de que esté domiciliado el demandado en la UE en el caso de la sumisión tácita, así lo ha entendido, aunque no se recoja expresamente en el Reglamento, la doctrina mayoritaria y el TJUE.

${ }^{119}$ Este sería el foro disponible -además, lógicamente, de que pueda existir sumisión- en caso de que se ejercitara una acción real sobre un bien mueble, sobre lo cual el Reglamento no dispone normas de competencia específicas.

${ }^{120}$ Literalmente: "Una persona domiciliada en un Estado miembro podrá ser demandada en otro Estado miembro: 1) a) en materia contractual, ante el órgano jurisdiccional del lugar en el que se haya cumplido o deba cumplirse la obligación que sirva de base a la demanda;"

${ }^{121}$ Siendo el concepto de "contrato" que se mantiene en la normativa europea muy amplio, entendiéndose como "compromiso libremente asumido de una parte frente a otra" u "obligación libremente consentida por una parte respecto de otra". Vid., STJUE 21 abril de 2016, C-572/14, asunto Austro-Mechana, [ECLI: ECLI:EU:C:2016:286], FD.36, y jurisprudencia allí citada. Solamente en el infrecuente caso de que la donación suscitara obligaciones no contractuales (porque no exijan aceptación, esto es, se trate de una donación "forzosa"), se aplicaría el artículo 7.2 y serían competentes en virtud del mismo los del país en el que se formalizó la donación (según el criterio causal) y los del país donde debía entregarse el bien donado (criterio de resultado), si fueran distintos, a elección del demandante. En el mismo sentido, vid., J. CARRASCOSA GonZÁLEz, “Apuntes...”, op.cit., p. 322 y amplia bibliografía citada en nota 6 sobre los ilícitos a distancia y la determinación de la competencia judicial internacional

${ }^{122}$ Vid., amplia jurisprudencia citada en el estudio de este artículo por A.L. Calvo Caravaca y J. Carrascosa GonzÁlez (dir.), Derecho..., Vol. II, op.cit., pp. 910-931.

${ }^{123}$ Literalmente: Una persona domiciliada en un Estado miembro podrá ser demandada en otro Estado miembro: 1) a) en materia contractual, ante el órgano jurisdiccional del lugar en el que se haya cumplido o deba cumplirse la obligación que sirva de base a la demanda. Esta es, según el TJUE, la obligación correspondiente al derecho contractual en el que se fundamenta la acción del demandante. Vid., en ese sentido, la STJCE de 6 de octubre de 1976, asunto De Bloos, 14/76, [ECLI: EU:C:1976:134], FD. 10- 13.

${ }^{124}$ N. GoÑ UrriZa, "Las liberalidades...”, op.cit., p. 1789.

${ }^{125}$ Vid., STJUE 15 de junio de 2017, C-249/16, as. Kareda-Benkö, [ECLI: ECLI:EU:C:2017:472], FD. 44-46. 
95. La aplicabilidad del foro especial del 7.1 a una acción de anulación de una donación de un inmueble en la que se alega incapacidad del donante ha sido confirmada por el TJUE en el asunto Schmidt $^{126}$, ya abordado supra ${ }^{127}$.

96. En el caso de que estemos en una donación entre cónyuges que hemos llamado "puramente contractual" y el demandado no se encontrara domiciliado en un país de la UE, y siempre que no fuera de aplicación una norma supraestatal - por ejemplo, por tratarse de un foro exclusivo o existir sumisión válida- entonces recurrimos a las normas de competencia judicial internacional de producción interna que, en el sistema español de DIPr, se localizan en el artículo 22 LOPJ. Generalmente en este supuesto, será de aplicación el foro previsto en el artículo 22 quinquies a), por el que los tribunales españoles serán competentes, en defecto de sumisión expresa o tácita (en cuyo caso se aplicaría el 1215/2012) y aunque el demandado no tuviera su domicilio en España, (...) "a) En materia de obligaciones contractuales, cuando la obligación objeto de la demanda se haya cumplido o deba cumplirse en España", con idéntico criterio que el art. 7.1.a) del Reglamento 1215/2012.

\section{Determinación de la ley aplicable}

\section{A) Consideraciones previas: ámbito de aplicación del Reglamento Roma I respecto de las dona- ciones entre cónyuges}

97. Como ya avanzamos en el epígrafe primero, la naturaleza híbrida de las donaciones entre cónyuges y la pluralidad de fuentes que pueden llegar a regular los aspectos de DIPr vinculados a las mismas hacen que, con frecuencia, pueda producirse el fenómeno de "dépeçage" ${ }^{128} \mathrm{o}$ fragmentación de la ley reguladora del fondo de la donación, además del fraccionamiento de la ley que regula cada uno de los aspectos que concurren en la misma, distintos del fondo (forma, capacidad, efectos, etc.), también usual. Por tanto, en sede de ley aplicable, añadimos otro análisis en tanto que los diferentes aspectos de la donación entre cónyuges pueden estar regulados por ordenamientos diversos al someterse, por distintos motivos, a normas de conflicto distintas. Analizaremos en primer lugar, en este epígrafe, la ley aplicable al fondo de la donación, esto es, a los aspectos obligacionales de la donación entre cónyuges y el ámbito de aplicación de esta lex donationis. Dejaremos para epígrafes siguientes la ley aplicable a la capacidad de los cónyuges para ser parte en la donación y la ley aplicable a la forma de la donación, junto con otros aspectos.

98. Pues bien, en lo relativo a los aspectos obligacionales de la donación, al igual que en sede de competencia, la naturaleza esencialmente consensual de la donación entre cónyuges hace que debamos acudir, en primer término, al Reglamento 593/2008, cit. supra, también llamado Roma I. Esto es así para todos los aspectos obligacionales de la donación, esto es: interpretación de los términos de la donación, consentimiento, plazo de prescripción de las obligaciones nacidas de la misma, las consecuencias de un incumplimiento total o parcial de las obligaciones que genere, las consecuencias de la nulidad de la donación, etc. ${ }^{129}$. Quedarían fuera de su ámbito de aplicación, en principio, la obligación de reintegrar

\footnotetext{
${ }^{126}$ STJUE, 16 noviembre de 2016, as. Schmidt, cit. supra, FD. 34-39.

127 Como precisa N. GoÑ URRIZA, aunque la capacidad no se encuentra incluida en el ámbito de aplicación del Reglamento, al presentarse esta cuestión como una cuestión previa sin que sea el objeto principal de la acción, que se refiere a la validez de la donación, no hay motivos para excluir la aplicación de Bruselas I bis. Vid., "Las liberalidades...", op.cit., p. 1790.

${ }_{128}$ B. ANCEL, "Donation. Donation entre époux", Repértoire international, Dalloz, 2005, pp. 1-16, citado en: N. GoÑI URRIZA, "La ley...", op.cit., p. 101, nota 3.

${ }^{129}$ Sobre el ámbito de aplicación de la lex contractus, vid., art. 12 del Reglamento Roma I (lista abierta). Según algunos autores, no entrarían dentro del ámbito de aplicación del Reglamento la admisibilidad de la donación entre esposos, porque encuentra su fundamento en la relación familiar. Vid., P. WAUtelet, Les donations dans un contexte international. Guide pratique., Anthemis, 2011, pp. 213-249. La posibilidad de revocar una donación es un tema delicado y polémico, ya que existe mucha diversidad en Derecho comparado.
} 
o computar donaciones o liberalidades, adelantos o legados a fin de determinar las cuotas sucesorias de los beneficiarios de una herencia, cuestión incluida en el R 650/2012 art. 23.2, así como la ley aplicable a la forma y su eficacia jurídico real, que veremos más adelante conforme a lo dispuesto en las normas de producción interna.

99. En el sistema español de Derecho internacional privado, el Reglamento Roma $I^{130}$ determina, en la actualidad ${ }^{131}$, la ley aplicable a las donaciones, entre ellas, las donaciones que se verifiquen entre cónyuges, siempre que: 1) generen obligaciones contractuales en materia civil o mercantil y, 2), no estén excluidas por el mismo Reglamento, lo cual ocurre si generan obligaciones que derivan de “( ...)relaciones familiares y de relaciones que la legislación aplicable a las mismas considere que tienen efectos comparables, incluida la obligación de alimentos”(artículo 1.2. b)) o de“(...) regímenes económicos matrimoniales, de regímenes económicos resultantes de relaciones que la legislación aplicable a las mismas considere que tienen efectos comparables al matrimonio, y de testamentos y sucesiones"(artículo $1.2 \mathrm{c}))^{132}$.

En relación a la primera condición, ya vimos en el epígrafe tercero que se trata de un concepto autónomo y que, tal y como lo ha concretado el TJUE, no exige aceptación del donatario sino que basta con que se trate de una obligación (la donación) libremente asumida por una parte -esto es, el donanterespecto de la otra (vid. supra para más detalles).

100. En cuanto a las exclusiones, que también fueron ya abordadas en el epígrafe tercero dedicado a la calificación, al que nos remitimos ahora, el análisis de las mismas es esencial para delimitar la aplicación del Reglamento Roma I al supuesto de una donación entre cónyuges o a determinados aspectos de ella. Recordamos que, siguiendo con la vocación de complementariedad de los distintos Reglamentos de la UE aplicables al caso, a las donaciones -o aspectos de las mismas- que se entiendan incluidas dentro del concepto autónomo de "régimen económico matrimonial" se les aplicará el Reglamento 2016/1103 y a las vinculadas a la sucesión, el Reglamento 650/2012 (vid. epígrafes 3 y 4). Nos centraremos en este punto en la exclusión relativa a las "obligaciones derivadas de relaciones familiares o equivalentes" ${ }^{133}$, por su especial complejidad.

${ }^{130}$ La doctrina, como ya apuntamos en la introducción, ha abordado con poca profundidad y escasamente el tema de la ley aplicable a las donaciones y, en especial, a las donaciones entre cónyuges. Referencias tangenciales encontramos en muchas de las obras generales sobre el Reglamento Roma I, entre otras muchas posibles, vid., T. BaLlarino, "Il Regolamento Roma I: forza di legge, effetti, contenuto", Cuadernos de Derecho Transnacional, 2009, Vol. 1, № 1, pp. 5-18; S. FrancQ, "Le Règlement 'Rome I' sur la loi applicable aux obligations contractuelles”, Journal du Droit International Clunet, 2009, pp. 40-69; F.J. Garcimartín Alférez, "El Reglamento 'Roma I' sobre ley aplicable a las obligaciones contractuales: ¿Cuánto ha cambiado el Convenio de Roma de 1980?”, Diario La Ley, núm. 6957, Sección Doctrina, 30 Mayo 2008, online; H. KenFaCK, "Le Règlement (CE) n593/2008 du 17 juin 2008 sur la loi applicable aux obligations contractuelles ("Rome I"), navire stable aux instruments efficaces de navigation?", Journal du Droit International Clunet, 2009, pp. 2-39; A. QuiÑones EsCÁmEz, "Ley aplicable a los contratos internacionales en la Propuesta de Reglamento "Roma I" de 15.12.2005", Indret No. 3, 2006 (www. indret.com); A. Rodríguez Benot, "La exclusión de las obligaciones derivadas del Derecho de familia y sucesiones del ámbito material de aplicación del Reglamento Roma I", Cuadernos de Derecho Transnacional, 2009, Vol. 1, № 1, pp. 112-130 y más bibliografía citada en J. CARRASCOSA GonZÁlez, “Apuntes sobre...”, op. cit., p. 323, nota 14.

${ }^{131}$ El Reglamento Roma I deja inaplicable el artículo 10.7 Cc, que resolvía con solvencia los problemas vinculados a la determinación de la naturaleza jurídica de las donaciones. Dicha norma de producción interna solo se aplica ya a los conflictos de leyes interregionales. Valoración sobre la misma en: N. GoÑ Urriza, "La ley ...”, op.cit., p. 101; J. Carrascosa GonzÁlez, “Apuntes sobre...", op.cit., pp. 322-323; F.J. Garcimartín Alférez, “Artículo 10”, en R. Bercovizt Rodríguez Cano (Dir.), Comentarios al Código Civil, Tirant lo Blanch, 2013, pp.250-325, esp. pp. 302-304.

${ }_{132}$ Recordamos que, de manera general, la interpretación de los conceptos incluidos en la normativa de la UE debe ser uniforme y coherente para garantizar el principio de igualdad. En este sentido, y aunque no sea vinculante, el concepto que el TJUE desarrolla de un determinado término jurídico, por ejemplo, de "régimen matrimonial", abordado supra, o de "obligación contractual", debe ser semejante con el que se dé a esos mismos términos en otros instrumentos europeos. Así se refleja en numerosa jurisprudencia del TJUE. Respecto a ello, vid., V.M. RoJAs AMANDI, "La interpretación...”, op. cit., pp. 49, 57, 58. Si no existiera norma supraestatal institucional, esto es, de la UE, aplicable al caso, entonces la calificación se haría, salvo aclaración expresa en el mismo convenio eventualmente aplicable que permitiera su calificación directa, ex lege fori como dispone nuestro Código civil.

${ }^{133}$ Sobre la misma, vid., A. Rodríguez Benot, “La exclusión...”, op.cit., pp. 112-130. 
101. Recordamos que, el Informe Oficial Giuliano/Lagarde, anejo al Convenio de Roma de $1980^{134}$, ya interpretó, muy escuetamente, esta exclusión a propósito de dicho convenio, predecesor normativo del Reglamento Roma I. Según aquel ${ }^{135}$, hay que entender que se excluirán del Reglamento aquellas obligaciones que estén reguladas por el Derecho de familia ${ }^{136}$. Esto es, no basta que una obligación se verifique en el ámbito de la familia para que esté excluida del ámbito de aplicación del Reglamento sino que debe "estar regulada" por el Derecho de familia. La intención de dicha remisión, muy criticada, a los Derechos nacionales y, por tanto, a la calificación lex causae, es la de respetar las limitaciones que determinados ordenamientos (por ejemplo, el italiano, vid. supra) imponen a los cónyuges a la hora de realizar donaciones entre ellos, regulándolas específicamente.

102. La cuestión es determinar, por tanto, en qué casos las donaciones entre cónyuges, aunque tengan carácter "consensual" en el sentido ya visto, "están reguladas por el Derecho de familia", ya que para todas las que no lo estén -y lógicamente tampoco se vinculen a la institución sucesoria- se determinará la ley aplicable en base al Reglamento Roma ${ }^{137}$.

103. La primera pregunta que parece necesario contestar es a qué Derecho de familia nos referimos si aún no hemos determinado la ley aplicable a la donación, ya que además la regulación de esta cuestión no es homogénea en absoluto en los Estados miembros. Nos situaríamos ante un círculo sin solución que ha planteado enormes problemas interpretativos y de aplicación: se necesita saber cuál es la ley aplicable para saber si la donación está o no regulada por el Derecho de familia de ese ordenamiento pero, a su vez, no se puede aplicar el Reglamento Roma I para determinarlo sin saber si dicha donación está o no regulada por el Derecho de familia.

104. En el ámbito del sistema español de Derecho internacional privado, doctrina reconocida ${ }^{138}$ ha solventado esta cuestión de la siguiente manera:

105. $1^{\circ}$ ) En primer lugar, el tribunal competente aplicará las normas de conflicto recogidas en el Reglamento 2016/1103, de regímenes económico-matrimoniales ${ }^{139}$, para saber cuál es la ley aplicable a la donación a efectos, solamente, de determinar si está o no está regulada dicha obligación por el Derecho de Familia (de ese ordenamiento estatal señalado, se entiende).

106. $2^{\circ}$ ) Si de acuerdo a dicha ley material la obligación queda sujeta al Derecho de familia, entonces se aplicará dicho Derecho. Si no es así, entonces se aplicará el Reglamento Roma I para determinar la ley aplicable a la donación entre los cónyuges. En este último supuesto estaríamos si, por ejemplo, la

${ }^{134}$ M. Giuliano y P. Lagarde, Informe..., op.cit., pp. 17-19.

${ }^{135}$ Interpretación según doctrina cualificada, citada en epígrafe 3, vid. nota 48.

${ }^{136}$ Parte de la doctrina considera que sólo se excluirían aquellos aspectos de la donación directamente relacionados con el vínculo familiar que escaparan al ámbito contractual, como puede ser la posibilidad de revocar una donación por el nacimiento de un hijo del donante (artículo $644 \mathrm{Cc}$ ), mientras que todo lo demás entraría dentro del ámbito de aplicación de Roma I siempre que no quede regulada por el Reglamento sobre régimen económico matrimonial o el de sucesiones. Así lo recoge N. GoÑI UrrizA, "La ley...", op.cit., p. 105, citando a P. WAUTELET, Les donations..., op.cit., p. 218.

${ }^{137}$ Según N. GoÑ Urriza, "Las liberalidades ...”, op.cit., p. 1793: "parte de la doctrina mantiene incluso la aplicación del Reglamento Roma I a todas las donaciones, incluso las que derivan de las relaciones de familia", citando a H. PEROZ ET E. Fongaro, Droit international privé patrimonial de la famille, Paris, Litec, 2010, p.287, nº745 y p. $288 \mathrm{n}^{\circ} 751$. Para algunos autores, como H. Muir WatT y D. BuREAU, cuya opinión compartimos, pueden surgir problemas de compatibilidad por aplicar normas de conflicto relativas a los contratos con los regímenes imperativos de las donaciones entre cónyuges, mencionando por ejemplo el riesgo de revocabilidad ad nutum de las donaciones de bienes futuros entre cónyuges. H. MuIR WatT y D. BUREAU, Droit International Privé, Tome II: Partie spéciale, $2^{a}$ ed. Themis Droit, Paris, 2010, p. 117 y 252 . Por ello, en Francia la jurisprudencia se ha pronunciado a favor de aplicar a las donaciones entre esposos de bienes muebles e inmuebles la ley rectora de las relaciones entre esposos. Vid., N. GoÑ URRIZA, "Las liberalidades...", op.cit., p. 1795.

${ }^{138}$ Vid., entre otros, P. JimÉnez Blanco, “El derecho aplicable...”, op.cit., pp. 63-90; A.L. CAlvo Caravaca y J. CARrascosa GonZÁlez, Derecho ..., op.cit., pp. 1057-1078, p. 1067, citando también a H. Gaudemet-TALlon.

${ }^{139}$ O el Reglamento (UE) 2016/1104 del Consejo, de 24 de junio de 2016, de uniones registradas. En caso de que estos no puedan aplicarse por razón temporal, entonces habrá que estar a los artículos 9.2 y $9.3 \mathrm{Cc}$. 
ley señalada por el Reglamento 2016/1103 (o en su caso, el Reglamento 2016/1104) fuese la española, que no regula las donaciones entre cónyuges en su Derecho de familia, en su Derecho común-salvedad hecha de las donaciones en razón de matrimonio-. Algunos autores ${ }^{140}$ señalan que el Reglamento 2016/1103 -y de idéntica manera el 2016/1104- no incluye en su ámbito de aplicación las donaciones entre cónyuges ex artículo 27. No obstante, recordamos que la lista que ofrece el artículo 27 del Reglamento es abierta, esto es, el ámbito de aplicación no se limita necesariamente a las cuestiones en él mencionadas ${ }^{141}$.

107. Pongamos un ejemplo: $A$, alemán, y $B$, francesa, casados en febrero de 2019 , con residencia habitual en España, concluyen una donación en enero de 2020 sin que esta se incluya en capitulaciones matrimoniales ni guarde relación con el régimen económico matrimonial. Deciden que sea el Derecho francés el que regule la misma. En principio se trata de una donación contractual porque es una obligación libremente asumida por una parte respecto de la otra. Ahora bien, ¿está regulada por el Derecho de familia? El tribunal competente, español, deberá aplicar el Reglamento 2016/1103 para saber cuál sería el Derecho aplicable al fondo. Al ser España el primer lugar de residencia común tras la celebración del matrimonio, el Derecho español regirá el régimen económico matrimonial y, como este no regula específicamente las capitulaciones matrimoniales, entonces no estaríamos en la exclusión del art. 1.2 b) de Roma I y por tanto se utilizaría este Reglamento para determinar la ley aplicable, aplicándose entonces el Derecho francés al ser la ley elegida por las partes (art. 3.1 Reglamento Roma I). Si la residencia habitual común tras la celebración del matrimonio fuera en Italia, país que sí regula dichas donaciones en su Derecho de familia, entonces la respuesta sería distinta, ya que habría que aplicar el Derecho italiano (a falta de elección válida), que sí regula específicamente dichas donaciones.

108. Recientemente, una sentencia nacional ha tenido que plantearse esta cuestión sobre el ámbito de aplicación del Reglamento Roma I, a propósito, precisamente, de una donación internacional entre cónyuges. Así, en la sentencia del Tribunal Superior de Justicia de Cataluña de 18 de marzo de $2019^{142}$, en la que se debate la norma de conflicto aplicable ${ }^{143}$ para determinar el ordenamiento que regirá la forma y el fondo de una donación de una finca ubicada en Suiza entre cónyuges de nacionalidad española y vecindad civil catalana, el tribunal se detiene en la interpretación del concepto de "régimen económico matrimonial" ya que en su razonamiento describe el concepto autónomo que se ha dado en el Reglamento 2016/1103 (aún no aplicable al caso en cuestión para la determinación de la ley aplicable, ya que el matrimonio se celebró con anterioridad al 29 de enero de 2019).

109. Así, en ella, el tribunal precisa que el concepto de relaciones patrimoniales generadas entre los cónyuges por razón directa del matrimonio aludiría tanto al régimen económico matrimonial primario (regulado en los artículos 1318-1322 Cc, o en los artículos 231.5-231.9 CCCat, para Cataluña), como al régimen económico secundario, que es el acordado por los cónyuges en capitulaciones matrimoniales o el supletorio legal si no lo han pactado (arts. 1315-1316 Cc y art. 231.10 CCCat), y también a los negocios hechos en consideración al matrimonio, que en Derecho catalán son las adquisiciones onerosas con pacto de supervivencia ${ }^{144}$, las donaciones por razón de matrimonio otorgadas fuera de capitulaciones

140 N. GoÑI UrrizA, “Las liberalidades...”, op.cit., p. 1794.

141 Se deduce del texto literal del artículo que incluye la precisión de "entre otras cuestiones".

142 Sentencia del Tribunal Superior de Justicia de Cataluña de 18 de marzo 2019 (Sala de lo civil y penal, sección $1^{\text {a }}$, núm. 23/2019, RJ/2019/2021 [ECLI: ES:TSJCAT:2019:1691]. Para ver un análisis de la misma, vid., N. GoÑI URRIZA, "La ley aplicable a la forma...", op.cit, pp. 586-595.

${ }^{143}$ Entre las normas de producción interna -al no poder aplicar aún el Reglamento 2016/1103 por razón temporal- (artículos 9.2, 9.3, 10.7 y 11.2 del Cc) o el Reglamento Roma I (artículos 4.1, c), 11.1 y 11.5).

144 También conocido como adquisición de bienes con pacto de supervivencia, está regulado por el Libro II del Código civil catalán y es frecuente en las escrituras de compraventa de inmuebles por cónyuges. Cuando los cónyuges o futuros contrayentes adquieren conjuntamente un bien a título oneroso, pueden pactar en el mismo título que, cuando uno muera, el cónyuge supérstite se convertirá en titular único de la totalidad del bien. Este pacto de supervivencia otorgado por los futuros contrayentes caduca si el matrimonio no se celebrara en el periodo de un año. Vid., Cambra de la Propietat Urbana de Barcelona, 23 enero 2018, disponible en: https://www.cpubcn.com/es/adquisiciones-onerosas-con-pacto-de-supervivencia/ [Consulta:10/2/2020]. 
y los derechos de viudedad familiares (arts. 231.15 -231.18 y 231-27-231.31 CCCat) ${ }^{145}$. En este caso, al considerar que la donación no se encuentra enmarcada en ninguna de estas categorías, el tribunal decide aplicar el Reglamento Roma I al fondo del asunto, algo que, paralelamente en sede de competencia que en este caso no se discute-, equivaldría, dada la interpretación uniforme que debe hacerse de estos términos jurídicos del Derecho de la UE, a aplicar el Reglamento 1215/2012, al considerar su carácter contractual/consensual sin que ninguna de las exclusiones previstas por su artículo 1 sean aplicables ${ }^{146}$.

110. El tribunal, que aplica finalmente al fondo el Reglamento Roma $\mathrm{I}^{147}$, afirma que el propio concepto de régimen económico matrimonial que el Reglamento 2016/1103 ha incorporado, ex Considerando 18 y art. 3.1, refuerza su interpretación ya que, a juicio del tribunal, esta norma evidencia que el legislador europeo ha creído conveniente dejar fuera de su ámbito de aplicación tanto la regulación de los aspectos estrictamente personales vinculados al matrimonio -que siguen estando sometidos a la norma de conflicto interna (art. 9.2 CC)-, como la materia relativa a los negocios patrimoniales que realizan los cónyuges ente ellos amparados por la libertad de contratación y que no son el resultado directo del matrimonio, quedando estos últimos sometidos al Reglamento Roma I ${ }^{148}$. Esto es, el Reglamento, según el tribunal, limita el concepto de "efectos personales" a los que se refiere el artículo 9.2 Cc, estrictamente a las obligaciones de "respecte, ajuda mútua i actuació en interès de la família enumerades en els articles 67 i 68 CC $i$, en el cas de Catalunya, en els articles 231-2 i 231-3 CCCat" y, el concepto " efectos patrimoniales" o "relaciones patrimoniales generadas por razón directa del matrimonio" al "règim econòmic secundari, que és l'acordat pels cònjuges en capitols matrimonials o el supletori legal si no n'hi ha (articles 1315 - 1316 CC i 231-10 CCCat), i també als negocis fets en consideració al matrimoni, que en el dret català són les adquisicions oneroses amb pacte de supervivència, les donacions per raó de matrimoni atorgades fora de capitols i els drets viduals familiars (articles 231-15 a 231-18, i 231-27 a 231-31 CCCat)".

111. Por ello, afirma el tribunal, no forman parte de dichos efectos y por tanto sí estarían reguladas por el Reglamento Roma I los demás negocios jurídicos de causa onerosa o gratuita que los cón-

${ }^{145}$ La traducción es nuestra. El texto literal, en catalán, es el siguiente: "Mentre que el concepte de relacions patrimonials generades entre els cònjuges per raó directa del matrimoni al ludiria tant al règim econòmic matrimonial primari regulat en els articles 1318 a 1322 CC o en el articles 231-5 a 231-9 CCCat pel que fa a Catalunya, com al règim econòmic secundari, que és l'acordat pels cònjuges en capitols matrimonials o el supletori legal si no n'hi ha (articles 1315 - 1316 CC i 231-10 CCCat ), i també als negocis fets en consideració al matrimoni, que en el dret català són les adquisicions oneroses amb pacte de supervivència, les donacions per raó de matrimoni atorgades fora de capitols i els drets viduals familiars (articles 231-15 a 231-18, i 231-27 a 231-31 CCCat). Vid, STSJCat, 18 de marzo de 2019, cit. Supra, motivo 1, po3, p.4.

${ }_{146}$ Por tanto, quedarían excluidos del Reglamento 1215/2012 los litigios relativos a una donación que no pueda enmarcarse dentro del "régimen económico primario" del matrimonio, de las relaciones patrimoniales entre los cónyuges que son objeto de una regulación especial en Derecho nacional (por ejemplo, los contratos entre esposos en determinados Estados o los trusts, cuando afectan al régimen económico matrimonial). También se entenderían excluidos los pleitos entre excónyuges sobre liquidación de bienes adquiridos durante al matrimonio, al entenderse vinculados a las relaciones jurídicas patrimoniales que derivan de la disolución del matrimonio. Vid., Auto TJUE 14 junio 2017, C-67/17, (petición de decisión prejudicial planteada por el Rayonen sad Varna - Bulgaria) — Todor Iliev/Blagovesta Ilieva), as. Iliev, ) DO C 112 de 10.4.2017. También, A.L. Calvo Caravaca y J. Carrascosa González, Derecho...., Vol. II, op.cit., pp. 724 y 725.

${ }^{147}$ Con anterioridad nos constan sentencias que siguen otro criterio. Vid., STS de 5 de junio de 2000, $\mathrm{n}^{\mathrm{o}} 551 / 2000$ [ECLI: ES:TS:2000:4611] y STS 10 de junio de 1995, nº 0558 [ECLI: ES:TS:1995:3361], que aplican el art. 10.7 Cc.

148 Así, como recoge la sentencia, al pretender regular "todos los aspectos de Derecho civil de los regímenes económicos matrimoniales, relacionados tanto con la administración cotidiana del patrimonio matrimonial como con la liquidación del régimen, en particular como consecuencia de la separación de la pareja o del fallecimiento de uno de los cónyuges" (considerando 18) y proponer un concepto autónomo de "régimen económico matrimonial" ("conjunto de normas relativas a las relaciones patrimoniales entre los cónyuges y los terceros, como resultado del matrimonio o de su disolución" ex artículo 3.1), abarcando tanto las normas imperativas para los cónyuges como las normas opcionales que los cónyuges puedan acordar de conformidad con el Derecho aplicable, así como cualesquiera normas por defecto del Derecho aplicable (por tanto toda relación patrimonial, entre los cónyuges y en sus relaciones con terceros, que resulte directamente del vínculo matrimonial o de su disolución), pretende no solo dejar sin efecto el artículo 9.3 Ce sino también dejar a un lado la regulación de los efectos personales vinculados al matrimonio y otros posibles negocios jurídicos que lleven a cabo los cónyuges amparados en la libertad de contratación pero que no son resultado directo del matrimonio. STSJ Cataluña, 18 de marzo 2019, op.cit., vid. FJ 2, motivo de casación $n^{\circ} 1$, punto 4 . 
yuges lleven a término en ejercicio de la libertad de contratación -recogida tanto en el Derecho catalán como el común- y que no resulten o deriven directamente del vínculo matrimonial. Esto es, aquellos que a pesar de tener lugar en el ámbito familiar se producen con independencia del régimen matrimonial. Así, el tribunal califica el supuesto de acuerdo a los arts. 9.2 y $9.3 \mathrm{Cc}$, parece que ex lege fori, por las continuas referencias al Derecho catalán sin que se haga referencia directa a la solución dada por la doctrina de comprobar primero si, en el Derecho aplicable al fondo según los arts. 9.2 y 9.3 Cc, están reguladas dichas donaciones. En cualquier caso, el resultado sería el mismo ya que, suponiendo que se aplique al fondo el Derecho catalán, al no estar regulada dicha donación en cuestión, tendríamos que descartar la exclusión del 1.2 b) y por tanto, sin que tampoco se entienda contemplada en el régimen económico matrimonial (calificando ex lege fori, aunque viéndose reforzada, como afirma el tribunal, dicha calificación por el concepto autónomo que propone el Reglamento 2016/1103, no aplicable al caso por razones temporales), se aplicaría igualmente el Reglamento Roma I.

112. Según N. GoÑI URRIZA ${ }^{149}$, el tribunal da una solución que evita los problemas que plantean las complejas propuestas doctrinales -descritas supra, a las que la autora hace referencia- que además ignoran el problema de la previa determinación de la competencia judicial internacional mediante el Reglamento 2016/1103. Por otra parte, interpreta la excepción del art. 1.2 Reglamento Roma I de manera coherente con el ámbito de aplicación del Reglamento 2016/1103 al aplicar Roma I por entender que "la donación nace de la voluntad de las partes y no resulta directamente del matrimonio".

113. En cualquier caso, sí parece conveniente que la aplicación -por la interpretación de su ámbito de aplicación- del Reglamento 2016/1103 sea la misma en competencia y en ley aplicable, ya que el concepto de "régimen económico matrimonial" no debe variar para ambas cuestiones ni, más allá, respecto de otros Reglamentos de la UE. Por ello, el criterio interpretativo y, por tanto, la técnica de calificación que se utilice para determinar el ámbito de aplicación del Reglamento 2016/1103 debe ser similar en sede de competencia y de ley aplicable, y a su vez compatible y complementario al del Reglamento 1215/2012, en sede de determinación de la competencia judicial internacional, y Roma I, en sede de determinación de la lex causae.

114. Pues bien, visto el ámbito de aplicación de Roma I, pasamos a analizar a continuación el ámbito de aplicación de la lex donationis y las normas de conflicto aplicables al caso.

\section{B) Ámbito de aplicación de la lex donationis}

115. Sea cual sea la ley aplicable a la donación, esta rige generalmente, ex art. 12 del Reglamento Roma I, la interpretación de la misma, el cumplimiento de las obligaciones que genere; las consecuencias de un incumplimiento total o parcial de estas obligaciones, dentro de los límites de los poderes conferidos al tribunal por su Derecho procesal, incluida la evaluación del daño en la medida en que la gobiernen normas jurídicas los diversos modos de extinción de la donación, así como la prescripción y la caducidad basadas en la expiración de un plazo y las consecuencias de la nulidad de la misma. Esto es, se incluyen cuestiones como los bienes que pueden donarse, las condiciones posibles de una donación, la prohibición de donar o recibir por donación - por ejemplo, la posibilidad de recibir por donación del nasciturus-, la causa de revocación de la misma y si esta es posible ${ }^{150}$, la validez sustancial y sus efectos.

116. No obstante, no regulará cuestiones como la capacidad para ser parte en una donación -regulada por la ley personal de cada interviniente, como veremos en el siguiente epígrafe-, la ley aplicable a la forma de la misma cuando se trate de un inmueble o se trate de una donación en el marco matrimonial o sucesoria -vid. supra-, la eficacia jurídico real de la misma-que abordaremos infra-o el

149 N. GoÑ URrizA, "La ley aplicable a la forma...", op.cit, p. 595.

${ }^{150}$ Sobre el régimen de revocabilidad de las donaciones en Derecho comparado, vid., P. WAUTELET, op.cit., p. 220. 
régimen particular de protección de determinados herederos, como ya vimos, en el marco de la sucesión del donante ${ }^{151}$.

\section{C) Las normas de conflicto en el Reglamento Roma I}

117. Si resulta aplicable el Reglamento Roma I, al no prever este ninguna norma de conflicto específica para las donaciones, la donación entre cónyuges se regirá:

118. $1^{\circ}$ En primer lugar, por la ley libremente elegida por las partes (art. 3.1), de manera clara e inequívoca. Esta ley no tiene por qué tener relación con la donación o el lugar de donación, ni corresponderse con la ley personal del donante o del donatario ${ }^{152}$. Puede realizarse en una cláusula en el mismo contrato de donación o en un acuerdo paralelo en el que el donatario acepte esas y otras posibles cuestiones. Se entiende que al elegir el donante una ley y aceptar el donatario la donación, también acepta la ley elegida, de manera que este artículo mantiene su aplicación a pesar de la naturaleza aparentemente unilateral de la donación, por ejemplo, en una donación hecha en un contrato de seguro de vida en el que se designa a un tercero como beneficiario.

119. En caso de existir elección de ley y de que las partes elijan varias distintas (algo que no creemos que sea frecuente en este ámbito), cabe recordar que el dépeçage que permite el Reglamento Roma I tiene varios límites ${ }^{153}: 1^{\circ}$ ) No debe conducir a una "incoherencia" del contrato -bien porque se elijan leyes incompatibles entre sí bien porque los derechos y deberes de cada parte se rijan por Derechos distintos, bien porque se hayan sometido a leyes distintas los elementos nucleares necesarios para la existencia misma del contrato (en Derecho español, los contemplados en el art. $1261 \mathrm{Cc}$ ). $2^{\circ}$ ) Ese fraccionamiento nunca podrá evitar la aplicación de las leyes de policía ex art. 9 Reglamento Roma I.

120. En este sentido, en caso de que el Estado del foro fuera el español, algunos autores ${ }^{154}$ señalan como ejemplos de normas imperativas españolas que serían aplicables con independencia de la ley que regulara la donación, la prohibición de reversión estipulada por el donante a favor de tercero (art. $641 \mathrm{Cc}$ ), la irrevocabilidad de las donaciones como principio general o las limitaciones de los bienes que pueden ser objeto de donación (arts. 634, 635 y 636 Cc). Como dispone el Reglamento, la elección de otra ley que no guarde conexión con el caso no obsta para que se apliquen todas las normas imperativas del Derecho que se hubiere aplicado en defecto de elección de ley y que no puedan, por su naturaleza, eludirse mediante acuerdo (por ejemplo, la posibilidad de revocación).

121. $2^{\circ}$ A falta de elección, debemos distinguir dos supuestos. 1) Si se donan bienes inmuebles, se aplicará la ley del lugar en que se encuentran, en aplicación del artículo 4.1.c), por lo que la donación quedará sujeta a la ley del país donde se ubique el inmueble, con independencia de que las partes residan ambas habitualmente en un Estado distinto ${ }^{155}$.2) En el resto de los bienes aplicará a la donación la norma

${ }^{151}$ También, según parte de la doctrina, quedaría excluida de la lex contractus o donationis la revocación que tiene su causa en la supervivencia de hijos, que se regiría por la ley sucesoria. Vid., H. Peroz et E. Fongaro, Droit international ..., op.cit., p. $289, \mathrm{n}^{\circ} 757$.

${ }^{152}$ Esto sin perjuicio de que, si todos los elementos de la donación -situación del bien, domicilio y nacionalidad de las partes, etc.- se conectan con un país, por ejemplo, España, siendo la ley elegida -extranjera- el único elemento extranjero, se apliquen las normas imperativas españolas ex art. 3.3 del Reglamento (y de manera paralela respecto de la elección de la ley de un Estado no miembro, ex art. 3.4).

${ }^{153}$ P. Mankowski, “Article 3” en: U. Magnus \& P. Mankowski, op.cit., pp. 211-214.

${ }^{154}$ N. GoÑ URRIZA, “Las liberalidades...”, op.cit., p. 1800. La autora precisa que en el caso del art. 636 hay que analizar si los términos de la donación son compatibles con lo previsto en la ley nacional y de la residencia habitual del donante -que podrán ser aplicadas como ley aplicable a la sucesión ex art. 21 y 22 Reglamento 650/2012-.

${ }^{155}$ Sin que pueda entrar por tanto en juego en este caso el art. 4.3 del Reglamento. Así lo ha aplicado la Audiencia Provincial de Las Palmas en su sentencia de 15 de enero de 2013, al conocer de un caso de donación de un inmueble sito en España y realizada entre finlandeses. [ECLI:ES:APGC:2013:28]. 
del artículo 4.2, esto es, la ley de la residencia habitual de la parte que realice la prestación característica del contrato, que entendemos es el donante. ${ }^{156}$.

122. Si se donaran en un mismo acto bienes muebles e inmuebles, podemos pensar en principio en dos soluciones distintas. La primera sería "dividir" el acto de donación en varios, de manera que se aplicaría a la donación del bien inmueble la ley del lugar de situación del bien y a la donación del bien o bienes muebles la ley del lugar de la residencia habitual del donante. Este fraccionamiento de la ley aplicable "por bloques" -adicional al que ya de por sí se dará con la ley aplicable a la forma o a la capacidad de las partes, entre otros, como veremos más adelante- complejiza aún más la solución del conflicto de leyes y la solución sustantiva del caso, con muchos Derechos extranjeros concurriendo en su resolución y con las consecuentes dificultades de prueba, compatibilidad entre ellos, riesgo de resultados incongruentes, inseguridad jurídica para los operadores jurídicos, las partes y los terceros. Por otra parte, algunos autores han propuesto, basándose en la distinta calificación que puede recibir el contrato, acto, de donación, que se aplique el artículo 4.2 respecto de todos los bienes donados ${ }^{157}$.

\section{La ley aplicable a otras cuestiones}

\section{La ley aplicable a la forma de una donación entre cónyuges}

123. En caso de estar ante una donación sometida al Reglamento Roma I, en cuanto a la ley aplicable a la forma de la donación, debemos acudir al art. 11 dicho instrumento ${ }^{158}$, ya que el art. $11 \mathrm{Cc}$ queda relegado por la aplicación preferente del Reglamento de la UE para todos los contratos sometidos a aquel.

124. Según el art. 11 del Reglamento, debemos distinguir dos supuestos: que la donación se celebre entre cónyuges que se encuentran en el mismo país en el momento de su celebración, en cuyo caso la donación será válida en cuanto a la forma si reúne los requisitos de forma de la ley que lo rija en cuanto al fondo en virtud del presente Reglamento, o de la ley del país donde se haya celebrado. O, que la donación se celebre entre cónyuges que se encuentran en distintos países en el momento de su celebración será válido en cuanto a la forma si reúne las condiciones de forma de la ley que lo rija en cuanto al fondo en virtud del presente Reglamento, o de la ley de los países en que se encuentren cualquiera de las partes, o cualquiera de sus representantes, en el momento de la celebración, o de la ley del país en que cualquiera de las partes tuviera su residencia habitual en ese momento. De esta forma, si por ejemplo los cónyuges eligen la ley española para regir una donación de un bien mueble otorgada en Francia, se evitarían los requisitos formales que prevé dicha ley; o si se celebra en España, aunque se aplique otra ley, por ejemplo, la francesa, al fondo. Si el único elemento extranjero fuese la ley elegida por las partes para regular el fondo, nótese que ex art. 3.3, no podrán evitarse las disposiciones imperativas del Derecho con el que la situación está vinculada y, por tanto, las exigencias formales previstas en dicho Derecho, como podría ser, en el ordenamiento francés, la exigencia de otorgar escritura pública ex art. 931 y ss. de su Código civil.

${ }^{156}$ Vid., F.B. IrIARTE ÁNGel, "El problema de la interacción entre las sucesiones y las donaciones con elemento internacional a la luz de la norma de conflicto", Boletín JADO. Bilbao. Año XII. N 24. Junio 2013, pp. 185-193, p.189. Sobre el artículo 4 del Reglamento Roma I hay una amplísima bibliografía y no es objeto de este artículo revisarla. Sobre su aplicación e interpretación, vid, entre otros muchos posibles: U. Magnus, “Article 4", en: U. Magnus \& P. Mankowski, European Commentaries on Private International Law, Commentary, Rome I Regulation, Ottoschmidt, 2017 pp. 263-441; C. CaAmiña Domínguez, "La ley aplicable al contrato en defecto de elección. El art. 4 del Reglamento Roma I", en A.L. Calvo CARavaca y J. CARrascosa GonZÁlez (dir.), Litigación internacional en la Unión Europea II. La ley aplicable a los contratos internacionales, Thomson Reuters, Aranzadi, 2017, pp. 151-196; vid., una revisión crítica del artículo 4 de Roma I: Z. TANG, "Law Applicable in the Absence of Choice. The New Article 4 of the Rome I Regulation”, The Modern Law Review, vol. 71, №5, 2008, pp. 785-800.

${ }^{157}$ Vid., P. WaUtelet, op.cit., p.224., citado también en N. GoÑ URRIZA, "La ley aplicable...”, op.cit., p.224.

${ }^{158}$ El Informe Giuliano/Lagarde, op.cit., da una definición autónoma de lo que son "cuestiones de forma", incluyendo, por ejemplo, la exigencia de uso de un idioma determinado, el requisito de forma escrita o la intervención de fedatario público, entre otras. 
125. Nos interesa también el apartado 5 del artículo 11 en el que se prevé que, no obstante lo dispuesto en los apartados 1 a 4, todo contrato que tenga por objeto un derecho real sobre un bien inmueble o el arrendamiento de un bien inmueble estará sometido, en cuanto a la forma, a las normas de la ley del país en que el inmueble esté sito, siempre y cuando, en virtud de dicha ley: a) la aplicación de dichas normas sea independiente del país donde se celebre el contrato y de la ley que rija el contrato, y b) dichas normas no puedan excluirse mediante acuerdo ${ }^{159}$.

126. Así, en la sentencia, cit. supra, del TSJ de Cataluña de 2019, el tribunal aplica el apartado 1 y 5 de este artículo 11, en lugar del art. $11 \mathrm{Cc}$-que pretendía el recurrente-, para determinar aplicable a la forma de la donación de la finca ubicada en Suecia realizada entre esposos la ley sueca, algo que resulta determinante en el caso ya que según esta ley la donación era válida y, por el contrario, según la ley española era nula por defectos de forma (art. $633 \mathrm{Cc}$ ). Al estar los cónyuges en el mismo país en el momento de la perfección de la donación, y cumplirse los requisitos de forma que exige la ley sueca, que es la ley aplicable al fondo, el tribunal considera que la donación es válida formalmente. Además, el tribunal afirma la prevalencia de la regla especial del epígrafe 5 dedicada a los bienes inmuebles, siendo así que mediante esta también se trata de una donación válida al situarse el inmueble en Suecia y haber accedido al Registro de la Propiedad en Suecia, aunque no analiza los requisitos de dicho apartado 5 del art. 11 en la sentencia.

127. No obstante, hay que señalar que esta interpretación no responde a una postura unánime de la doctrina, ya que algunos autores defienden la aplicación del art. 11.2 Cc como norma de policía del foro (aplicable ex art. 9 Reglamento Roma I) y, por tanto, en un pleito seguido ante tribunales españoles, la elevación a escritura pública del contrato de donación de un inmueble sería requisito para su validez $^{160}$. El tribunal no lo considera así, argumentando que el art. 11 del Reglamento desplaza al art. $11 \mathrm{Cc}$ en su conjunto. Además, cabe argumentar que la exigencia formal de elevación a público, ad solemnitatem, de un inmueble situado en el extranjero -en un país donde además no es necesario dicho requisito-, no parece que sea esencial para la salvaguardia de intereses públicos españoles - más polémico podría resultar situándose aquel en territorio español, caso en el que entendemos que, al no poder excluirse el art. $633 \mathrm{Cc}$ mediante acuerdo y ser esto un requisito del Reglamento, sí debería aplicarse dicha exigencia para garantizar, entre otros motivos, la oponibilidad del acto frente a terceros- ${ }^{161}$.

128. Una vez determinada la ley aplicable a la donación, esta determinará no solo la validez formal del acto, sino también los modos de subsanar posibles defectos formales o las consecuencias jurídicas de estos, si se plantearan. En caso de fraccionamiento de la ley aplicable a la donación, se aplicará la ley que más estrechamente se relacione con la cuestión de forma de que se trate ${ }^{162}$.

129. Cabe considerar también la ley aplicable a la forma de la donación cuando ésta esté excluida del ámbito de aplicación del Reglamento Roma I. En ese caso, habrá que distinguir varios supuestos. Si se entiende incluida en el ámbito del Reglamento 2016/1103, y está contenida en capitulaciones, entonces habrá que estar a lo dispuesto en el art. 25 de dicho instrumento normativo ${ }^{163}$. Si no está conte-

${ }^{159}$ Esto es, en aplicación de esta norma la SAP de Las Palmas considera inválida una donación de bien inmueble sito en España otorgada en el extranjero por dos sujetos finlandeses que no respeta la forma de escritura pública, requerida en nuestro ordenamiento. Vid., SAP Las Palmas, 15 enero 2013, cit. supra.

${ }^{160}$ Vid., al respecto, F. J. Garcimartín Alférez, “Art. 11” en: R. Bercovitz Rodríguez-Cano (Dir.), Comentarios al Código civil, Tomo I, Tirant lo Blanch, Valencia, 2013, p. 331; M. GUZMÁn ZAPATER (Dir.), Lecciones de Derecho internacional privado, Tirant lo Blanch, 2019, p. 187; N. GoÑ UrRIZA, "La ley aplicable a la forma..”, op.cit., p. 594.

161 Vid., A. L. Calvo Caravaca y J. Carrascosa González, Derecho internacional..., op.cit., vol. II, p. 1035, quienes consideran dudosa la aplicación de las normas de policía ex art. 9 Reglamento a la forma de los contratos, señalando, además, que los ordenamientos jurídicos nacionales no suelen contener normas imperativas relativas a los contratos sobre inmuebles, citando a J.D. GonzÁlez Campos y F.J. Garcimartín AlfÉrez.

162 Vid., Ibidem, p.1036.

${ }^{163}$ Las capitulaciones matrimoniales se expresarán por escrito, fechado y firmado por ambos cónyuges. Se considerará como escrito toda comunicación efectuada por medios electrónicos que proporcione un registro duradero del acuerdo. 2. Si la 
nida en capitulaciones o, estándolo, puede considerarse su naturaleza independiente, entendemos que se aplicaría a los requisitos de forma el art. $11 \mathrm{Cc}$. No obstante, si fuera una donación excluida de Roma I por encajar en la exclusión del art. 1.2 b), por estar regulada específicamente por el Derecho de familia, entonces, a tenor del espíritu del legislador de proteger regulaciones específicas que contemplen las donaciones entre cónyuges de manera particular, cabe cuestionarse si la forma no debiera regirse por lo dispuesto en dicha ley, ya que probablemente en su regulación se contemplen requisitos formales.

130. Por último, si una donación se considera sucesoria -normalmente concretada en un pacto sucesorio- entonces habrá que estar al art. 27 del Reglamento de sucesiones en materia de forma (y no al Convenio de La Haya de 5 de octubre de 1961 sobre los conflictos de Leyes en materia de forma de las disposiciones testamentarias, que sí se aplicaría a las donaciones hechas en los testamentos y testamentos mancomunados pero no en los pactos sucesorios).

\section{Ley aplicable a la capacidad para ser parte en una donación entre cónyuges}

131. La capacidad jurídica de los cónyuges para ser parte en una donación está excluida de los Reglamentos de la UE en materia de sucesiones y del Reglamento Roma I que hemos estudiado ${ }^{164}$. A falta de otros instrumentos supraestatales aplicables, se regirá pues la cuestión de la capacidad para ser parte en una donación por las normas de producción interna lo cual, en el caso español, nos remite al artículo 9.1 del Código civil. Según este artículo, la capacidad se regirá, para donante y donatario, por sus respectivas leyes personales, esto es, por la ley de la nacionalidad de cada uno de ellos y, supletoriamente, por su residencia habitual. Esta ley o estas leyes (si tuvieren distinta nacionalidad) regularán quién y en qué medida puede donar sus bienes y quién y en qué medida recibirlos mediante donación (piénsese en menores de edad, emancipados, mayores de edad, incapaces...).

132. La teoría del interés nacional, recogida en el artículo 13 del Reglamento Roma I, sí sería aplicable en materia de capacidad, de manera que en los contratos celebrados entre dos personas que se encuentren en un mismo país, las personas físicas que gocen de capacidad de conformidad con la ley de ese país solo podrán invocar su incapacidad resultante de la ley de otro país si, en el momento de la celebración del contrato, la otra parte hubiera conocido tal incapacidad o la hubiera ignorado en virtud de negligencia por su parte.

133. En relación al Reglamento 2016/1103, este excluye de igual manera la capacidad jurídica en su artículo 1.2 a), por lo que será la ley nacional de los cónyuges la que regule la validez del matrimonio por la capacidad de los esposos y, también, la que determine si los acuerdos a los que pueden llegar los cónyuges, como puede ser una elección de ley, son válidos o no. Ahora bien, en el artículo 27 dispone que "La ley aplicable al régimen económico matrimonial con arreglo al presente Reglamento regulará, entre otras cosas: (...) d) las facultades, derechos y obligaciones de cualquiera de los cónyu-

ley del Estado miembro en el que ambos cónyuges tengan su residencia habitual en el momento de la celebración de las capitulaciones establece requisitos formales adicionales para las capitulaciones matrimoniales, dichos requisitos serán de aplicación. Si los cónyuges tienen su residencia habitual en distintos Estados miembros en el momento de la celebración de las capitulaciones y las leyes de ambos Estados disponen requisitos formales diferentes para las capitulaciones matrimoniales, el acuerdo será formalmente válido si cumple los requisitos de una de las dos leyes. Si en la fecha de celebración de las capitulaciones, solo uno de los cónyuges tiene su residencia habitual en un Estado miembro y la ley de ese Estado establece requisitos formales adicionales para las capitulaciones matrimoniales, dichos requisitos serán de aplicación. 3. Si la ley aplicable al régimen económico matrimonial impone requisitos formales adicionales, dichos requisitos serán de aplicación.

${ }^{164}$ Vid., artículo 1.2. a) Reglamento 583/2008; artículo 1.2 b) del Reglamento 650/2012 (nótese no obstante que el Reglamento de sucesiones, en sus art. 23 y 26 sí regula la capacidad para testar y suceder). Dicha exclusión deriva, principalmente, de la diversidad de tratamiento de esta cuestión en los ordenamientos de los Estados implicados. Mientras en los países del Common Law es una cuestión contractual, en los países de la Europa continental la capacidad está regulada por una norma específica (vid., entre otras, art. 9.1 Cc en España, art. 3.3 del Código civil francés, art. 7 del BGB alemán). Vid., al respecto, N. GoÑI UrRIZA, “Las liberalidades...”, op.cit., p. 1797. 
ges o de ambos con respecto al patrimonio. Esto es, que será la ley resultante de aplicar el Reglamento 2016/1103 la que regule las posibilidades de disponer del patrimonio para donarlo entre cónyuges (por ejemplo, porque pueden existir prohibiciones o limitaciones en este sentido), más allá de la capacidad jurídica y de obrar general de ambos, que estará regulada por la ley personal.

\section{Ley aplicable a los derechos reales que se transmiten o crean mediante el acto de donación entre los cónyuges}

134. Esta cuestión es particularmente relevante puesto que, en la donación de un bien, habrá que diferenciar los aspectos obligacionales de los derechos reales que se derivan de la misma. Estos, excluidos del ámbito de aplicación de los Reglamento Roma I (ex art. 1.2), 650/2012 y 2016/1103, se regirán por la lex rei sitae (art. 10.1 y 2 del Cc).

135. Esta ley regulará cuestiones como el modo de constitución o adquisición de los derechos reales, los derechos subjetivos de su titular, el contenido del derecho, los bienes sujetos al mismo, la posibilidad y condiciones de inacatabilidad del derecho real, su publicidad y acceso al Registro público, etc $^{165}$. Si no se cumple lo dispuesto en esta ley, aun siendo el contrato válido de acuerdo a la que lo regule, no se generarán efectos "reales", esto es, el bien continuaría perteneciendo al donante. Por ejemplo, esto podría ocurrir si se produce una donación entre cónyuges, aplicándose a la misma el Derecho francés pero encontrándose el bien en España, sin que se produzca la traditio de la cosa donada, requisito necesario en Derecho español ${ }^{166}$. Aunque en la donación sea perfectamente válida y produzca efectos de acuerdo a Derecho francés, no se producirán efectos reales.

\section{Artículo 10.7 Cc. Norma de conflicto interna específica para las donaciones}

136. El art. 10.7 Cc queda relegado, tras la entrada en vigor del Reglamento Roma I, de aplicación erga omnes, a reglamentar solo la determinación de la ley aplicable a los conflictos interregionales. No hay mucha jurisprudencia al respecto. Nos constan las Sentencias del Tribunal Supremo de 5 de junio de 2000, en la que el tribunal aplicó el articulo 10.7 aunque por falta de prueba del Derecho extranjero no pudo aplicar el Derecho danés que es el que señalaba la norma de conflicto ${ }^{167}$, y la STS 10 de junio de 1995, en la que se aplicó dicho artículo y finalmente el Derecho alemán, por ser la ley nacional del donante. Este (la ley nacional del donante) es el punto de conexión para determinar la ley aplicable a la donación, por lo que se aplicará, en el marco de los conflictos interregionales, la ley de la vecindad civil del cónyuge donante.

137. Por su parte, hay que decir que el Reglamento 2016/1103 no obliga, aunque sí permite, a los Estados miembros plurilegislativos con sus propias normas en materia de regímenes económicos matrimoniales a aplicarlos a los conflictos de leyes que se planteen entre dichas unidades territoriales exclusivamente (artículo 35). En el caso de España, ante la existencia de una norma específica de conflicto de leyes en materia de donaciones, lo cual facilita mucho su interpretación y aplicación, cabe pensar que el legislador tenderá a aplicar esta, esto es, el artículo $10.7 \mathrm{Cc}$, a los conflictos de leyes interregionales, razonamiento que pensamos sería extrapolable respecto del Reglamento 650/2012.

${ }^{165}$ SAP Islas Baleares de 16 de julio de 2009 [ECLI: ES:APIB:2009:862]. Se recurrirá por tanto a la lex rei sitae para determinar la validez de una clausula limitativa de las facultades del donatario, en tanto que propietario del bien o para garantizar la validez de una cláusula limitativa de la facultad de disposición del donatario incluida con la finalidad de garantizar la eficacia de una cláusula de reserva o de reversión de la donación (artículos 639 y 641 CC). Vid., N. GoÑ̃ URRIZA, "La ley aplicable a la forma...", op.cit., p. 112.

${ }^{166}$ Sobre cómo se concretaría dicho requisito, en las condiciones que se conocen como "de segundo escalón”, vid., A. L. Calvo Caravaca y J. Carrascosa González, Derecho internacional..., op.cit., vol. II, p. 1216.

${ }^{167}$ Vid. supra nota 147. 


\section{Efectos en España de las donaciones otorgadas en el extranjero}

138. Ante una donación entre cónyuges con residencia habitual en España pero que se haya otorgado en el extranjero, o cuando el bien donado esté situado en España, puede ser relevante analizar los posibles efectos de la misma en nuestro país.

139. Si la donación se otorgó en escritura pública en el extranjero, el análisis de su validez según los requisitos formales debe someterse al régimen general de los actos públicos extranjeros. A falta de normas supraestatales ${ }^{168}$, acudiremos a la Ley $29 / 2015$, de cooperación jurídica internacional en materia civil ${ }^{169}$, especialmente a su art. 60, que recoge la "teoría de equivalencia de formas", creada por la jurisprudencia del TS y por la práctica registral de la Dirección General de los Registros y el Notariado. Según esta, para equiparar un documento público extranjero a un documento público español, es necesario que haya sido autorizado por fedatario extranjero - esto es, que sea titular de la función pública de dar fe y controlar la legalidad de los actos extrajudiciales- que ha realizado funciones equivalentes ${ }^{170}$ a las que desarrolla el notario español. Además, debe venir acompañado, para que resulte auténtico, de legalización o trámite que lo sustituya, como la apostilla ${ }^{171}$, y de traducción, salvo que el Registrador, bajo su responsabilidad, exima de la misma por conocer el idioma en cuestión, ex art. 37 de la Ley Hipotecaria.

140. En relación al fondo, la donación otorgada mediante documento público extranjero será eficaz si así lo es conforme a la ley que resulte aplicable según las normas españolas de DIPr vistas anteriormente, lo cual podrá resultar en la aplicación de Derecho extranjero o español, según el caso. En el caso de donaciones entre cónyuges, ya vimos que la aplicación de la ley aplicable al régimen económico matrimonial o de la ley sucesoria pueden ser fundamentales a la hora de determinar si es eficaz una donación otorgada en el extranjero bien respecto de la posibilidad o capacidad de disposición del donante, bien respecto la reducción de la donación o la adaptación si se trata, por ejemplo, de derechos no reconocidos en nuestro ordenamiento jurídico que deban inscribirse en el Registro de la Propiedad español ${ }^{172}$.

\section{Especial referencia a donaciones complejas}

141. Terminamos haciendo referencia a las donaciones complejas que pueden tener especial relevancia en el marco de las relaciones entre cónyuges, ya que con intención de eludir el pago de mayores impuestos, puede ser frecuente -más que fuera del ámbito familiar- el recurso de estas figuras jurídicas para transmitir la propiedad de los bienes, especialmente cuando el impuesto de sucesiones y donaciones es elevado.

142. Ejemplos de estas donaciones son la donación modal o con cargas -esto es, aquella en la que el donante impone algún tipo de carga-, la donación con reserva de usufructo o condición al donatario o la donación remuneratoria.

${ }^{168}$ El Reglamento 1215/2012 solo prevé disposiciones sobre la fuerza ejecutiva de los actos auténticos (vid., arts. 2 c y 58).

${ }^{169}$ Ley 29/2015, de cooperación jurídica internacional en materia civil, BOE nº182, de 31 de julio. También, vid., Disp. Adic. Tercera de la Ley 15/2015, de Jurisdicción Voluntaria,1 b)., BOE nº 158 , de 3 julio de 2015.

${ }^{170}$ Esto es, que su intervención haya sido equivalente, en intensidad o grado de involucración en la comprobación de la legalidad, a la que tendría un notario español para un caso de donación entre cónyuges, según sea el caso (esto es, capitulaciones matrimoniales, contrato de donación independiente, pacto sucesorio, etc.)

${ }^{171}$ Esta está prevista en el caso del Convenio de La Haya de 5 de octubre de 1961, relevante por tanto en materia de donaciones sucesorias entre cónyuges. Vid., A.L. Calvo Caravaca y J. Carrascosa González (dir.), Compendio de Derecho internacional privado, Rapid Centro Color, Murcia 2019, p. 227.

${ }^{172}$ Más al respecto, en: N. GoÑI UrRIZA, “Las liberalidades..”, op.cit., p. 1814 citando a H. MuIR Watt, Revue Critique, 2005. 
143. Al respecto es importante tener en cuenta que las categorías que nos ofrece nuestro Derecho interno civil común, solo serán relevantes en defecto de instrumentos supraestatales institucionales aplicables ${ }^{173}$ que, como ya hemos visto, especialmente en el epígrafe dedicado a la calificación, contienen conceptos autónomos. Sí serían determinantes al aplicar normas de producción interna ${ }^{174}$ en materia de competencia judicial internacional o de determinación del ordenamiento aplicable, supuestos ambos que ya hemos estudiado con anterioridad.

144. Ahora bien, teniendo en cuenta el ámbito de aplicación del Reglamento Roma I y el escaso margen de aplicación de las normas de producción interna, esta calificación ex lege fori, de acuerdo a categorías contenidas en nuestro Derecho de producción interna tendrá relevancia: 1) Cuando se trate de conflictos interregionales, respecto de la aplicación del art. 10.7 Cc y 2) Cuando estemos en presencia de una donación vinculada al régimen económico matrimonial cuya ley aplicable se determine en base al art. $9.3 \mathrm{Cc}$, como vimos supra. 3) Respecto de los derechos reales o efectos reales del acto de donación, ya que aplicaremos el art. 10.1 Cc como vimos supra. 4) En sede de competencia judicial internacional, en el caso de que estemos en una donación entre cónyuges no vinculada a sucesión ni a régimen económico matrimonial y el demandado no se encontrara domiciliado en un país de la UE, y siempre que no fuera de aplicación una norma supraestatal - por ejemplo, por existir sumisión válidarecurriríamos al art. 22 quinquies a) -y esto no cambia por el hecho de que se trate de una donación compleja-; en ningún caso si se trata de donaciones vinculadas al régimen económico matrimonial por la aplicación del Reglamento 2016/1103 o de donaciones vinculadas a la sucesión, a las que se aplicará el Reglamento 650/2012 $2^{175}$.

145. Así, por ejemplo, para el caso de una donación remuneratoria, el TS afirma que “(...) El artículo 633 no hace ninguna excepción de lo que preceptúa para ninguna donación además de que la remuneratoria no tiene ningún régimen especial, es el móvil remuneratorio el que guía el animus donandi del donante nada más; móvil indiferente jurídicamente para el Derecho, que no causa, del negocio jurídico" ${ }^{176}$. Esto es, el hecho de que sea remuneratoria no altera su carácter de donación ni por tanto las formalidades a ella asociadas frente a la libertad de forma que rige, de manera general, en el marco de la compraventa.

146. Por otra parte, en el caso, mayoritario, de que se apliquen normas de la UE de DIPr, atenderemos, por ejemplo, a las siguientes consideraciones:

${ }^{173}$ Vid., el análisis que nos ofrecen autores como N. GoÑ URRIZA de las donaciones complejas respecto de las normas de DIPr, atendiendo a criterios del TS interpretando disposiciones de nuestro código civil, Vid.,"La ley aplicable..." (2019), op.cit., pp. 110-112 y “Las liberalidades...”, op.cit., pp. 1802-1806. La autora concluye, entre otras cosas, que si la naturaleza jurídica de la donación no cambia por la imposición de una carga -según sentencia del TS de 16 de enero de 2013, respecto de los artículos 619 y 622 Cc-, tampoco debe hacerlo su tratamiento desde el punto de vista del Derecho internacional privado por lo que se aplicará el Reglamento Roma I para determinar la ley aplicable a esta modalidad de donación -véase, la donación con cargas(vid., Ibidem, "La ley aplicable...", op.cit., pp.110). Entendemos que se estaría calificando la donación, en este caso, ex lege fori.

${ }^{174} \mathrm{O}$, entendemos, normas de carácter supraestatal convencional a falta de disposiciones específicas que definan y concreten los términos jurídicos en cuestión en los mismos convenios. Esto último tendrá poca relevancia, pensamos, en el supuesto que nos ocupa, en parte por el amplio ámbito de aplicación de los Reglamentos de la UE con vocación de ser aplicados al caso, muchos de ellos erga omnes, y en parte por la ausencia de convenios específicos en los que España forme parte que puedan aplicarse a esta cuestión (solo mencionamos, en el caso de una donación ligada a la institución sucesoria, el Convenio de la Haya de 5 de octubre de 1961 en materia de forma de las disposiciones testamentarias).

${ }^{175}$ Salvo en lo previsto en el artículo 22 sexies LOPJ respecto de medidas cautelares y provisionales que se solicitaran en España aunque sea otro Estado el que está conociendo o va a conocer de la sucesión en virtud de la regla específica que prevé el Reglamento 650/2012 en el art. 19 que remite a las normas internas de competencia judicial internacional en esta cuestión.

${ }^{176}$ Aunque no se trata de un caso de DIPr, sirva para ver que no se entiende desvirtuada la naturaleza de la donación y, por tanto, no se alteraría, de ser un caso de DIPr, la norma de conflicto, vid., la STS de 16 de enero de 2013, Sala de lo civil, $\mathrm{n}^{\mathrm{o}}$ 1152/2013, $\mathrm{n}^{\mathrm{o}}$ Recurso: 828/2012, [ECLI: ES:TS:2013:1152], respecto de la nulidad de la donación de bien inmueble disimulada bajo escritura pública de compraventa, cuando el animus donandi resulte acreditado en la sucesión testamentaria del donante, siendo la donación una donación remuneratoria. 
a) Si puede seguir considerándose un acto "consensual" o "contractual", siguiendo el concepto autónomo del Derecho de la UE, su tratamiento desde el punto de vista de la determinación de la competencia judicial internacional y de la ley aplicable no variará.

b) Si, por la naturaleza de la carga (por ejemplo, porque se mantenga en el tiempo una vez fallecido el cónyuge donante) debe considerarse donación ligada a la institución sucesoria $o$ no, se determinará de acuerdo al ámbito de aplicación del Reglamento 650/2012 y a la jurisprudencia del TJUE al respecto. En este sentido, por ejemplo, como ya vimos, según el art. 23.2 del Reglamento, se someten a la ley rectora de la sucesión la obligación de reintegrar o computar donaciones "con el fin de determinar las cuotas sucesorias de los distintos beneficiarios" o para la colación en la herencia.

c) Si el litigio versa sobre una donación en la que se transfiere un derecho real sobre un bien con limitaciones a las facultades del donatario, por ejemplo, debemos distinguir, como ya comentamos supra: la ley aplicable a los aspectos obligacionales que derivan del acto de donación será la que determine el Reglamento Roma I, mientras que los aspectos reales que puedan derivar de la donación (transmisión, modificación o constitución de un derecho real) se regularán por la norma que determine el art. 10.1 y 2 Cc (lex rei sitae), ante la exclusión del art. 1.2 del Reglamento Roma I.

d) Si se trata de una donación con reserva de usufructo, por ejemplo, siendo la donación de la nuda propiedad al cónyuge y la del usufructo a un hijo, podría considerarse: por una parte, su posible vinculación con la institución sucesoria si su consideración es necesaria -por ejemplo- a efectos de determinar la masa hereditaria, en cuyo caso aplicaríamos el R 650/2012 ${ }^{177}$. Por otra parte, habría que valorar si se trata de aspectos obligacionales, a lo que seguiríamos aplicando Roma I, o aspectos reales derivados de la donación, en cuyo caso aplicaríamos el art. 10.1 Cc. En el caso de aplicar Roma I, lógicamente la ley que designe el Reglamento regulará, entre otras posibles cuestiones, si están permitidas las cláusulas que fijan las facultades y limitaciones de usufructuario y propietario respectivamente o la posible irrevocabilidad de la donación hecha de esta forma ${ }^{178}$.

\section{Conclusiones y reflexión final}

147. Como hemos visto, el tratamiento de las donaciones entre cónyuges en DIPr dibuja un auténtico mosaico normativo cuyo principal problema parece ser la calificación de la donación y la delimitación de los aspectos que en ella confluyen y que pueden ser considerados "obligacionales" o "reales", entre otros, implicando esto el recurso a normas diversas de DIPr. La confluencia del Derecho de familia por darse la donación "entre cónyuges" dificulta aún más la cuestión. Todo ello contribuye al fraccionamiento de la ley rectora de la donación para cada cuestión, y a la fragmentación de su regulación, en cada aspecto, por distintos instrumentos normativos, como hemos visto, y exige a los operadores jurídicos considerar diversas leyes nacionales, con las dificultades que esto conlleva en el proceso. Sin duda, una elección de ley común o compatible, al menos, para las diversas cuestiones relacionadas que hemos estudiado -sucesión, donación en sí misma y régimen económico matrimonial-, y de tribunales competentes, facilita la resolución de las cuestiones clásicas de DIPr y la solución jurídica al caso en cuestión.

148. El principal reto parece ser el desarrollo de los conceptos autónomos contenidos en las normas europeas, especialmente, del Reglamento 2016/1103 para favorecer la compatibilidad y complementariedad entre los instrumentos normativos de la UE y así evitar lagunas indeseables e injustificables en el espacio europeo de Justicia. También ayudaría en la consecución de estos objetivos la profundización, jurisprudencial y doctrinal, en la exclusión sobre las obligaciones "que derivan" de relaciones familiares

${ }^{177}$ En sentido contrario, en base a una calificación lege fori, vid., N. GoÑI UrRIZA, “La ley aplicable...”, 2019, op. cit., p. 112.

${ }^{178}$ Siempre con consideración a las leyes de policía que pudieran ser de aplicación en el caso ex art. 9 Reglamento Roma I, como nos recuerda la autora cit. supra en la p. 112. 
del Reglamento Roma I, su calificación e intersección con la exclusión relativa a los regímenes económicos matrimoniales y su implicación normativa desde el punto de vista del Derecho internacional privado.

149. No queremos terminar el trabajo sin mencionar que el mismo podría presentar una estructura totalmente diferente en atención a la diversidad de interpretaciones de la exclusión que el Reglamento Roma I contiene respecto de las donaciones "derivadas de las relaciones familiares", y que nos parece relevante explicar aquí. Básicamente encontramos dos opciones:

150. a) Interpretar que la intención del legislador con la exclusión de las donaciones "derivadas de relaciones familiares" fue la de dejar fuera del régimen contractual todas aquellas donaciones que, según la lex causae, estuvieran específicamente reguladas por el Derecho de familia, para respetar los ordenamientos de esos Estados. Entonces la estructura que hemos planteado encaja y además, refuerza la coherencia "entre" y "de" los instrumentos de la UE, por respetar las interpretaciones "autónomas" de los mismos y por tanto los principios de igualdad y de unidad en la interpretación y aplicación de las normas europeas, y esto sin vulnerar la calificación ex lege causae que propone el legislador en la exclusión 1.2.b) del Reglamento Roma I.

151. b) Interpretar que la intención del legislador con la exclusión de las donaciones "derivadas de relaciones familiares" fue la de regular todas aquellas donaciones "libres" del Derecho de familia o "no reguladas" por el mismo según la lex causae. Esto, que parece lo mismo, no lo es, porque en el primer caso se permitiría que otros instrumentos regularan donaciones eventualmente no reguladas por el Derecho de familia aplicable al fondo, por ser la donación, por ejemplo, calificable dentro del concepto autónomo de "régimen económico matrimonial" o encontrarse vinculada a la sucesión según el concepto del Reglamento 650, mientras que en este segundo supuesto, si es una donación "libre" del Derecho de familia en la lex causae, su régimen debería ser el contractual de Roma I y de Bruselas I bis-.

152. Pongamos un ejemplo: tenemos una donación por razón de matrimonio que se entiende que pertenece al concepto de "régimen económico matrimonial" pero la lex causae aplicable no las regula de manera específica y por tanto no está regulada por el Derecho de familia en cuestión. En este supuesto, dadas las dos interpretaciones, tenemos: a) en la primera, da igual, al considerarse parte del concepto autónomo de "régimen económico matrimonial" se aplicaría el Reglamento 2016/1103 tanto a la determinación de la CJI como a la ley aplicable, sin importar el "contenido" de la lex causae; b) en la segunda interpretación, en cambio, en primer lugar habría que ver si la lex causae las regula o no; como no las regula, entonces debe recibir un tratamiento contractual, porque así lo quiso el legislador con la exclusión del Reglamento Roma I (según interpretemos éste y el Informe Giuliano/LaGarde), por lo que debemos aplicar Roma I para la determinación de la ley aplicable. Incluso puede defenderse que tal comprobación sobre el contenido de la lex causae habría que hacerla en sede de determinación de competencia, para que la misma se determine en base al Reglamento 1215/2012 y no al 2016/1103, como ocurriría al considerarse la donación por razón de matrimonio parte del "régimen económico matrimonial", pudiendo ocurrir entonces que la competencia judicial internacional se determine en base al Reglamento 2016/1103 y luego la ley aplicable en base a Roma I.

153. En este segundo caso, la estructura propuesta en este trabajo carecería de sentido, ya que la calificación de "donación con efectos sucesorios" o "donación vinculada al régimen económico matrimonial" o "donación puramente patrimonial" no serviría a efectos de determinar el instrumento de la UE aplicable, sino que habría que consultar en primer lugar la lex causae según Roma I, en una especie de "presunción iuris tantum" de que la donación encaja dentro de su ámbito de aplicación, para acudir en primer lugar a dicho instrumento. Si la donación está "regulada" por el Derecho de familia de la lex causae, en los términos vistos, entonces queda excluida del régimen contractual y la regularía el 2016/1103. Si no lo está, entonces usamos el 1215/2012 y Roma I. Por ello, si siguiéramos esta interpretación, habría sido más lógico organizar el trabajo partiendo de dicha determinación para, en función de ella, establecer la competencia judicial internacional y, especialmente, la ley aplicable. 
154. Quizás el legislador del Convenio de Roma no contempló al redactar la exclusión que nos ocupa la posible existencia de instrumentos de aplicación erga omnes, con conceptos autónomos y vocación omnicomprensiva, como son los Reglamentos 650/2012 y 2016/1103 que ya están en pleno funcionamiento, y la posible coordinación de dicho instrumento y de dicha exclusión con los mismos.

155. En cualquier caso, esperamos que el TJUE y una doctrina más cualificada que la autora de este artículo, contribuyan a aclarar la cuestión con el desarrollo, especialmente, del concepto de "régimen económico matrimonial" y de la interacción entre los diversos instrumentos aplicables al caso. Sin duda es una tarea necesaria para facilitar la tarea a los operadores jurídicos y la coherencia -e igualdaden la interpretación y aplicación de las normas de la UE en DIPr en una materia que, por su especial vinculación al Derecho de familia, no resulta de fácil consenso ni armonización, por lo que puede que consensuar una norma de conflicto específica, como ocurría en Derecho interno español con el artículo 10.7 Cc, sea prácticamente inimaginable. En esta labor de clarificación será importante no perder de vista que la elección de la solución más sencilla rechazando y obviando la complejidad de la cuestión puede llevar a situaciones dispares y de difícil solución pero que, a su vez, la excesiva complejidad en la comprensión y aplicación de las normas, como ocurre en este caso, no garantiza, a juicio de la autora, una buena aplicación de las mismas y, por tanto, tampoco contribuye a generar la seguridad jurídica y la igualdad que el Espacio europeo de justicia defiende y necesita. 